\title{
APPLYING GIS AND SWAT TO UNDERSTAND THE STREAM NETWORK, HYDROLOGY, SEDIMENT AND NUTRIENT EXPORT FROM THE GRAND RIVER WATERSHED INTO LAKE ERIE
}

\author{
by \\ Aslam Hanief \\ Associate Degree Geological Engineering, University of Guyana, 1999 \\ Associate Degree Biology, University of Guyana, 2005 \\ B.Sc. Biology, University of Guyana, 2007 \\ M.Sc. Molecular Science, Ryerson, 2011 \\ A dissertation presented to Ryerson University \\ in partial fulfillment of the requirements for the degree of \\ Doctor of Philosophy \\ in the program of \\ Environmental Applied Science and Management
}

Toronto, Ontario, Canada, 2017

(C)Aslam Hanief, 2017 


\section{Author's Declaration}

I hereby declare that I am the sole author of this dissertation. This is a true copy of the dissertation, including any required final revisions, as accepted by my examiners.

I authorize Ryerson University to lend this dissertation to other institutions or individuals for the purpose of scholarly research.

I further authorize Ryerson University to reproduce this dissertation by photocopying or by other means, in total or in part, at the request of other institutions or individuals for the purpose of scholarly research.

I understand that my dissertation may be made electronically available to the public. 


\begin{abstract}
APPLYING GIS AND SWAT TO UNDERSTAND THE STREAM NETWORK, HYDROLOGY, SEDIMENT AND NUTRIENT EXPORT FROM THE GRAND RIVER WATERSHED INTO LAKE ERIE

Doctor of Philosophy 2017

Aslam Hanief

Environmental Applied Science and Management

Ryerson University
\end{abstract}

Headwater streams are important lotic systems that represent more than $80 \%$ of the total stream lengths in watersheds. The dynamic coupling of hydrological and biogeochemical processes in headwaters is responsible for regulating the chemical form, residence time and longitudinal transport of nutrients. Over time, stream modification (e.g. to enhance drainage in agricultural watershed) has altered natural stream flow-paths and thus, stream functionality. Such alteration has resulted in degradation of habitat and water quality, both in upland and downstream waters. Currently, nutrients exported from the Grand River (Ontario) watershed are contributing to eutrophication and Harmful Algal Blooms in Lake Erie. With respect to the Grand River watershed, this thesis examined (1) the impact of agriculture on the existing stream network, (2) the utility of the Soil and Water Assessment Tool to simulate hydrology, sediment and nutrient export that closely correlate with measured data, and (3) the application of Best Management Practices in the watershed with the intent of meeting provincial and transnational nutrient targets. The results showed that compared to the actual ground-truthed stream network, the predicted stream network based on topography underpredicted a total of $2,535 \mathrm{~km}$ of actual channel present in the watershed. Channels not anticipated by topography were mostly first-order, with low sinuosity, and were most common in areas with high agricultural land use, and are likely excavated 
extensions to headwater streams to facilitate drainage. Then, the sediment and nutrient loading at Dunnville, discharging to entering Lake Erie, was predicted to be $2.3 \times 10^{5} \mathrm{t} \mathrm{yr}^{-1}$ of total suspended

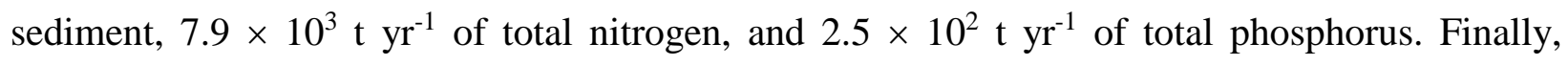
implementing wide buffer strips, stabilizing channel banks and grassed waterways were found to be the most effective practices for reducing sediment and phosphorus loading into Lake Erie. 


\section{Acknowledgements}

My sincere gratitude is extended to my committee members - Drs. Vadim Bostan, Andrew Millward and Andrew Laursen for their guidance and support throughout this research.

Learning and keeping it all together can be quite challenging at times. However, these challenges were met with ease due to the kind understanding and flexible nature of my very thoughtful and caring supervisor, Dr. Laursen. He is truly a rock for all his students to rely on.

My family has never wavered in their support of my pursuits. To all of them, my mom, sister, extended family and my brilliant wife, I say from the bottom of my heart, your kindness and assistance will never be forgotten.

And I cannot forget to say thank you to all my friends, especially Karen Puddephatt. Karen has been just the right kind of friend whom I will forever appreciate. 


\section{Table of Contents}

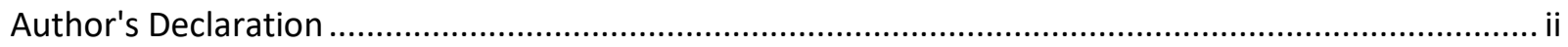

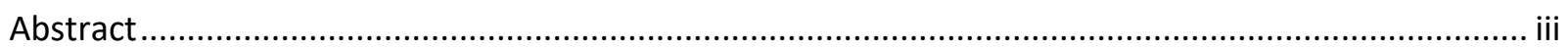

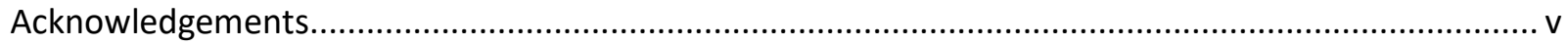

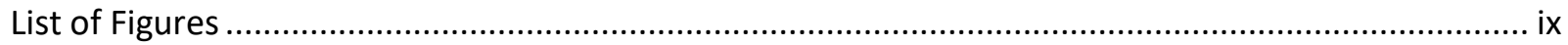

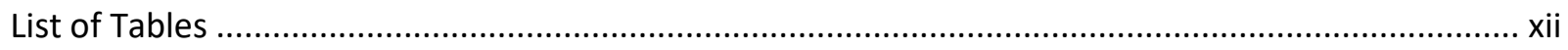

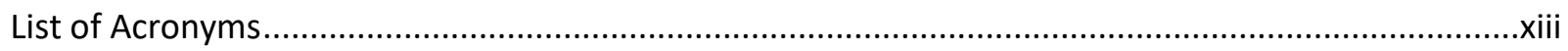

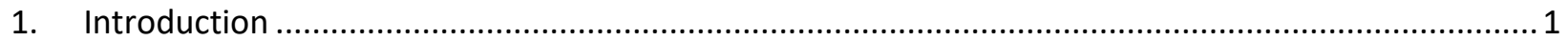

1.1 Perspective on Streams and Land Use Modifications............................................................... 1

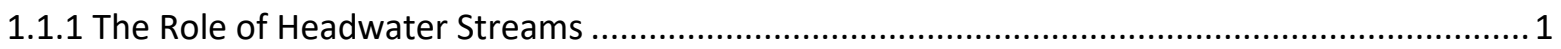

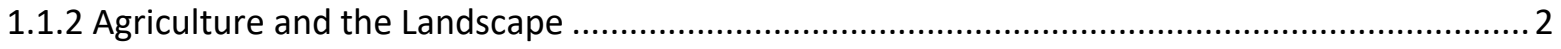

1.1.3 Agriculture and Stream Modification .............................................................................. 3

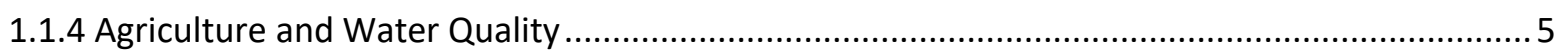

1.2 Use of Models and Application of Geographic Information System in Modelling: ......................... 8

1.2.1 Historical Perspective of the Use of Models and Modelling .................................................. 8

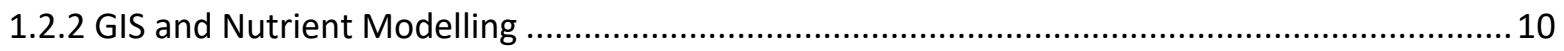

1.2.3 The Grand River Basin (GRB), Southwestern Ontario ......................................................15

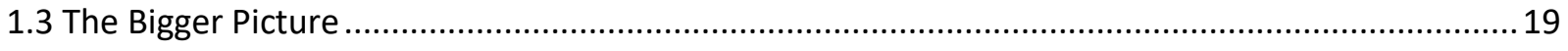

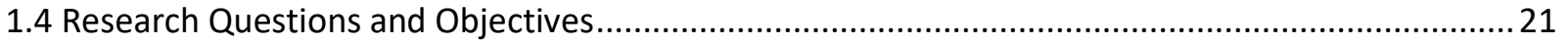

2. SWAT modeling of hydrology, and sediment and nutrients export into Lake Erie from the Grand

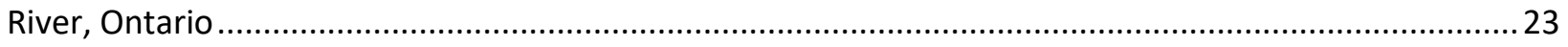

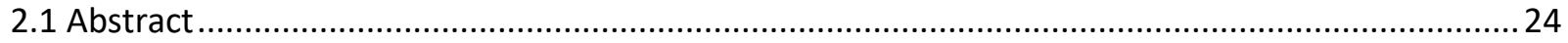

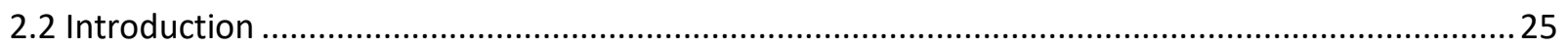

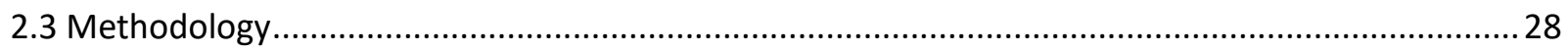

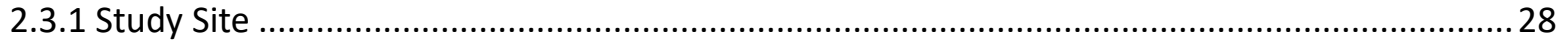

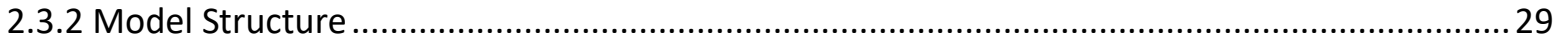

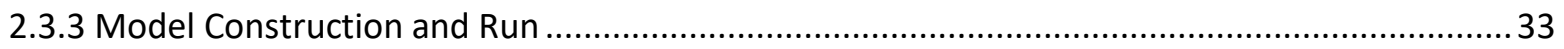

2.3.4 Sources and Preparation of SWAT Model Input Data............................................................ 33

2.3.5 Sensitivity Analysis, Calibration, Validation and Uncertainty Analysis .................................. 38

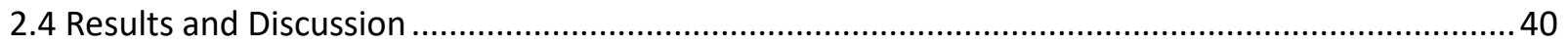

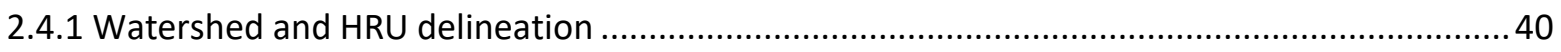

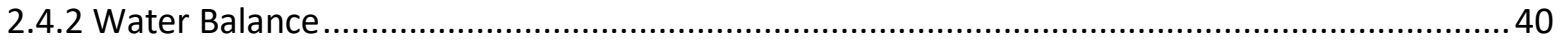




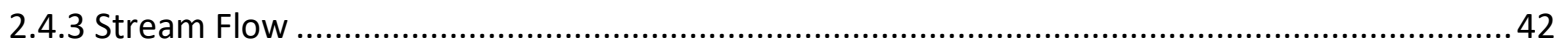

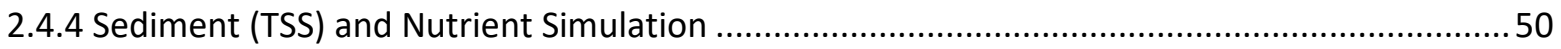

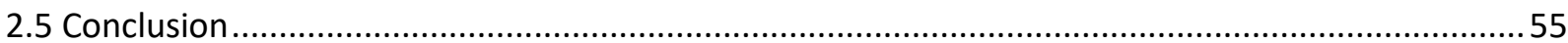

3. Modeling the natural drainage network of the Grand River, southern Ontario based on digital elevation models: agriculture may increase total channel length of low-order streams.........................56

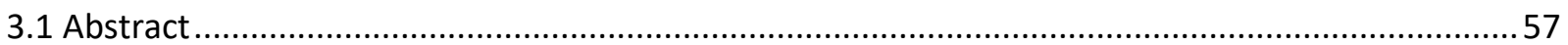

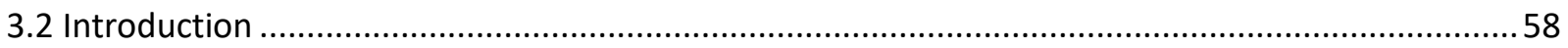

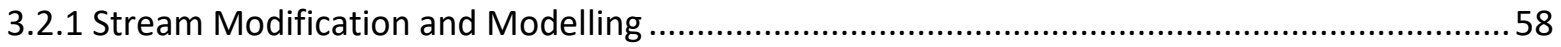

3.2.2 The Grand River Basin, southern Ontario ......................................................................... 61

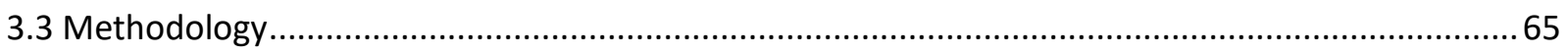

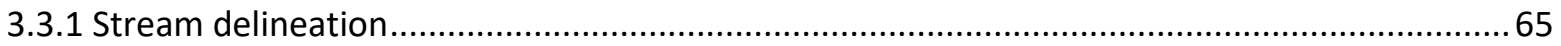

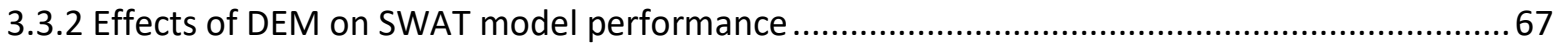

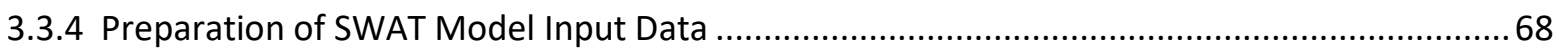

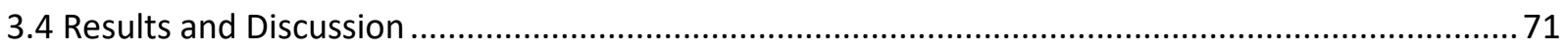

3.4.1 Stream network delineation ........................................................................................ 71

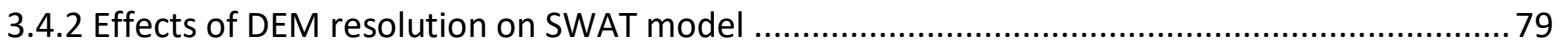

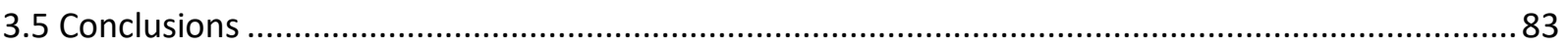

4. Impact of Best Management Practices (BMPs) on Sediment and Phosphorus loading from the Grand River Watershed to Lake Erie using the Soil and Water Assessment Tool (SWAT) .................................85

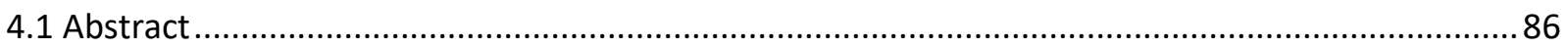

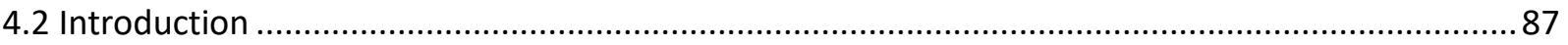

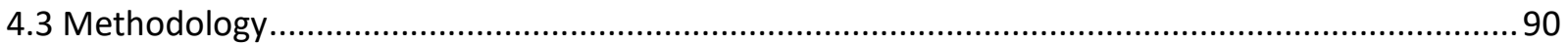

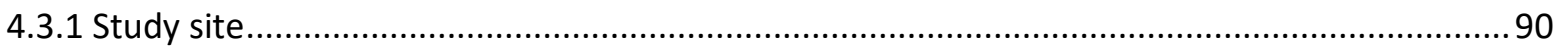

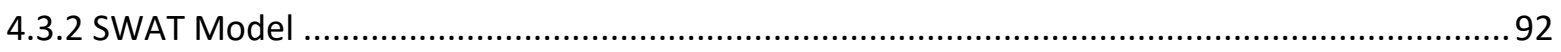

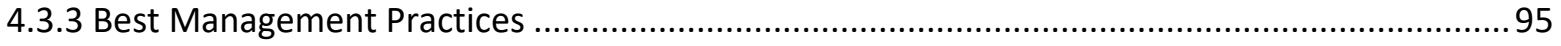

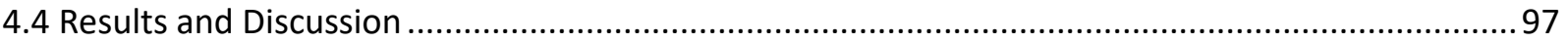

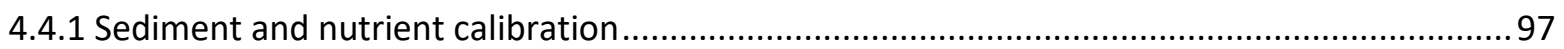

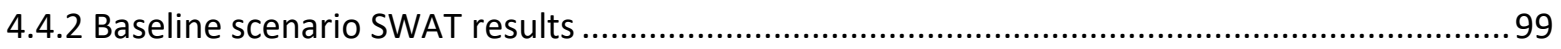

4.4.2 SWAT results with various BMPs implemented................................................................ 102

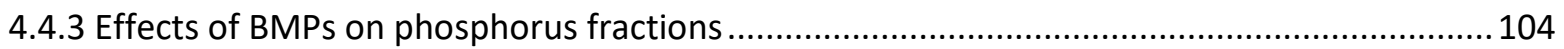

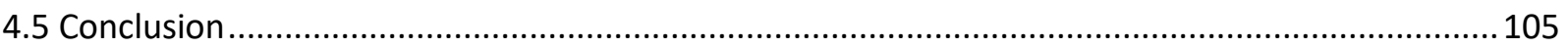




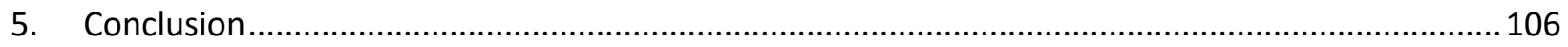

5.1 The need for data in the modelling environment.............................................................. 106

5.2 SWAT and hydrology, sediment and nutrient export from the GRW into Lake Erie ...............109

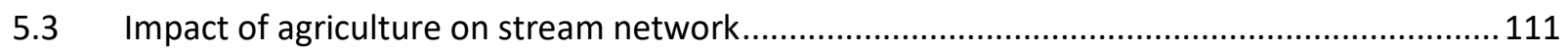

$5.4 \quad$ Remediating agricultural watersheds with BMPs ............................................................. 112

$5.5 \quad$ Future application of the SWAT model in the GRW ........................................................113

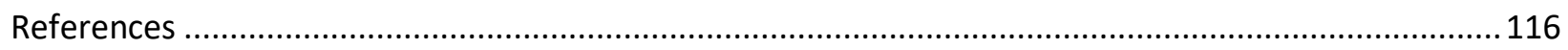




\section{List of Figures}

Figure 1.1: Lake Erie algal bloom (October 9, 2011) is recurring on an annual basis especially in the western section of the lake. (Image credit: NASA Earth Observatory/Landsat-5) .............7

Figure 1.2: Models exist on a continuum ranging from statistical to deterministic (Image modified

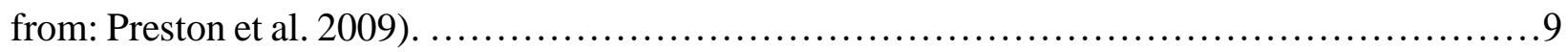

Figure 1.3: SWAT model processing in a GIS environment. ..............................11

Figure 1.4: Schematic of SWAT developmental history (Image credit: Gassman et al. 2007)...13

Figure 1.5: The Grand River watershed, located in southwestern Ontario, drains into Lake

Erie. .17

Figure 2.1: Location of tile drains in the Grand River watershed (Produced using information under License with the Grand River Conservation Authority (C) Grand River Conservation

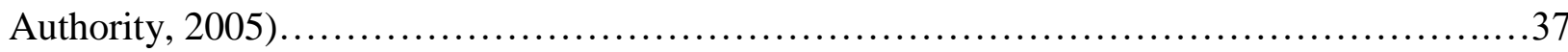

Figure 2.2: Landscape water balance in the Grand River for the simulation years (20012010)

Figure 2.3: Hydrographs for stations used in calibration and validation. At Dunnville station, only a simulated hydrograph is presented since no flow measurements are taken at this location for the period 2001-2010. The 95PPU band contains the 95\% of predictive uncertainty corresponding to the behavioural parameter sets used during the simulation.

Figure 2.4: Monthly summaries of average water yield at different stations in the Grand River watershed. 
Figure 2.5: SWAT simulated values of a) average monthly total suspended sediment concentrations at different sites in the Grand River watershed for the years 2001-2010; b) average monthly sediment yield at different sites in the Grand River watershed for the years 2001-2010; c) average monthly total phosphorus yields at different sites in the watershed; d) average monthly nitrate concentration at different sites in the watershed.

Figure 3.1: The Grand River watershed is located in southwestern Ontario and drains into Lake Erie. The latitude, altitude and proximity to Lake Erie influence the climate of the Grand River area. The headwaters of the Grand River lie in the north and as it makes its way to Lake Erie in the south, it traverses four different climate zones. On average, the GRB receives $93.3 \mathrm{~cm}$ of precipitation each year (GRCA 2013). The mean temperature of headwater streams is around $6^{\circ} \mathrm{C}$ while Lake Erie is around $9^{\circ} \mathrm{C}$ while the average annual temperature of the watershed is $7.8^{\circ} \mathrm{C}$ (Mayer and Delos Reyes 1996). (Credit: Sub-basins division modified from GRCA geospatial datasets).

Figure 3.2: Comparison of the actual stream network to topographically derived stream networks demonstrating higher stream density in the actual stream network versus the topographically extracted stream network in the Conestogo (A) and Upper Grand (B) sub-basins

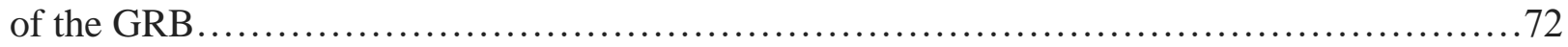

Figure 3.3: Stream length of different stream order of the Grand River stream network........74

Figure 3.4: a) simulated stream flow (1980-2010) predicted by SWAT model using DEMs of varying resolutions, b) comparison of average monthly simulated stream flow (over period 1980 - 2010) predicted by SWAT model using DEMs of varying resolutions, c) simulated total 
suspended solids (1980-2010) predicted by SWAT model using DEMs of varying resolutions, d) comparison of average monthly total suspended solids (over period 1980 - 2010) predicted by SWAT model using DEMs of varying resolutions...................................... 82

Figure 4.1: The Grand River watershed in southern Ontario is an intense agricultural basin that originates at the Dundalk Highlands and flows through Dunnville into Lake Erie. .91

Figure 4.2: Comparison of simulated total suspended sediment (TSS) and measured TSS at York monitoring station, 2002-2010. Measured TSS data from Ontario's Provincial (Stream) Water Quality Monitoring Network.

Figure 4.3: SWAT simulated sub-basin baseline yields of a) annual average sediment; b) annual average soluble P (DRP); c) annual average soluble P (DRP); d) annual average sediment P (particulate P), for the years 2001-2010 in the Grand River Watershed. 101 


\section{List of Tables}

Table 2.1: Hydrological algorithms used to construct the SWAT model of the Grand River watershed.

Table 2.2: Location and operators for different flow gauges used in the calibration and validation

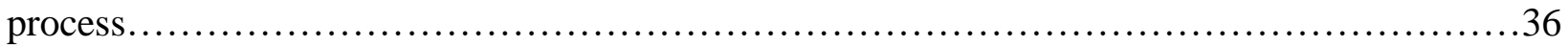

Table 2.3: Parameters used during first iteration of hydrology calibration.....................39

Table 2.4: Parameters values that were used for hydrology calibration and validation..........42

Table 2.5: Calibration and validation objective function values for different stations, observed and

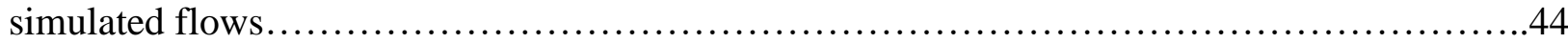

Table 2.6: Sensitivity analysis for parameters used in headwater streams calibration............47

Table 2.7: Sensitivity analysis for parameters used in the main Grand River calibration .48

Table 3.1: Total $\mathrm{km}$ of the predicted channels in stream networks derived from DEM models that overlap or lie within varying distances of the existing channels in the Grand River Basin........73 Table 3.2: Performance of stream network models derived from $10 \mathrm{~m}$ and $25 \mathrm{~m}$ DEMs in predicting locations of first and second order channels............................... 74

Table 3.3: Analysis of stream network and land use in major sub-basins in the GRB...........78 Table 3.4: Comparison of SWAT models constructed using different DEM resolutions, compared against a SWAT model constructed using a ground-truthed stream network

Table 4.1: Sediment, orgP, particulate $\mathrm{P}$, and TP loading at the Dunnville under various BMP scenarios, values in parentheses represent percent reduction relative to baseline model. ... 


\section{List of Acronyms}

BAP Bioavailable Phosphorus

BMPs Best Management Practices

DRP/SRP Dissolved/Soluble Phosphorus

GLWQA Great Lakes Water Quality Agreement

GRCA Grand River Conservation Authority

GRW/GRB Grand River Watershed/Basin

HABs Harmful algal blooms

IJC International Joint Commission

SUFI2 Sequential Uncertainties Fitting Ver-2

SWAT Soil and Water Assessment Tool

SWATCUP SWAT Calibration and Uncertainty Procedures

TN Total Nitrogen

TP Total Phosphorus

USEPA Environmental Protection Agency

USGS United States Geological Survey 


\section{Introduction}

\subsection{Perspective on Streams and Land Use Modifications}

\subsubsection{The Role of Headwater Streams}

Strahler (1952) described headwater streams as those streams which are first order, or that can be viewed on a 1:100,000 scale. Over time, this definition has been modified and has now included those tributaries that have a stream order of less than three (Freeman et al. 2007), possess a riparian distance not exceeding $10 \mathrm{~m}$ (Peterson et al. 2001), or drain less than $1 \mathrm{~km}^{2}$ surface area (Gomi et al. 2002). In a stream network, headwater streams are most abundant both in terms of length and number (Horton 1945) and may represent over $80 \%$ of the total stream lengths of all watersheds (Horton 1945; Seitzinger et al. 2002). Headwaters are important lotic systems that represent hydrological connectivity (Freeman et al. 2007) between upland and downstream waters (King et al. 2009) by facilitated transferral of mass, momentum, energy, or biota within or between various components of the hydrologic cycle (Nadeau and Rains 2007).

Whether perennial or intermittent, headwater streams are important sites for biogeochemical transformation of nutrients (King et al. 2009). With over $80 \%$ of total stream length being headwaters, detailed research on their functions and importance is much needed since they play a major role in determining water quality downstream. Due to their dendritic patterns and their large width to depth ratio, these streams are critical in controlling the amount of nutrients that are exported downstream (Peterson et al. 2001). Alexander et al. (2007) have shown that it is the dynamic coupling of hydrological and biogeochemical processes in headwaters that regulates not only the chemical form of the nutrient that is being transported but also its residence time and longitudinal transport to downstream receiving waters. For example, Peterson et al. (2001) have 
concluded that the fastest uptake and subsequent transformation of nitrogen takes place in headwater streams. Alexander et al. (2000) have further quantified nitrogen transport from headwaters to downstream waters and found that first-order streams account for as much as $65 \%$ of the nitrogen flux in second-order streams. On the other hand, a review by Withers and Jarvie (2008) concluded that phosphorus cycling includes many facets (ranging from forms, transformation and sinks) that have varying significance across the continuum of headwaters and high order streams. Furthermore, headwater streams play a major role in processing and retaining phosphorus, hence, regulating downstream delivery to receiving waterbodies (Withers and Jarvie 2008).

\subsubsection{Agriculture and the Landscape}

Land cover and land use (LCLU) modifications at the hands of humans have affected between one-third and one-half of all terrestrial and aquatic environments (Vitousek et al. 1997) and are projected to increase due to the growing demand for various human related land uses (Carpenter 2006). Land cover refers to the actual surface cover of the ground, for example, vegetation, bare soil, rocks, or water, while land use refers to the purpose for which an area is being used, such agriculture, residential, industrial or recreation. The additive effects of rapid increases in human population, industrialization and modern agricultural operations have completely modified and transformed natural systems into unsustainable ecosystems that exist to varying temporal and spatial extents on different continents. Over the past 300 years, global forests and woodlands have decreased by around 25\% (5,440 MHa to 4,150 MHa), agricultural lands have increased 5.5-fold (265 MHa to 1,491MHa) and pastures have increased 6.6-fold (524 Mha to 3,451 Mha) (Goldewijk 2001). In the United States and Canada, agricultural lands have increased over 70-fold in the past 300 years (Goldewijk 2001). According to Vitousek et al. (1997), 10-15\% 
of the total land surface is occupied by row-crop agriculture and or by urban-industrial sites. Wetlands have suffered a fate similar to that of forests, and are among the most affected ecosystems globally. A review of 189 reports by Davidson (2014) suggested that the long-term loss of natural wetlands was between $54-57 \%$ on average, but has been as much as $87 \%$ since 1700. In short, agriculture has been the greatest modifier of land cover in human history.

\subsubsection{Agriculture and Stream Modification}

A stream is naturally sinuous and meanders in response to the geomorphology and topography of the landscape. Stream channelization occurs when the length of a winding stream channel is reduced and replaced by a straightened course with drastically altered stream width, depth and bank slopes. Such straightened streams now exert more energy and hence the erosive capacity of the stream increases. Although farmers dislike losing their farmland to the erosive forces of streams, stream channelization offers the trade-off of effective drainage and enhanced crop growth in wet soils. In addition to tile drains, stream channelization is widespread around croplands resulting in channelized headwaters in agricultural watersheds of Canada, the Midwestern United States, and Europe (Jordan et al. 2016). Schoof (1980) has stated that between 1820 and 1970, over 321,000 miles of streams in the US have been channelized and over $80 \%$ of the total channelization had taken place in 15 states.

Streams exist in harmony with their drainage basins; however, transformation of the natural meandering features of streams and rivers into straightened courses have resulted in drastic changes in their hydrologic characteristics (for example, high flows are higher and low flows are lower), sediment transport, geomorphic features, water-quality, and ecologic characteristics, as well as creating numerous negative economic and social consequences (Alexander et al. 2012). In 
short, channelized streams are morphologically unstable, biologically unproductive, and aesthetically displeasing (Nunnally 1978).

Vegetation affects stream flow in three significant ways: it decreases the effective size of the channel; it increases the resistance of stream banks to erosion; and, it increases the hydraulic resistance (Nunnally 1978). High sediment transport in streams results in increased turbidity, causing the sediments to overwhelm benthic organisms and limit light penetration within the water column. Primary productivity and food webs can be disrupted, thus affecting species richness and diversity not only in headwaters but also in downstream waters (USEPA 2005). However, vegetation in the riparian zone traps sediments and reduces its impact on the ecology of downstream systems. In addition, trees along the river bank contribute valuable shade to streams, helping to stabilize water temperature to the benefit of many fish and invertebrate species. Leaves that fall into the streams serve as a food source and some eventually decay into small organic carbon molecules that serve as electron donors during denitrification (USEPA 2005). Loss of vegetation from the riparian zone due to land use or land cover modification can, then, have substantial effects on the ecology of streams.

Channelization is also responsible for spatial harm, particularly the degradation of the aquatic ecosystems in the downstream waters. Residence time is lower in channelized streams, and as such, enough time is not available for nutrients such as phosphorus or ammonium to be assimilated rapidly by primary producers into their biomass or nitrates to diffuse into the hyporheic zone and be denitrified. Since the 1980s, excessive application of fertilizer along with intense subsurface drainage and stream channelization in the agricultural watersheds have resulted in a substantial increase in riverine nutrient exports (David et al. 2001). There are additional financial costs associated with the increased erosive power of channelized streams. During floods, more 
sediment is eroded from the stream banks and from the stream beds thus increasing the load that is transported by the stream. Where channelization ends, the stream returns to its natural sinuosity, bed roughness, slope and flow rate. This transition triggers deposition in the unchannelized reaches and in nearby lakes. Land owners are now at increased risks of flooding in the area of deposition and they may opt to dredge this section, thus compounding the problem. Many natural streams and lakes are used for recreational purposes such as fishing and canoeing. Unnavigable streams and streams with poor water quality streams offer limited social or economic opportunities.

\subsubsection{Agriculture and Water Quality}

The USEPA (1994) has identified agricultural practices as the main reason for water quality (sediment, nutrient, pesticides, dissolved oxygen) degradation in rivers and lakes in the US. Agriculture contributes to at least $50 \%$ of nutrient input into lakes and over $60 \%$ into rivers resulting in cultural eutrophication (USEPA 1994). Eutrophication is the most widespread water quality issue in the US and in many countries worldwide (USEPA 1996; Carpenter et al. 1998) and occurs when primary productivity is stimulated due to the input of nutrients - reactive phosphorus, nitrogen or silica - that were previously limiting growth. Over the past forty years agriculture in Canada has similarly become the leading non-point source of pollution in Canadian surface waters (Rousseau et al. 2013).

Dead zones have perhaps now become the largest, most persistent global water-quality issue, and a chief stressor on aquatic ecosystems (Diaz and Rosenberg 2008; Conley et al. 2011). Globally, there are over 400 recorded dead zones and their distribution closely matches the global human footprint in the northern hemisphere (no inference can be drawn for the southern hemisphere since dead zones are now being identified) (Diaz and Rosenberg 2008). In North 
America, eutrophication and consequent dead zones formations have consistently plagued the Great Lakes and many estuarine environments such as the Gulf of St. Lawrence, Gulf of Maine, the Louisiana shelf and coastal California. Also, dead zones have developed in many continental seas, which include the Baltic (largest dead zone in the world), Kattegat, Black Sea, and East China Sea - all of which have supported historically important fisheries (Diaz and Rosenberg 2008). Riverine runoff of fertilizers and combustion of fossil fuels are chiefly responsible for exacerbating eutrophication in all of these areas (Diaz and Rosenberg 2008).

Temperate freshwater lakes are most commonly phosphorus limited (Vollenweider 1968; Schindler 1977, 1978; Hecky and Kilham 1988). During the 1960s, excessive phosphorus was responsible for severe Anabaena, Aphanisomenon, and Microcystis blooms in Lake Erie (USEPA 2011). Although algal blooms continued through the 1970 s, a $60 \%$ reduction of phosphorus by 1985 resulted in a corresponding 89\% decrease in Aphanizomenon (USEPA 2011). However, Microcystis blooms returned to the lake in the 1990s and have continued to date, especially in the western basin (fig. 1.1) (USEPA 2011). During seasonal stratification, excess nutrients that are exported from the surrounding watersheds stimulate phytoplankton growth. Upon senescence, the phytoplankton's biomass sinks to the bottom where the already oxygen deficient hypolimnion now has to support bacterial decomposition of the organic matter. Consequently, demersal, epi-benthic and benthic species can no longer be supported in areas of hypoxic conditions. Hypoxia affects growth and feeding, which eventually affect individual fitness (Wu 2002). 


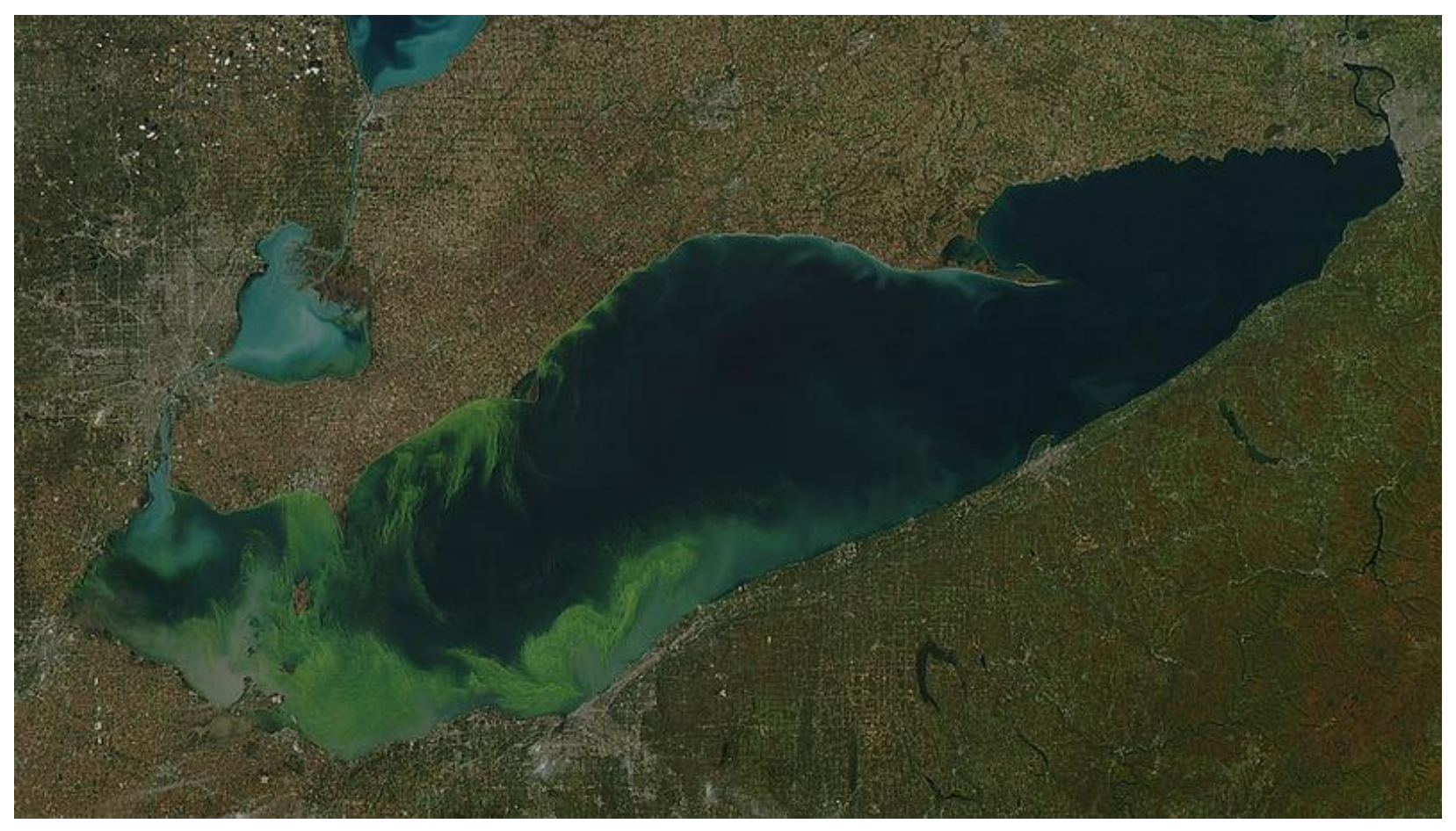

Figure 1.1: Lake Erie algal bloom (October 9, 2011) is recurring on an annual basis especially in the western section of the lake. (Image credit: NASA Earth Observatory/Landsat-5)

There are many social and economic costs associated with cultural eutrophication. Properties that are adjacent to rivers and lakes are worth substantially more when the water is suitable for leisure activities. Similarly, eutrophication in nearby streams and lakes can have significant impact on house prices. For example, in Maine, lakeside property prices decreased up to $\$ 6,200$ per 10 metre of shoreline frontage for each metre loss in water clarity (as measured by Secchi depth light penetration) (Michael et al. 1996). Dodds et al. (2009) have quantified a potential annual cost of $\$ 2.2$ billion associated with cultural eutrophication in US freshwaters with respect to recreational water usage, waterfront real estate, spending on recovery of threatened and endangered species, and drinking water. 


\subsection{Use of Models and Application of Geographic Information System in Modelling:}

\subsubsection{Historical Perspective of the Use of Models and Modelling}

A scientific model is a set of constructs that describe a natural process. According to Ritchley (2012), for a model to be referred to as scientific, it must satisfy two criteria: the model must have at least two mental constructs that will function as variables that can support a range of values or states, and there must be a way to establish relationships between the variables.

Models have been around for centuries. For example, in 1896 Arrhenius used a simple model to calculate how $\mathrm{CO}_{2}$ emissions could affect radiation and how the amount of $\mathrm{CO}_{2}$ itself may change over time. Chamberlin (1897) followed up with the remarkable statement on the use of assumptions in modelling and the speculative nature of the information derived from his model, “...it (carbon dioxide) is an element of supreme importance and should be persistently attacked

until it yields up its truths. This must be my excuse for offering a paper which, I am painfully aware, is very speculative in many of its parts. All our attempts at the solution of climatic problems proceed on some conscious or unconscious assumption concerning the extent and nature of the atmosphere at the stage involved." [p. 653]

Historically, models have also been used to account for and predict changes in water quality. The evolution of water quality modelling began with the works of Streeter and Phelps (1925) who constructed a mathematical model to predict the effects of organic waste on downstream dissolved oxygen concentration in the Ohio river (Reichert 2001). This early model took only two processes into consideration: bacterial decomposition in the stream and atmospheric reaeration (Reichert 2001). This model was improved to include BOD removal, biodegradation, 
and settling, the effects of dispersion, sediment, nitrogenous and carbonaceous oxygen demand and the biological processes of photosynthesis and respiration (Reichert 2001). In 1971, the USEPA added various nitrogen processes and the model was called QUAL1; thereafter, phosphorus cycling and algae were added and the model was then called QUAL2 (Reichert 2001). At present, the working version is QUAL2K.

Water-quality models are basically of two types: deterministic or statistical (fig. 1.2) (Preston et al. 2009). Deterministic models utilize mass balance for explicit physical environmental processes and are applied to small sites or single streams (Preston et al. 2009). Statistical models estimate water quality by relating field measurements to causative environmental factors and use simple-multiple or linear-nonlinear regression tools (Preston et al. 2009).
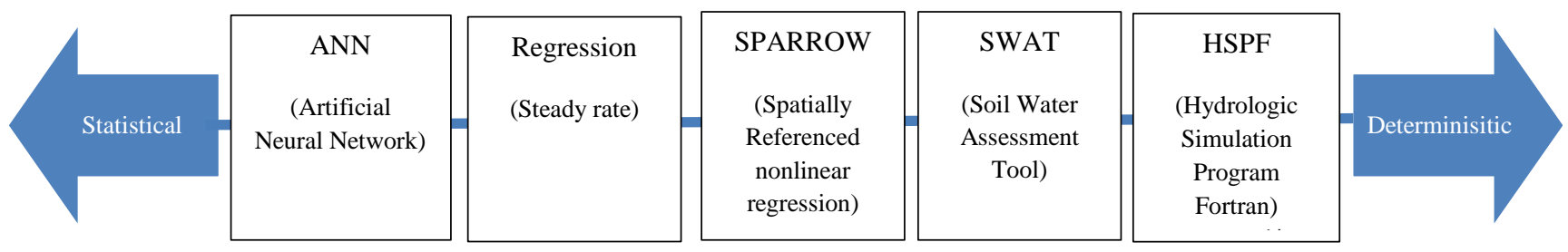

Figure 1.2: Models exist on a continuum ranging from statistical to deterministic (Image modified from: Preston et al. 2009).

Many nutrient models have been built and tested in different environments in order to predict nutrient export from watersheds. All nutrient models rely on simple assumptions pertaining to the loading rate, landscape characteristics, transport mechanisms and transformation rates. Alexander et al. (2002) compared the predictive abilities of six empirical and quasi-empirical nitrogen export models that reported $\mathrm{R}^{2}$ values of 50 to 90 percent in the spatial variability for 16 watersheds in the US. In addition to $\mathrm{R}^{2}$, the degree of bias and precision were used to determine 
the models' accuracy. With respect to the explanatory and response variables in their models, $\mathrm{R}^{2}$ was very sensitive to several of their statistical variables, thus making $\mathrm{R}^{2}$ an unreliable predictor of a model's performance (Alexander et al. 2002). The SPARROW (Smith et al. 1997) and HOWARTH (Howarth et al. 1996) models were capable of predicting total nitrogen export while others, such as GLOBAL (Seitzinger and Kroeze 1998; Caraco and Cole 1999), LS1-GLOBAL (Seitzinger and Kroeze 1998) and LS2-GLOBAL (Caraco and Cole 1999), were only capable of predicting nitrate-nitrogen export (Alexander et al. 2002). A closer examination of the models revealed that they differ in their levels of spatial resolution as well the complexity of processes (Alexander et al. 2002). All models showed some degree of bias in predicting nutrient export; however, SPARROW, LS1-GLOBAL, and GLOBAL reported less than 5\% median prediction error. The degree of complexity influences a model's accuracy: models that incorporated more details on nutrient sources, land and water attenuation, and water flow paths are able to produce lower degree of biases and higher precision and $\mathrm{R}^{2}$ values (Alexander et al. 2002).

\subsubsection{GIS and Nutrient Modelling}

GIS has been incorporated widely into hydrological and watershed nutrient export models. With GIS, these models can now add spatial elements and also perform analysis of variables such as slope, aspect or watershed size (Heywood et al. 2006). Digital Elevation Models (DEM) allow users to determine slope and aspect which can then be used to predict runoff and stream-flow within a watershed (Heywood et al. 2006). Queries can then be run on attribute tables to extract areas that either function as contributors or distributors to the watershed variable (Heywood et al., 2006). Other watershed variables, such as climate, soil type, vegetative cover, population density, point sources of pollution, and farming practice, are widely available in digital raster or vector 
format (Heywood et al. 2006). As with any GIS data, its accuracy is completely dependent on the integrity of the source data, as well as how it was encoded and referenced.

The Soil and Watershed Assessment Tool (SWAT) (Srinivasan et al. 1993; Arnold et al. 1998) was developed by USDA Agricultural Research Service (USDA-ARS) and Texas A\&M AgriLife Research and is completely dependent on a GIS system which is needed to store and display relevant maps, to delineate watersheds, and to identify the stream reaches within the drainage basin (fig. 1.3).

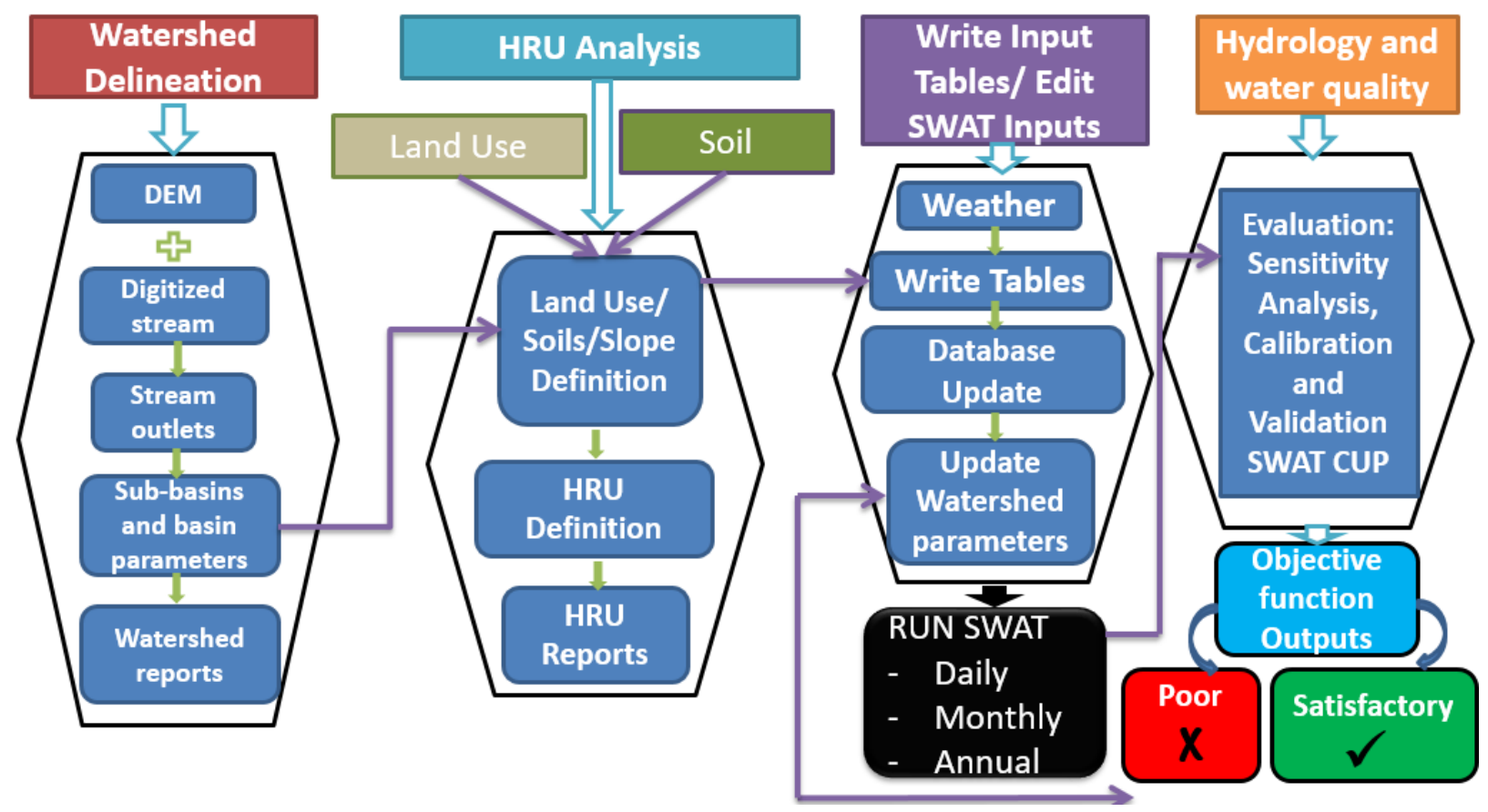

Figure 1.3: SWAT model processing in a GIS environment.

SWAT is a freeware that is continuous-time, semi-distributed, physically-based watershed model that operates on a daily time step (Gassman et al. 2007; Arnold et al. 2012). Due to SWAT being physically based, it provides the unique opportunity to simulate the hydrology and water quality of ungauged streams and to quantify the relative impacts of alternative input data on 
hydrology and water quality in watersheds. Today, SWAT is widely used to assess the environmental impacts of land use management on water quantity and quality in small agricultural fields to continental size watersheds with varying soil types, topography and land uses (Gassman et al. 2007; Arnold et al. 2012). Furthermore, SWAT being a continuous time model, is capable of simulating periods ranging from 1 to 100 years, and provides output on daily, monthly or annual time scales.

SWAT has incorporated a number of previous models into its model structure (figure 1.4). Initially, SWAT was developed by incorporating the Simulator for Water Resources in Rural Basins (SWRRB) model and the Routing Outputs to Outlet (ROTO) model (Gassman et al. 2007; Arnold et al. 2012). The SWRRB model, a nonpoint source loading model, was itself composed of three existing ARS models: the Chemicals, Runoff, and Erosion from Agricultural Management Systems 2 (CREAMS2) model, the Groundwater Loading Effects on Agricultural Management Systems 3 (GLEAMS3) model, and the Environmental Impact Policy Climate 4 (EPIC4) model. Gassman et al. (2007) indicated that the original intent of the SWAT model was to simulate management impacts on water and sediment transfer in ungauged rural watersheds across the United States. 


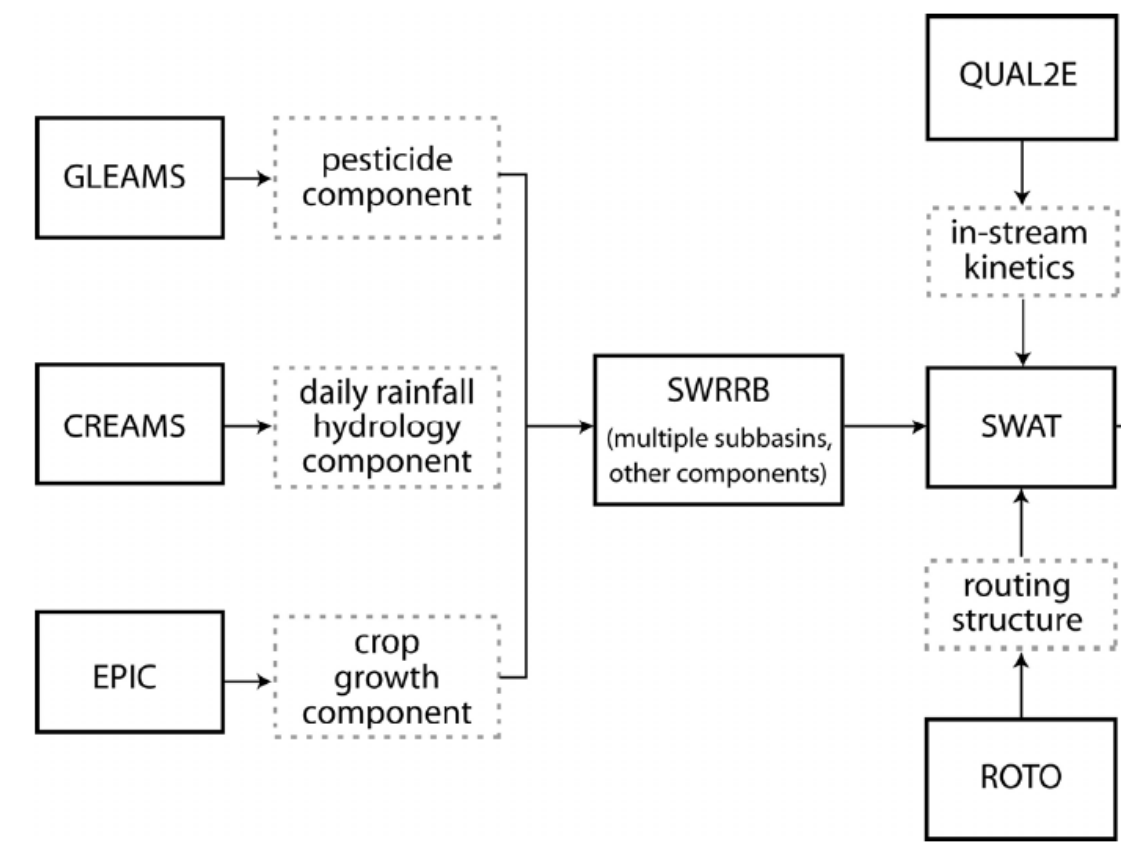

Figure 1.4: Schematic of SWAT developmental history (Image credit: Gassman et al. 2007)

The first released version of SWAT was utilized in the early 1990s and with subsequent development and incorporation of other routines such as routing components, enhanced sediment transport, in-stream kinetics from the QUAL2E model, phosphorus, nitrogen and carbon cycling, and best management practices, a number of versions were released over time (Gassman et al. 2007; Arnold et al. 2012). In SWAT's algorithm, the watershed is first divided into sub-basins. Sub-basins are defined by unique geographic location and are spatially linked to each other. Each sub-basin contains a tributary channel, a reach (main channel) and at least one hydrologic response unit (HRU). HRUs are the next level of subdivision and represents a unique combination of soil attributes, land use and slope class. HRUs were later incorporated into the SWAT model from the Hydrologic Unit Model for the United States (HUMUS) modelling tool. During a SWAT run, all similar HRUs are combined. It is expected that since their compositions are the same, they will be behave the same way with respect to crop growth and management practices, surface and 
subsurface hydrology, nutrient cycling, and sediment, nutrient, pesticide and bacterial loadings. Loading from a sub-basin is calculated by combining the loadings from the sum of all unique HRUs in that sub-basin. While computation time increases significantly with the number of HRUs in a watershed, the trade-off is increased accuracy of the prediction of loading rates from the subbasins and the watershed.

Prior to settling upon the SWAT model, two other models were investigated with respect to their suitability for application in the nutrient modelling in the Grand River watershed. Firstly, the Global Nutrient Export from Watersheds (Global NEWS) model was selected by the researcher based on its utility, input data requirements and model outputs. This model was developed in 2002 by an international, interdisciplinary group that aimed on investigating the relationship between human induced activities and nutrient loading and enrichment in receiving waterbodies (Seitzinger et al. 2005, Mayorga et al. 2010). The Global NEWS model is made up of river-basin scale submodels that are capable of simulating sources and export of various components such as dissolved organic carbon, nitrogen and phosphorus (DOC, DON, DOP), dissolved inorganic nitrogen and phosphorus (DIN, DIP), total suspended solids (TSS), particulate organic carbon (POC), particulate nitrogen and phosphorus (PN and PP), and dissolved silica (DSi) (Seitzinger et al. 2005, Mayorga et al. 2010). Furthermore, the NEWS model can be applied retrospectively and prospectively, thus allowing for manipulation of climate and various land use scenarios (Seitzinger et al. 2005, Mayorga et al. 2010). After trying out the NEWS model on the GRW, the model was shelved due perhaps to the small size of GRW, making NEWS more applicable at larger regional to continental scales. Secondly, the USGS's SPARROW (SPAtially Referenced Regressions On Watershed attributes) model was also investigated for its applicability in modelling sediment and nutrient export from the GRW. SPARROW relates water-quality data collected from various 
monitoring sites throughout the watershed to attributes of the basin such as point and non-point sources and the many environmental conditions that impact delivery to streams and in-stream processing. This model is primarily a statistical model that is made up of nonlinear regression equations that relate the non-conservative transport of substances from the land surface to streams and receiving water bodies. In addition to outputting the concentrations, fluxes, and yields, SPARROW has the capacity for providing a statistical basis for simulated loading rates at unmonitored sites in the watershed (Smith et al. 1997; Schwarz et al. 2006). SPARROW was also shelved due to inadequacy of stream loading data. Too few areas are monitored in the GRW and even where monitoring occurs, monitoring is insufficient, thus, severely affecting the calibration and validation of the SPARROW model.

\subsubsection{The Grand River Basin (GRB), Southwestern Ontario}

Before the arrival of Europeans around the mid-1770s, forests and wetlands dominated the

GRB. Similar to the Grand Marsh, the GRB has been progressively modified to make way for lumber exploitation, agriculture, pasture, settlements and industry by removing almost $95 \%$ of historical forest, and by stream engineering of the waterscapes, especially damming (Scott and Imhof 2005). The GRB covers an area of around 7,000 $\mathrm{km}^{2}$, and is the largest watershed in southwestern Ontario. Spanning a length of $290 \mathrm{~km}$ and having an elevation differential of about $362 \mathrm{~m}$ from source to mouth, the Grand River originates at the Dundalk Highlands and flows through Port Maitland into Lake Erie (figure 1.5; Scott and Imhof 2005). By the early 1900s, there was noticed degradation in water quality due to changes in the landscape, and by 1934 the Grand River Commission had received its charter to find a solution to the degradation in stream flows and water quality (Scott and Imhof 2005). To restrict high flows in the spring and to augment low summer flows, the commission settled upon building three reservoirs in the area, the Shand Dam 
being the first dam built in Canada (1939) for the purpose of water conservation (Scott and Imhof 2005). Together with lengthening of ditches for agricultural purposes, current land use practices are contributing to further degradation in both water quality, via chronic nutrient loading, and degradation of habitat for many aquatic species within the watershed (Cooke 2006). 


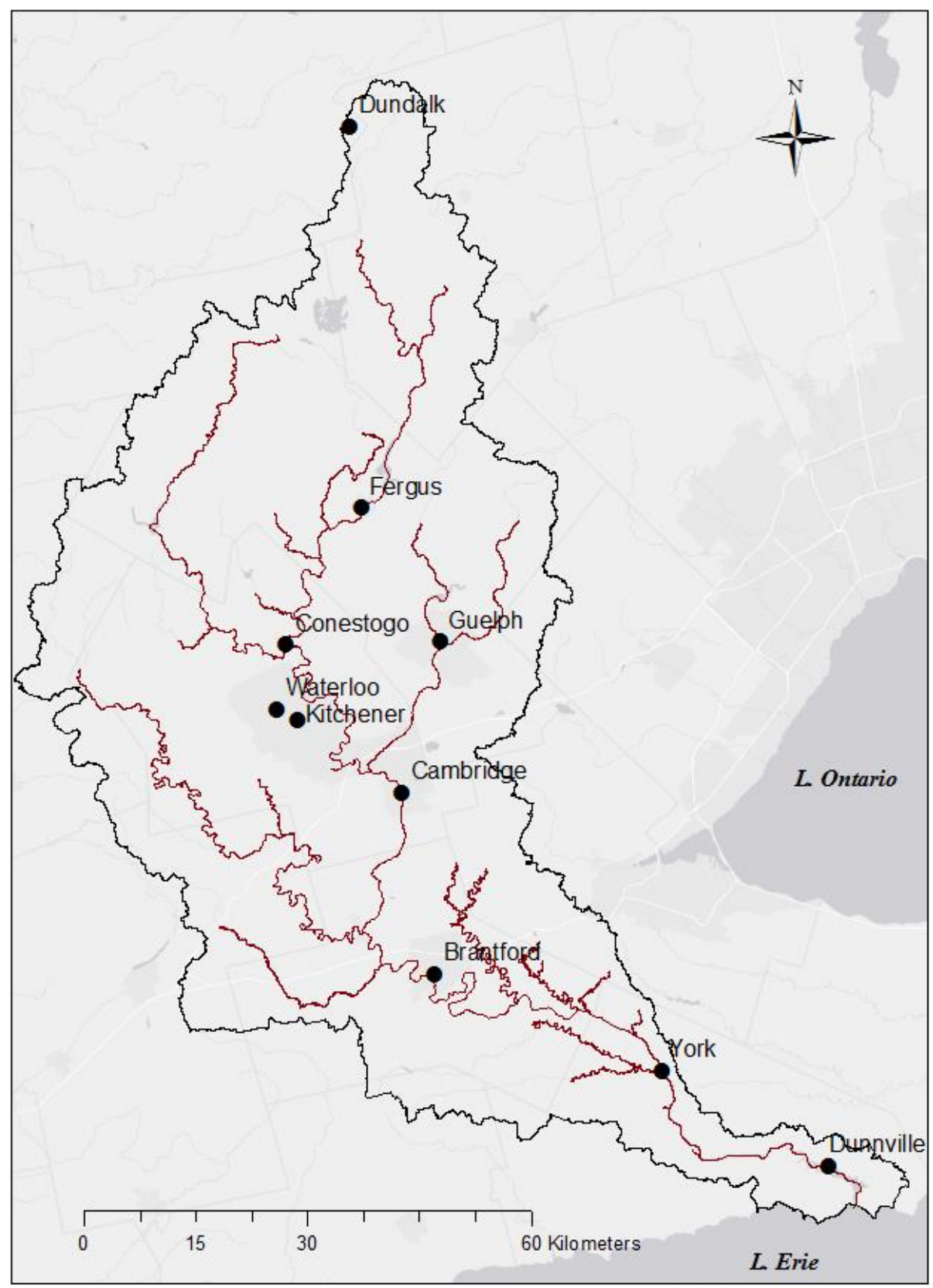

Figure 1.5: The Grand River watershed, located in southwestern Ontario, drains into Lake Erie. 
At present, most of the watershed is rich in agricultural (76\%) and forested areas (17\%), while the centrally located urban centres cover about $5 \%$ of the total area (Cooke 2006). Since the mid-1990s, cover (forests, grassed floodplains and riparian areas) has increased to 19\%. With about 6,000 farms, agriculture has remained the dominant land use (93\% of land is rural) in the GRB (Farwell et al. 2008). A 1982 Grand River Basin Water Management Study clearly identified intensive agricultural practices as the main nonpoint source of pollution responsible for the impairment of the water quality in the Grand River (GRIC 1982). In addition, intensive livestock operations are a dominant feature in the middle GRB (Mayer and Delos Reyes 1996). According to the 2001 census, there were 290,000 head of cattle, 500,000 head of swine and almost 8.8 million head of poultry in the Grand River area (GRCA 2005).

The discharge from sewage treatment plants further exacerbates water quality in the Grand River. Based on the Water Quality Index that is used by the Canadian Council of Ministries of the Environment, the headwaters of the Grand River are classified as 'good'; as the tributaries flow past major agricultural areas, they pick up contaminants and their status drops to 'fair'; and finally, as these larger tributaries and the main Grand River flow past urban centres, water quality drops to 'poor' due to the addition of high levels of phosphorus and nitrogen from storm water and sewage treatment plants (Scott and Imhof 2005; Cooke 2006). Over the years, water quality (based on DO, total nitrogen, phosphorus and suspended solids) has been consistently rated as poor when measured at the Dunnville Dam monitoring site prior to the Grand River entering Lake Erie (Cooke 2006). 


\subsection{The Bigger Picture}

Due to their dendritic patterns and large width to depth ratios, headwater streams are not only important sites for biogeochemical transformation of nutrients but are also critical in controlling the amount of nutrients that are exported downstream ((Peterson et al. 2001; Gomi et al. 2002; Alexander 2007; Drummond et al. 2016). Channelizing streams has improved drainage on farmlands; however, the process has resulted in numerous negative environmental, economic and social externalities. Channelized streams are unable to retain and transform nutrients as efficiently as natural streams, resulting in increased nutrient loads and TSS being carried from these headwater streams to downstream receiving water bodies (Mao et al. 2004).

The reality is farmers are not expected to stop farming and farmers want higher yields. A few sensible and responsible options are available which could allow farmers to have similar yields and at the same time, decrease nutrient export from their farms. Farmers could reduce the rate of fertilizer application by carefully studying best application timing for crop needs to reduce nitrogen leaching and volatilization into the atmosphere. However, due to the extensive presence of subsurface drainage in agricultural fields in southern Ontario such as the Grand, nutrients would still be exported downstream into receiving bodies such as Lake Erie. Channelized first and second order streams are unable to effectively attenuate higher nutrient loading in these watersheds. Most often, river restoration efforts focus on one (or a combination) of three aims: restoration of species, restoration of ecosystems or landscapes, and restoration of ecosystem services (Beechie et al. 2008). Burkaveckas (2007) attributed reduced velocity as being responsible for higher retention rate coefficients (30-fold for $\mathrm{N}$ and 3-fold for $\mathrm{P}$ ) and uptake velocities (10-fold for $\mathrm{N}, 0.6$-fold for P) in restored streams as compared to channelized reaches in Wilson Creek, KY. However, before any restoration can be attempted, one needs to understand the waterscape by knowing for example, 
the stream density, stream pattern, stream length, stream sinuosity, stream flow and physiochemical parameters (examples: TSS, TP, SRP, OP, TN, $\mathrm{NH}_{4}{ }^{+}, \mathrm{NO}_{3}{ }^{-}$, orgC, $\mathrm{pH}$ ). Many of these parameters can be predicted by GIS and modelling while others, such as the physiochemical parameters, have to be actually measured and used in the calibration and validation of hydrologic models such as SWAT. Thereafter, various scenarios referred to as Best Management Practices, such as a reduction in fertilizer application rates, adding riparian zones or adding cover crops, can be implemented in models with the output serving as predictions for scenario analysis. 


\subsection{Research Questions and Objectives}

This study intends to answer three questions:

1. Can SWAT be used to model hydrology, sediment and phosphorus within the GRW?

Specifically, this question will be addressed by the following objectives:

a. Build and test applicability of the SWAT hydrologic model under current climate, land use management, stream network and physiographic conditions in the Grand River Watershed.

b. Calibrate and validate SWAT in order to accurately and efficiently quantify surface water hydrology in the GRW. This calibrated and validated model will be referred to as the baseline model.

c. Predict the sediment and nutrients (phosphorus and nitrogen) loading from the GRW into Lake Erie.

2. Within the Grand River watershed, how has agriculture affected the stream network?

Specifically, this question will be addressed by the following objectives:

a. Use the Hydrology tool in GIS to construct stream network within the Grand River, Ontario, based on different resolutions of digital elevation maps (DEMs) $(10 \mathrm{~m} \times 10 \mathrm{~m}, 25 \mathrm{~m}$ $\mathrm{x} 25 \mathrm{~m})$. 
b. Compare positional accuracies, length and order (Strahler) of stream networks derived from DEMs at different resolutions with that of the published, ground-truthed stream network for the Grand River, Ontario.

c. Using the different resolutions of DEM (10m, 25m, 200m), apply the Soil and Water Assessment Tool (SWAT) model to the Grand River basin in order to simulate hydrology and sediment yields for the years 1980-2010.

And,

3. How would BMPs implementation within the GRW impact sediment and nutrient export from the GRW into Lake Erie?

Specifically, this question will be addressed by the following objective:

a. Use the baseline SWAT model to predict sediment and phosphorus yields that are exported from the basin at Dunnville into Lake Erie if different BMPs were implemented within the watershed. 


\title{
2. SWAT modeling of hydrology, and sediment and nutrients export into Lake Erie from the Grand River, Ontario
}

\author{
Aslam Hanief ${ }^{\mathrm{a}}$ and Andrew E. Laursen ${ }^{\mathrm{b}}$ \\ Street, Toronto, ON M5B 2K3 \\ M5B2K3 \\ GRW Grand River Watershed \\ SWAT Soil and Water Assessment Tool \\ SUFI-2 Sequential Uncertainty FItting \\ SWAT-CUP Calibration and Uncertainty Procedures \\ TP Total phosphorus \\ TN Total nitrogen
}

${ }^{a}$ Environmental Applied Science and Management Program, Ryerson University, 350 Victoria

${ }^{b}$ Department of Chemistry and Biology, Ryerson University, 350 Victoria Street, Toronto, ON

\section{Core Ideas}

Hydrological modelling provides stakeholders a reliable method that aids in the understanding of watershed processes.

SWAT was proven very reliable in predicting streamflow and other water quality parameters.

The robustness of SWAT is highly dependent upon the quality of the available environmental data and the parametrization process. 


\subsection{Abstract}

The Grand River watershed (GRW) occupies about $6,800 \mathrm{~km}^{2}$ and is an important agricultural area in Southern Ontario. As in many watersheds, there have been historical modifications to land use due to various human endeavors resulting in altered hydrology and greater exporting of sediment and nutrient loads into Lake Erie. The objective of this study was to predict the spatial and temporal patterns of hydrology, and sediment and nutrient (TN and TP) export from the GRW using the Soil and Water Assessment Tool (SWAT) model. The simulated results indicated that surface runoff contributed 59\% to stream flow while precipitation contributed 39\% to stream flow in the GRW. The Sequential Uncertainty FItting (SUFI 2) program was used to calibrate and validate streamflow for the years 2001-2010 in the GRW. For the calibration years 2001-2005, the coefficient of determination $\left(\mathrm{R}^{2}\right)$, Nasch-Sutcliffe, and percent BIAS for the monthly streamflow were $0.79,0.75$ and 0 at Brantford and $0.64,0.63$ and 7.1 at York station; whereas, for the validation years of 2006-2010, it was 0.82, 0.74 and 0.2 at Brantford and 0.75, 0.75 and 0 , at York, respectively. Thereafter, the calibrated hydrology model was applied to the entire GRW in order to determine sediment and nutrient export into Lake Erie. The sediment and nutrient loading at Dunnville, prior to entering Lake Erie, was predicted to be $2.3 \times 10^{5}$ tonnes $\mathrm{y}^{-1}$ of total suspended sediment, $7.9 \times 10^{3}$ tonnes $\mathrm{y}^{-1}$ of total nitrogen, and $2.3 \times 10^{2}$ tonnes $\mathrm{y}^{-1}$ of total phosphorus. 


\subsection{Introduction}

Temperate freshwater lakes are most commonly phosphorus limited (Schindler 1974, 1977), and during the 1960s, excessive phosphorus was responsible for harmful algal blooms (HABs) in Lake Erie (USEPA 2011). Although HABs continued through the 1970s, a $60 \%$ reduction of phosphorus by 1985 has resulted in a corresponding $89 \%$ decrease in the cyanobacteria Aphanizomenon (USEPA 2011). However, the water quality in Lake Erie continues to be under constant anthropogenic threats. Microcystis blooms returned to the lake in the 1990s and have continued to date, especially in the western basin of the lake (USEPA 2011). In 2011, the largest algal bloom in the lake's history occurred and agricultural practices coupled with changing climatic conditions were identified as the main drivers of the eutrophication of Lake Erie (Michalak et al. 2013), although the 2015 bloom is the most severe on record (based on biomass over peak 30-day period) (NOAA 2015).

The Grand River watershed (GRW) covers $25 \%$ of the Canadian land area within the Lake Erie watershed (and 10\% of the total Lake Erie basin) while contributing around $5 \%$ of total phosphorus to the whole basin (Scavia et al. 2014) and 40\% to the eastern basin (Shaker, 2014). Over the years, water quality (based on dissolved oxygen, total phosphorus and suspended solids) has been consistently rated as poor when measured at the Dunnville Dam monitoring site prior to the Grand River entering Lake Erie (Cooke 2006).

The Grand River watershed has been greatly altered over the past 150 years in terms of land use, particularly conversion to agriculture and growth in population density, and modifications of the stream network. Due to their dendritic patterns and large width to depth ratio, and land use in their immediate surrounding landscape, upland streams are important sites for 
biogeochemical transformation of nutrients, making them critical in controlling the amount of nutrients that are exported downstream. These low order streams represent hydrological connectivity (Freeman et al. 2007) between upland and downstream waters (King et al. 2009) through facilitated transfer of mass, momentum, energy, or biota within or between various components of the hydrologic cycle (Nadeau and Rains 2007). Land use management over time has resulted in changes in the natural meandering features of many of these smaller streams altering their ecological functions with ramifications for their hydrology, sediment and nutrient transport, water quality, and biological characteristics, as well as creating numerous negative economic and social consequences (Alexander et al. 2012).

Modelling is an important tool that is widely used to enhance our understanding of physical, chemical or biological processes that are occurring at the local or watershed scale. Water-quality models are basically of two types: deterministic or statistical (Preston et al. 2009). Deterministic models utilize mass balance for explicit physical environmental processes and are applied to small sites or single streams (Preston et al. 2009). A deterministic model assumes that a complex system, such as a watershed, can be best understood by exploring the processes occurring within its various components and the relation in which they are coupled together. On the other hand, statistical models estimate water quality by relating field measurements to causative environmental factors and use simple-multiple or linear-nonlinear regression tools (Preston et al. 2009). Whether statistical or deterministic, models vary with their operational scales (temporal and spatial), along with the depth of the processes being simulated and complexity (Singh 1995).

The Soil and Water Assessment Tool (SWAT) is a freeware that is a continuous-time, semidistributed, physically-based (i.e. deterministic) watershed model that operates on a daily time step 
(Gassman et al. 2007, 2014; Arnold et al. 2012). Developed by the USDA-ARS, SWAT was developed by incorporation of a number of previous models into its structure, including the Simulator for Water Resources in Rural Basins (SWRRB) model and the Routing Outputs to Outlet (ROTO) model (Gassman et al. 2007; Arnold et al. 2012). The SWRRB model, a nonpoint source loading model, was itself composed of three existing ARS models: the Chemicals, Runoff, and Erosion from Agricultural Management Systems 2 (CREAMS2) model, the Groundwater Loading Effects on Agricultural Management Systems 3 (GLEAMS3) model, and the Environmental Impact Policy Climate 4 (EPIC4) model. SWAT has seen subsequent development and incorporation of other routines such as routing components, enhanced sediment transport, instream kinetics from the QUAL2E model, phosphorus, nitrogen and carbon cycling, and best management practices (Gassman et al. 2007; Arnold et al. 2012).

Due to SWAT being physically based, it provides the unique opportunity to simulate the hydrology and water quality of ungauged streams and to quantify the relative impacts of alternative input data on hydrology and water quality in watersheds. Today, SWAT is widely used to assess the environmental impacts of land use management on water quantity and quality in small agricultural fields to continental size watersheds with varying soil types, topography and land uses (Conan et al. 2003; Gassman et al. 2007; Ahmad et al. 2011; Arnold et al. 2012; Yang et al. 2014; Almendinger et al. 2014; Abbaspour et al. 2015). Furthermore, SWAT being a continuous time model, is capable of simulating periods ranging from 1 to 100 years and provides output on daily, monthly or annual time scales.

The objective of this research was to build and test the applicability of a SWAT hydrological model for the Grand River Watershed (GRW) under current climate, land management, stream network, and physiographic conditions. The GRW is an important 
agricultural region in southern Ontario, predominantly rural but with several rapidly growing urban centres. The GRW is a major basin draining into Lake Erie, contributing to nutrient loading and likely to the associated ecological problems experienced in Erie. Here we describe the calibration and validation of the model for quantifying surface water hydrology in the GRW, and use the model to predict sediment, phosphorus, and nitrogen loading from the GRW to Lake Erie. We expect this will be a valuable tool for predicting sediment and nutrient export from the watershed in response to interventions in the watershed or to scenarios of land use and climate change.

\subsection{Methodology}

\subsubsection{Study Site}

The GRW covers an area of $6,800 \mathrm{~km}^{2}$ and it is the largest watershed in southwestern Ontario. Spanning a length of $290 \mathrm{~km}$ and having an elevation differential of about $362 \mathrm{~m}$ from source to mouth, the Grand River originates at the Dundalk Highlands and flows through Port Maitland into Lake Erie (Scott and Imhof 2005). The Grand River has eight major tributaries: Speed/Eramosa, Fairchild, Boston/McKenzie, Whitemans, Nith, Canagagigue, Conestogo, and Irvine rivers (Cooke 2006).

Land use in the watershed is dominated by agriculture (76\%), with about 6,000 farms located within the watershed (Farwell et al. 2008). Forested areas and the centrally located urban centres covering $17 \%$ about $5 \%$ of the total area, respectively (Cooke 2006). In intense agricultural sub-watersheds in southern Ontario, corn is the main crop type with $25 \%$ coverage, while soybeans, other grains, and forage and fodder covered 16\%, 12\% and 11\% respectively (OMOE 2012). In absence of more explicit coverage by crop, these percentages were assumed to apply to areas of the GRW in agricultural land use. In addition, intensive livestock operations are a 
dominant feature in the middle GRW (Mayer and Delos Reyes 1996). According to the 2001 census, there were 290,000 head of cattle, 500,000 head of swine and almost 8.8 million head of poultry in the Grand River area (GRCA 2005). These values were applied in modeling nutrient export from the GRW.

The GRW can be separated into three distinct geological areas. Due to the presence of the northern till plains that drain the upper Conestogo and Grand Rivers, a significant amount of surface runoff is generated which then travels to Belwood and Conestogo lakes. The central basin region is made up the Paris-Galt moraine that is characterized by highly permeable sands and gravels. These moraines cover huge underground aquifers and supply the drinking water needs of the central urban areas of the watershed (Cooke 2006). Finally, the Grand River traverses the southern clay plain which, like the northern till, is responsible for significant runoff which then empties into Lake Erie (Cooke 2006).

\subsubsection{Model Structure}

SWAT has two essential stages in its execution: watershed delineation and post-watershed delineation processing. The watershed/HRU delineation was done in a GIS environment using ArcSWAT, an ArcGIS add-on and graphical user input interface for the SWAT model (Arnold et al. 1998). In ArcSWAT's algorithm, the watershed is first divided into sub-basins defined by unique geographic location, and are spatially linked to each other. Each sub-basin contains a tributary channel, a reach (main channel) and at least one hydrologic response unit (HRU). HRUs are the next level of subdivision and represent a unique combination of soil attributes, land use and slope class. HRUs were later incorporated into the SWAT model from the Hydrologic Unit Model for the United States (HUMUS) modelling tool. During a SWAT run, all similar HRUs are 
combined together since it is expected that since their compositions are the same, they will be behave the same way with respect to crop growth and management practices, surface and subsurface hydrology, nutrient cycling, and sediment, nutrient, pesticide and bacterial loadings. Loading from a sub-basin was calculated by combining the loadings from the sum of all unique HRUs in that sub-basin.

SWAT divides modeling of the hydrology of the watershed into two parts. First, generating hydrological outputs (water, sediments, nutrients, pesticide, bacteria) from the land phase of the hydrological cycle that are loaded into the main reach of each sub-basin. Second, SWAT models the routing phase of the hydrological cycle which accounts for the movement of water, sediments, nutrients, pesticides and bacteria through the reach network within the watershed and finally into the outlet such a larger stream, lake, sea or ocean. A number of algorithms are available to simulate the different water hydrological component within SWAT; the algorithms used in generating the GRW SWAT model are provided in Table 2.1.

Table 2.1: Hydrological algorithms used to construct the SWAT model of the Grand River watershed.

\begin{tabular}{ll}
\hline Hydrologic Process & Algorithms \\
\hline Precipitation & Direct observation \\
Surface runoff & SCS Curve Number method \\
Channel routing & Variable storage routing method \\
Snowmelt & Mean Air Temperature and Soil Layer Temperature \\
Percolation & Storage Routing Combined With Crack-Flow Model \\
Groundwater & Base flow recession constant; groundwater storage; re- \\
& evaporation \\
Evapotranspiration & Hargreaves \\
Transmission loss & Lane's method \\
\hline
\end{tabular}

At each HRU, water is accounted for in four storage sites: snow, within the soil profile (0$2 \mathrm{~m})$, shallow aquifers $(2-20 \mathrm{~m})$ and deep aquifers $(>20 \mathrm{~m})$. Water in the soil is constantly moving 
and is accounted for by infiltration, percolation, evapotranspiration, plant uptake, and lateral flow within the soil and groundwater flow (Arnold et al. 1998).

Sediments are actively removed from HRUs by sheet and rill erosion. In SWAT, landscape erosion is simulated by the Modified Universal Soil Loss Equation (MUSLE) (Neitsch et al. 2011; Arnold et al. 2012). While the older Universal Soil Loss Equation (USLE) (Neitsch et al. 2011; Arnold et al. 2012) is based on the erosive energy of rainfall, MUSLE relies on the amount of runoff generated to simulate erosion. The sediment that has been eroded from the landscape now enters the reach where it is transported by water downstream to the outlet of the sub-basin. During this process, sediment yield is actively modified by two competing processes: degradation using stream power and deposition using fall velocity along the channel banks and bed (Neitsch et al. 2011; Arnold et al. 2012). SWAT utilizes the Bagnold's simplified stream power equation (Neitsch et al. 2011; Arnold et al. 2012) to transport sediment within a reach while the peak channel velocity is the major determining factor for the maximum amount of sediment transported within a reach (Neitsch et al. 2011; Arnold et al. 2012).

Phosphorus is modelled by SWAT to reflect its characteristics (i.e. dissolved, particulate, organic, inorganic, total). Phosphorus has low mobility in soils due to the formation of many insoluble compounds resulting in the accumulation of these compounds near the surface of the soil. Surface runoff is the main process responsible for the export of phosphorus from the landscape into adjacent streams and reaches. SWAT takes account of different phosphorus pools in soils; three pools are inorganic while three are organic. The inorganic pools are classified as solution, active, and stable pools. The solution pool is increased by the addition of inorganic P fertilizers and from the mineralization of fresh residue and organic P fertilizers. This pool is in rapid equilibrium with the active pool which is, in turn, in slow equilibrium with the stable inorganic 
pools. The organic pools are classified as fresh, stable and active pools. Fresh pools are primarily derived from plant residue and microbial biomass while active and stable pools are derived from extent of degradation of humic compounds. SWAT allows various soil, fertilizer, crop, surface water, and groundwater parameters that are related to phosphorus to be modified prior to a SWAT run. Together, these inputs are used to simulate the mineralization, decomposition, sorption, immobilization and leaching algorithms in SWAT (Neitsch et al. 2011). Based on enrichment ratios and nutrient lag in surface and lateral flow, SWAT determines the amount of sediment bound and soluble phosphorus that are removed from HRUs and using a loading function, the phosphorus yield from each sub-basin.

Nitrogen is modelled similarly in the SWAT model by using mineralization, decomposition, sorption, immobilization and leaching algorithms (Neitsch et al. 2011). SWAT takes account of five different nitrogen pools in soils, two inorganic and three organic. Ammonium and nitrates are the inorganic pools while crop residues and various humic substances make up the three organic pools. Additional algorithms in the model include nitrification and ammonia volatilization, denitrification, wet and dry atmospheric deposition, leguminous fixation, upward movement of nitrate in porewater, lateral movement of nitrate in shallow aquifers, and leaching (Neitsch et al. 2011). At suitable temperature, organic nitrogen is transformed to ammonia, nitrite, and then to nitrate or it may be removed from the reach by settling. A number of parameters can be modified in order to increase or decrease different processes in the transport of nitrogen and similarly, phosphorus. 


\subsubsection{Model Construction and Run}

The duration of the SWAT run was set up from 1996 to 2010 and it was divided into three five year phases: a setup or warm-up period from 1996-2000, a calibration period from 2001-2005, and a validation period from 2006-2010. The initial testing period was used to perform a water mass balance in order to check the accuracy and stability of model outputs. The model was run on monthly and annual time scales.

\subsubsection{Sources and Preparation of SWAT Model Input Data}

\section{Digital Elevation Data}

A Digital Elevation Model (DEM) for Ontario was obtained via the Scholars GeoPortal network. This DEM (version 2.0.0) is a 3-D raster data set which captures terrain elevations and has cell resolutions of 10 metres in southern Ontario. A rectangular clipped portion of the DEM was used to delineate the watershed and the pour point was snapped on the main stream network as it entered Lake Erie. The GRCA's virtual stream network was burned onto the raster during the watershed delineation process to produce more accurate sub-basin delineations in subsequent steps. The virtual stream layer is a single line, ground-truthed, fully connected network that represents the inferred flow through watercourses and water bodies.

\section{Land cover / land use}

A land cover / land use dataset was obtained from the Grand River Conservation Authority. This land cover classification was based on Landsat 7 TM Imagery in 1999, and updated in 2005. Pixel sizes are 25 metres in the land cover grid. The GRW was divided into 20 different land cover categories: built-up (residential), built-up (commercial / industrial), row crops, small 
grains, forage, pasture / sparse forest, dense forest (deciduous), dense forest (conifer), dense forest (mixed), plantation (mature), open water, wetlands, extraction / bedrock / roads / beaches, golf courses, and bare agricultural fields. A lookup table was created to link each category of land cover to a specific SWAT land use class. To date, SWAT has a library of 97 plant types and 8 urban land uses in its database.

Soil classification

Geospatial data were obtained from the Soil Landscapes of Canada's online geospatial database that is maintained by the Canadian Soil Information Service or CanSIS (http://sis.agr.gc.ca/cansis/). A soil database used in SWAT has to identify and link the physiochemical properties of the top 10 layers of the soil profile to the soil groups in the watershed. The names and characteristics of the different soil layers were downloaded from the CanSIS website in the Soil Name Table and the Soil Layer Table of SWAT. Characteristics of each layer used by SWAT included: soil hydrologic group, maximum rooting depth of soil profile, fraction of porosity from which anions are excluded, maximum crack volume of soil profile, texture of soil layer, depth from soil surface to bottom of layer, moist bulk density, available water capacity of the soil layer, saturated hydraulic conductivity, organic carbon content, clay content, silt content, sand content, rock fragment content, moist soil albedo, USLE K, electrical conductivity, soil $\mathrm{CaCO}_{3}$, and soil $\mathrm{pH}$. Whenever there were missing data, the original published soil reports were consulted. This database was then appended to the SWAT usersoil database. Soil slope was divided into three groups based on a modification of the Canada Slope Gradients classification; little or none ( $0-3 \%$ gradient), gentle-moderate ( $4-15 \%$ gradient), and steep-excessively steep (>15\% gradient). After the watershed has been delineated, SWAT generated HRUs by overlaying and combining land use, soil and slope. 


\section{Weather data}

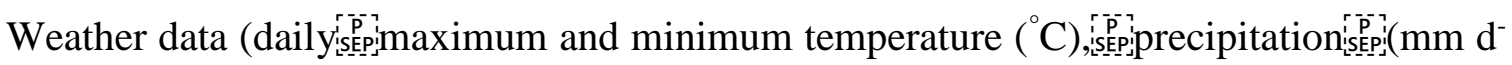
$\left.{ }^{1}\right)$ ), from stations located within or in proximity to the GRW. Station locations (latitude, longitude, and elevation) were inputs for SWAT, and weather data were assigned to every sub-basin using data from the station closest to the centroid of that sub-basin. In cases of missing weather data, SWAT's Global Weather Data tool was used to provide all missing data (http://globalweather.tamu.edu/). This simulated data set, referred to as the Climate Forecast System Reanalysis (CFSR), was prepared by the National Centers for Environmental Prediction (NCEP) over the 36-year period from 1979-2014. Also, due to sparse measured daily solar radiation, humidity and wind speed datasets, the Hargreaves' method of simulating potential evapotranspiration was selected for the model run. This method of inferring PET rates has shown reliable estimates when compared to measured values (Jensen et al. 1990; Itenfisu et al. 2003). Jensen et al. (1990) arrived at their conclusions based on investigations of PET rates from well-watered grasslands and agricultural lands in the western US, including Indiana and Minnesota. Similarly, Itenfisu et al. (2003) analysed weather data from 49 geographically diverse sites in the United States in order to determine PET rates that supported the Hargreaves method of simulating PET in watersheds. Given the close proximity of the Grand River of southern Ontario to the US, the Hargreaves method can safely be used to simulate PET in the GRW.

\section{Hydrological dataset}

Daily mean flow data at Drayton and York stations were collected from the GRCA. Additional data were downloaded from Environment Canada's DataExplorer which is a selfcontained application that has a browser and search engine for Environment Canada's HYDAT 
database. With the exception of York which began collecting data in 2002, all other station data spanned the years 2001-2010 (Table 2.2).

Table 2.2: Location and operators for different flow gauges used in the calibration and validation process.

\begin{tabular}{|c|c|c|c|c|c|c|}
\hline $\begin{array}{l}\text { Station } \\
\text { ID }\end{array}$ & Station name & $\begin{array}{l}\text { Locati } \\
\text { on } \\
\text { (sub- } \\
\text { basin) }\end{array}$ & Operator & Data years & Latitude & Longitude \\
\hline 2GAC09 & $\begin{array}{l}\text { Conestgo River at } \\
\text { Drayton }\end{array}$ & 162 & GRCA & $2001-2010$ & 43.756700 & 80.670189 \\
\hline 2GB001 & $\begin{array}{l}\text { Grand River at } \\
\text { Brantford }\end{array}$ & 428 & WSC & $2001-2010$ & 43.132200 & 80.266905 \\
\hline 2GA003 & Grand River at Galt & 569 & WSC & $2001-2010$ & 43.353200 & 80.315805 \\
\hline 2GA029 & $\begin{array}{l}\text { Eramosa River } \\
\text { above Guelph }\end{array}$ & 304 & WSC & $2001-2010$ & 43.548000 & 80.182584 \\
\hline 2GAC06 & Grand River at York & 626 & GRCA & $2002-2010$ & 43.021800 & 79.892040 \\
\hline
\end{tabular}

Tile drainage

Data on the extent and location of tile drains in Ontario was obtained from OMAFRA and the Ministry of Natural Resources (updated 2009). In the Grand River a total area of 141,037 ha (or 28\% of agricultural lands) are tile drained (Holeton 2013) (Fig. 2.1). SWAT required information on three parameters related to tile drainage: depth to drain, time to drain soil to field capacity, and tile drain lag time. Based on common practice in the similar watershed in southern Ontario, the depth to surface drain (mm) was assumed to be $900 \mathrm{~mm}$, the time taken to drain soil to field capacity was assumed to be 24 hours and tile drain lag time was assumed to be 3 hours (Yang et al. 2013). 


\section{Tile Drained Areas in the Grand River Watershed}

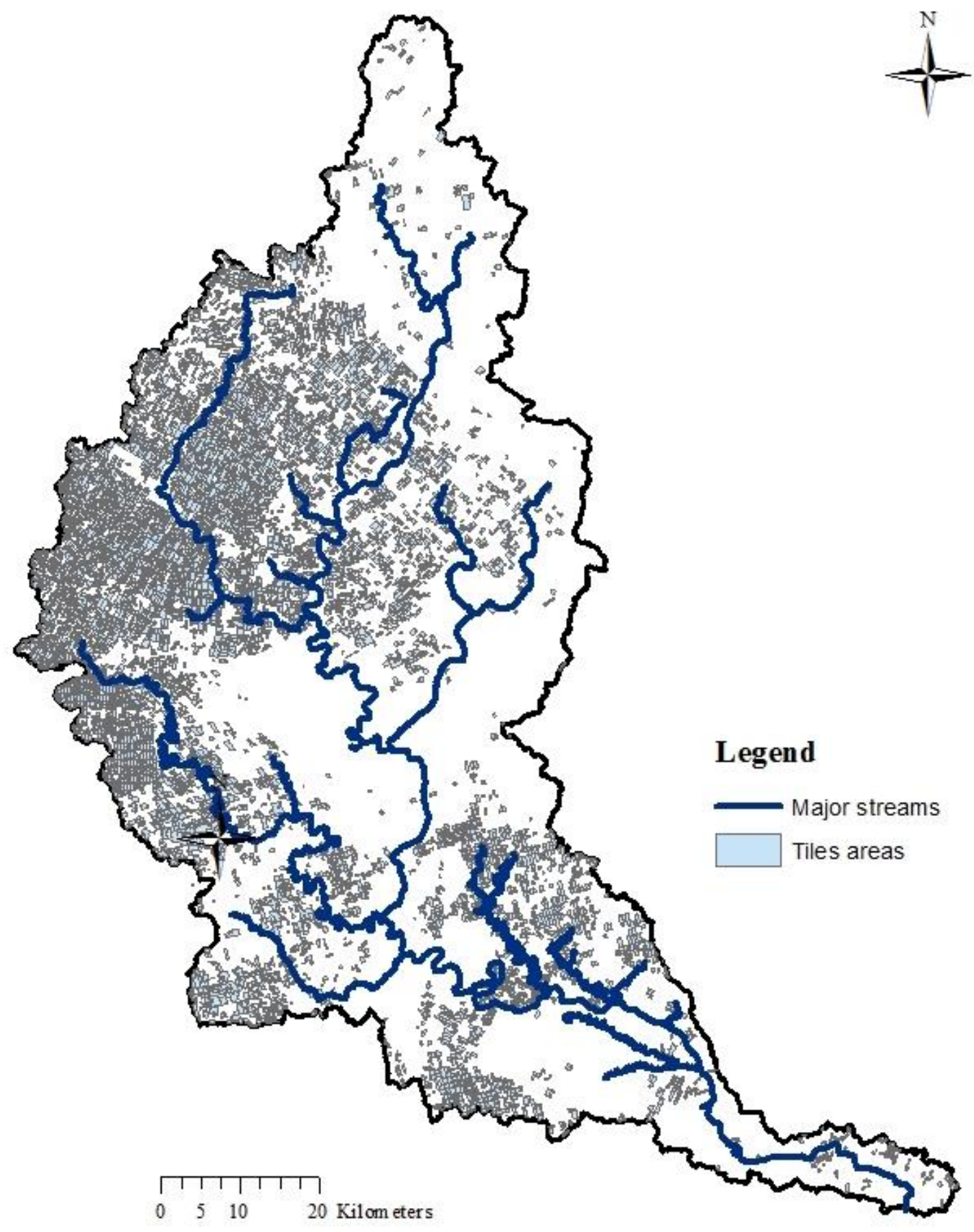

Figure 2.1: Location of tile drains in the Grand River watershed (Produced using information under License with the Grand River Conservation Authority (C) Grand River Conservation Authority, 2005). 


\subsubsection{Sensitivity Analysis, Calibration, Validation and Uncertainty Analysis}

The GRW SWAT model was calibrated and validated using the semi-automated software, SWAT-CUP4 using the Sequential Uncertainty FItting (SUFI2) algorithm. Prior to the calibration and validation processes, relevant parameters were examined to determine how sensitive they were with respect to the SWAT output (Table 2.3). Given these parameters and suitable ranges (based on literature values, direct knowledge of site measurements or from oneon-one sensitivity analysis testing, examples, (e.g. Abbaspour et al. 2007, 2015; Yang et al. 2013; Leon et al. 2014), random samples of parameter values from a multidimensional distribution were drawn up by Latin Hypercube Sampling (LHS) and thereafter, the objective function was calculated for each simulation (having its own parameter set) (Rouholahnejad et al. 2014). Compared to random sampling such as Monte Carlo, LHS is iterative and can reduce sampling times and provide a 10-fold greater computing efficiency (Vachaud and Chen 2002). 
Table 2.3: Parameters used during first iteration of hydrology calibration.

\begin{tabular}{|c|c|}
\hline Parameter & Definition \\
\hline $\mathrm{r} \_\mathrm{CN} 2 . \mathrm{mgt}$ & $\begin{array}{l}\text { Curve number: an empirical parameter used in hydrology for } \\
\text { predicting direct runoff or infiltration from rainfall excess }\end{array}$ \\
\hline a_GW_DELAY.gw & $\begin{array}{l}\text { Groundwater delay time (days). Water that moves past the } \\
\text { lowest depth of the soil profile by percolation or bypass flow } \\
\text { enters and flows through }\end{array}$ \\
\hline a_GWQMN.gw & $\begin{array}{l}\text { Threshold depth of water in the shallow aquifer required for } \\
\text { return flow to occur }\left(\mathrm{mm} \mathrm{H}_{2} \mathrm{O}\right)\end{array}$ \\
\hline$v_{\text {__EPCO.bsn }}$ & Amount of water taken up by plant \\
\hline v_GW_REVAP.gw & $\begin{array}{l}\text { Groundwater revap coefficient. Movement of water from } \\
\text { shallow aquifer into overlying unsaturated zone }\end{array}$ \\
\hline$v_{\text {___ESCO.bsn }}$ & Soil evaporation factor \\
\hline v__SURLAG.bsn & Surface runoff lag coefficient \\
\hline r_SOL_AWC().sol & $\begin{array}{l}\text { Available water capacity of the soil layer }\left(\mathrm{mm} \mathrm{H}_{2} \mathrm{O} / \mathrm{mm} \text { soil }\right) \\
\text { (layer\#) }\end{array}$ \\
\hline r__SOL_K().sol & Saturated hydraulic conductivity (mm/h) (layer\#) \\
\hline r_CH_K2.rte & Effective Hydraulic Conductivity in main channel \\
\hline r_CH_W2.rte & Average width of main channel at top of bank \\
\hline r_CANMX.hru & $\begin{array}{l}\text { Maximum canopy storage ( } \mathrm{mm} \mathrm{H} 2 \mathrm{O}) \text {. reduces erosive force of } \\
\text { water }\end{array}$ \\
\hline v__SFTMP.bsn & Snowfall temperature \\
\hline v__SMTMP.bsn & Snowmelt temperature \\
\hline v__SMFMX.bsn & Melt factor for snow on June 21 \\
\hline v__SMFMN.bsn & Melt factor for snow on December 21 \\
\hline r__SHALLST.gw & Initial depth of water in shallow aquifer $(\mathrm{mm})$ \\
\hline
\end{tabular}

The qualifiers $\mathrm{v}, \mathrm{r}$ and $\mathrm{a}$, are part of the parameter set-up process whereby ( $\mathrm{v}_{-}$) refers to the substitution of a parameter by a value from the given range, $\left(\mathrm{r}_{-}\right)$refers to a relative change in the parameter were the current values is multiplied by 1 plus a factor in the given range, and (a__ ) refers to a given value being added to the parameter value. For watershed spatial parameters $r$ or a was used while for non-spatial parameters, v was used. 


\subsection{Results and Discussion}

\subsubsection{Watershed and HRU delineation}

SWAT delineated a total of 699 sub-basins within the GRW with a mean and median size of 961 ha and 779 ha, respectively and the first and third interquartile ranges were 505 ha and 1,293 ha, respectively. HRUs are a function of slope, land use and soil type and represent the functional unit of the watershed. A total of 7,699 HRUs were delineated. The mean and median size of the HRUs were 30 ha and 6 ha, respectively, while the minimum and maximum size of the HRUs were 0.01 ha and 1,182 ha, respectively. The first and third interquartile ranges were 1 ha and 29 ha, respectively. There is no direct relationship between sub-basin size and number of HRUs, the only rule being that there should be at least one HRU for each sub-basin. For example, the smallest sub-basin (SB 77) had three HRUs, while the largest sub-basin had ten HRUs. Sub-basin 232 was 817 ha in size but contained 32 HRUs.

\subsubsection{Water Balance}

The process of evapotranspiration in the Grand River watershed was $58 \%$ of the total precipitation and represented that largest source of water loss from the watershed (Fig. 2.2). Approximately $23 \%$ is lost as surface runoff and enters stream flow during discrete precipitation events or snow melt, and the remaining $19 \%$ percolates to the shallow aquifer. Of the water entering the shallow aquifer, most will enter stream flow under base flow conditions ( $16 \%$ of the total precipitation to the watershed, thus $52 \%$ of total annual stream flow is surface runoff). The remainder is either lost to evaporation from the shallow aquifer (2\% of total precipitation) or recharges the deep aquifer ( $1 \%$ of total precipitation). Though not directly related to the SWAT modelling, a $1 \%$ deep aquifer recharge over the 10 years is quite worrisome given the 
high rate of water extraction for municipal and industrial purposes within the watershed. These values were similar to those obtained by Yang et al. (2013) in the Gully Creek watershed.

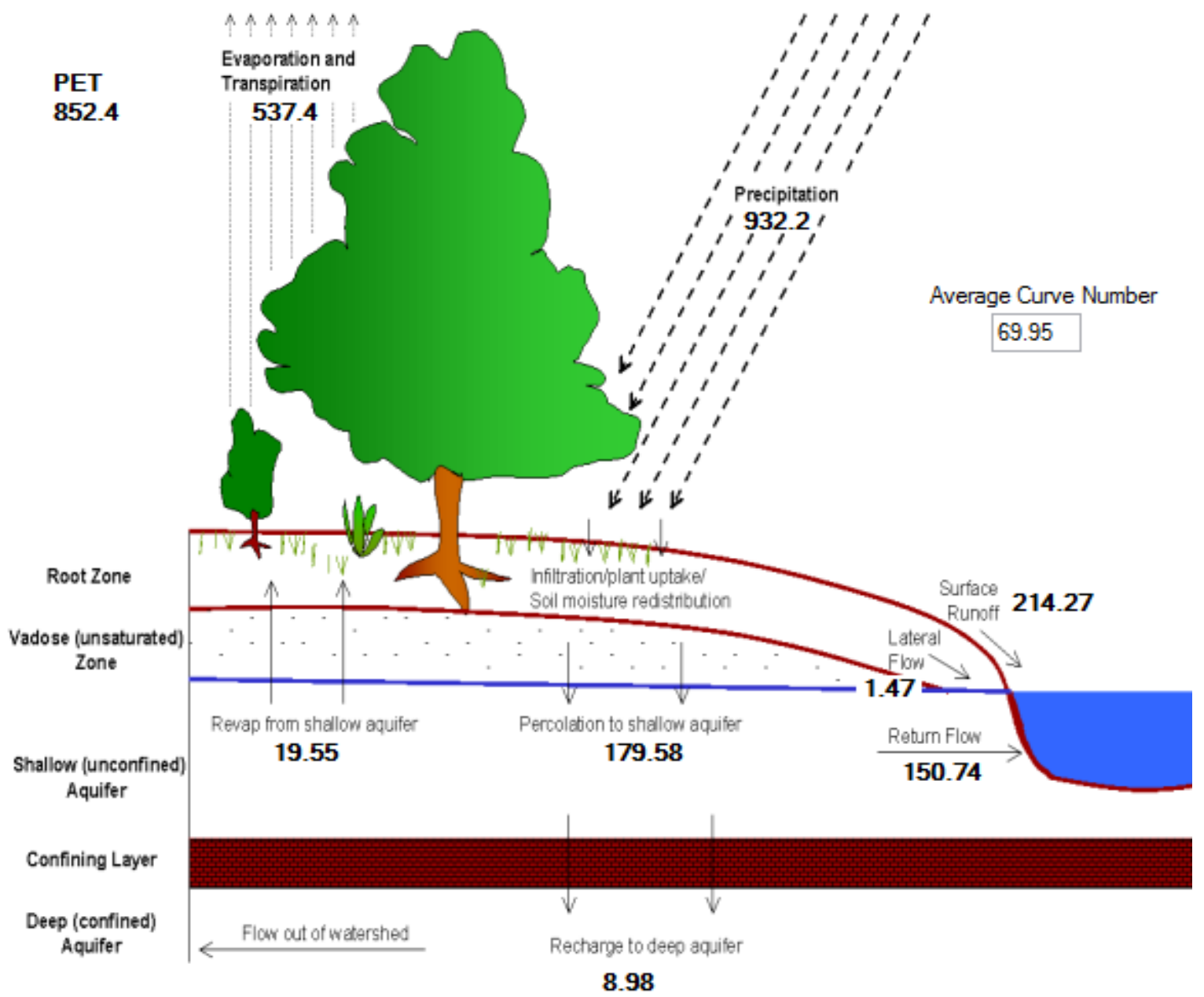

All Units mm

Figure 2.2: Landscape water balance in the Grand River for the simulation years (2001-2010). (Image credit: ArcSWAT model output of Hydrology). 


\subsubsection{Stream Flow}

Flow was the first variable calibrated in the SWAT model. Twenty-two parameters were initially chosen for flow calibration in the headwaters. The least sensitive parameters were excluded after two successive iterations of 500 simulations, with 14 parameters retained (Table 2.4). Two additional iterations consisting of 500 simulations were run to parameterize the watershed under its specific land use, slope and soil conditions. After the calibration process, the parameters, along with their minimum and maximum values were re-written by SWATCUP and the model was then ready for validation.

Table 2.4: Parameters values that were used for hydrology calibration and validation.

\begin{tabular}{llll}
\hline Parameter & Fitted Value & Min value & Max value \\
\hline 1:R_ALPHA_BNK.rte & -0.049874 & -0.14572 & 0.01812 \\
2:R_CN2.mgt & 0.012668 & -0.235807 & 0.054807 \\
3:A_GW_DELAY.gw & -9.959455 & -19.744036 & 13.42404 \\
4:V_EPCO.bsn & 1.263843 & 0.433751 & 1.281649 \\
5:V_GW_REVAP.gw & -0.012308 & -0.060414 & 0.113254 \\
6:V_SURLAG.bsn & 5.326689 & 0.468991 & 13.49231 \\
7:R_SOL_AWC(..).sol & 0.319879 & 0.08016 & 0.44064 \\
8:R_CH_W2.rte & -0.041506 & -0.17392 & 0.00872 \\
9:R_CANMX.hru & -0.247274 & -0.25424 & 0.04864 \\
10:V_SFTMP.bsn & 1.056189 & -1.875984 & 4.375984 \\
11:V_SMTMP.bsn & 2.956182 & 0.346413 & 3.449587 \\
12:V_SMFMX.bsn & 2.533915 & -0.718395 & 3.094395 \\
13:V_SMFMN.bsn & 3.342917 & 1.129606 & 3.390394 \\
14:R_SHALLST.gw & 0.284096 & 0.076962 & 0.431038 \\
\hline
\end{tabular}

All modelling has associated uncertainty due to our lack of understanding of all of the processes taking place in the watershed. Uncertainty arises from conceptual model uncertainty, input uncertainty and parameter uncertainty. Uncertainty is propagated in the model output and is represented by $95 \%$ probability distributions (95PPU). A 95PPU band represents the 
uncertainty that is measured at the $2.5 \%$ and $97.5 \%$ levels of the cumulative frequency distribution of all simulated values (Rouholahnejad et al. 2014). Other functions relating to model performance and commonly used in assessing hydrologic models include $\mathrm{p}$-factor, $\mathrm{r}$ factor, $\mathrm{R}^{2}$, PBIAS, $\mathrm{bR}^{2}$, and the Nash-Sutcliffe efficiency (NSE) value. The $\mathrm{p}$-factor is the proportion of the observed data encompassed by the 95PPU band, the closer this value is to 1 , the better the model is at predicting the variable using a fixed set of parameters (Abbaspour et al. 2007). The r-factor is a measure of the thickness of the 95PPU band and ideally, a small $r-$ factor is best (Abbaspour et al. 2007). While $\mathrm{R}^{2}$ only accounts for the dynamics between the observed and predicted data, $\mathrm{bR}^{2}$ also accounts for the differences in magnitude between signals. In other words, one can still have a good $\mathrm{R}^{2}$ value when the model consistently overor under predicts throughout the model run meaning that all the predictions are wrong (Krause et al., 2005); however, such a scenario will result in a poor $\mathrm{bR}^{2}$. NSE is a normalized statistic that measures the relative size of the residual variance when compared to the variance of the measured data (Nash and Sutcliffe, 1970). An optimal NSE value of 1 suggests that the plot of observed against simulated data fits the 1:1 line, perfectly. One major limitation of the NSE objective function is the fact that NSE is very susceptible to high extreme values in the observations or simulations which will result in a large NSE value. Moriasi et al. (2007) suggested that the model simulation is satisfactory with NSE $>0.5$. Gupta et al. (2009) suggested using Percent Bias (PBIAS) which measures how much larger or smaller the simulated data is when compared to the measured data. A PBIAS of 0 is ideal. Moriasi et al. (2007) suggested that if the value of PBIAS ranges from 15 to 25 , then the output from the SWAT model is evaluated as 'satisfactory', a range from 10 to 15 is evaluated as 'good' and less than 10 is 'very good'. 
The GRW SWAT model was able to simulate flow with a high degree of accuracy within the watershed. Based on the results of the model performance as measured by the objectives functions (Table 2.5), SWAT simulated stream flows were matched up well to the measured flows with respect to magnitude, peak time, and flow volume. The calibrated and validated model predicted flow rates similar to observed flow at all the monitoring stations in the watershed. This would imply that the model is very robust and would be able to predict flow at ungauged streams at different locations in the watershed, such as at Dunnville prior to entering Lake Erie.

Table 2.5: Calibration and validation objective function values for different stations, observed and simulated flows.

\begin{tabular}{|c|c|c|c|c|c|c|c|c|}
\hline \multirow[b]{2}{*}{ Station } & \multirow[b]{2}{*}{$\begin{array}{l}\mathrm{p}- \\
\text { factor }\end{array}$} & \multirow[b]{2}{*}{$\begin{array}{l}\mathrm{r}- \\
\text { factor }\end{array}$} & \multirow[b]{2}{*}{$\mathrm{R}^{2}$} & \multicolumn{3}{|c|}{ Calibration } & \multicolumn{2}{|c|}{ Elow $\left(\mathrm{m}^{3} \mathrm{~s}^{-1}\right)$} \\
\hline & & & & NSE & $\mathrm{bR}^{2}$ & $\begin{array}{l}\text { PBIA } \\
\text { S }\end{array}$ & $\begin{array}{l}\text { observe } \\
\text { d }\end{array}$ & $\begin{array}{l}\text { simulate } \\
\text { d }\end{array}$ \\
\hline Conestogo & 0.46 & 0.46 & 0.62 & 0.61 & 0.33 & 0.5 & 3.6 & 3.6 \\
\hline Eramosa/Guelph & 0.62 & 0.73 & 0.6 & 0.66 & 0.54 & -0.5 & 2.2 & 2.3 \\
\hline Galt & 0.42 & 0.42 & 0.66 & 0.63 & 0.53 & -0.1 & 39.9 & 39.7 \\
\hline Brantford & 0.45 & 0.36 & 0.79 & 0.75 & 0.75 & 0 & 57.9 & 57.6 \\
\hline York & 0.68 & 0.44 & 0.64 & 0.63 & 0.38 & 7.1 & 71.2 & 69.0 \\
\hline \multicolumn{9}{|l|}{ Validation } \\
\hline Conestogo & 0.28 & 0.25 & 0.67 & 0.67 & 0.42 & 0.7 & 5.1 & 5.1 \\
\hline Eramosa/Guelph & 0.48 & 0.42 & 0.82 & 0.72 & 0.73 & -0.7 & 2.9 & 2.9 \\
\hline Galt & 0.5 & 0.39 & 0.86 & 0.78 & 0.77 & 0 & 46.2 & 46.7 \\
\hline Brantford & 0.43 & 0.33 & 0.82 & 0.74 & 0.76 & 0.2 & 65.8 & 66.3 \\
\hline York & 0.35 & 0.37 & 0.75 & 0.75 & 0.62 & 0 & 80.9 & 78.7 \\
\hline
\end{tabular}

When the hydrographs are examined (Fig. 2.3), it is apparent that the model is underpredicting summer flows in the main channel of the watershed but not in the headwaters. One factor that may account for under predicting flow is the effect of numerous dams within the watershed. In addition to 28 dams owned and operated by the GRCA, over 200 more dams in the watershed are owned by municipalities and private landowners. The seven major dams 
controlled by the GRCA, including the Shand, Conestogo and Guelph dams, are capable of reducing spring flood peaks by at least $50 \%$ in Kitchener, Cambridge, Guelph, Paris, Brantford, Caledonia, Cayuga and Dunnville. However, in the summer and fall seasons, water stored in the reservoirs is released to maintain minimum flows at Guelph, Kitchener and Brantford. This minimum flow is required to supply municipal drinking water systems that draw directly from the Grand, and to dilute effluent from wastewater treatment plants that empty directly into the Grand. The main variable required as an input for SWAT is the volume of water released from all reservoirs on a daily basis. These data are not collected; however, this volume may contribute substantially to flow in certain portions of the Grand River at certain times of year. Flow generated by water released from dams may represented $53 \%-90 \%$ of total flow in Grand Valley, Guelph, Brantford, and Doon during Fall 2003 (GRCA 2005). Another unknown variable is the amount of water that is removed from various reaches. By 2000, there were over 800 active water extractions in the watershed that included municipalities, farm irrigators, golf courses, aggregate producers and industry. SWAT requires the location of each site of water extraction, the day of extraction and the quantity of water extracted either from the reach or aquifer. Again, these data are not known except for a few scattered in GRCA's reports. These unknowns contribute to the discrepancies in the SWAT flow output when compared to the measured flow during dry seasons. 

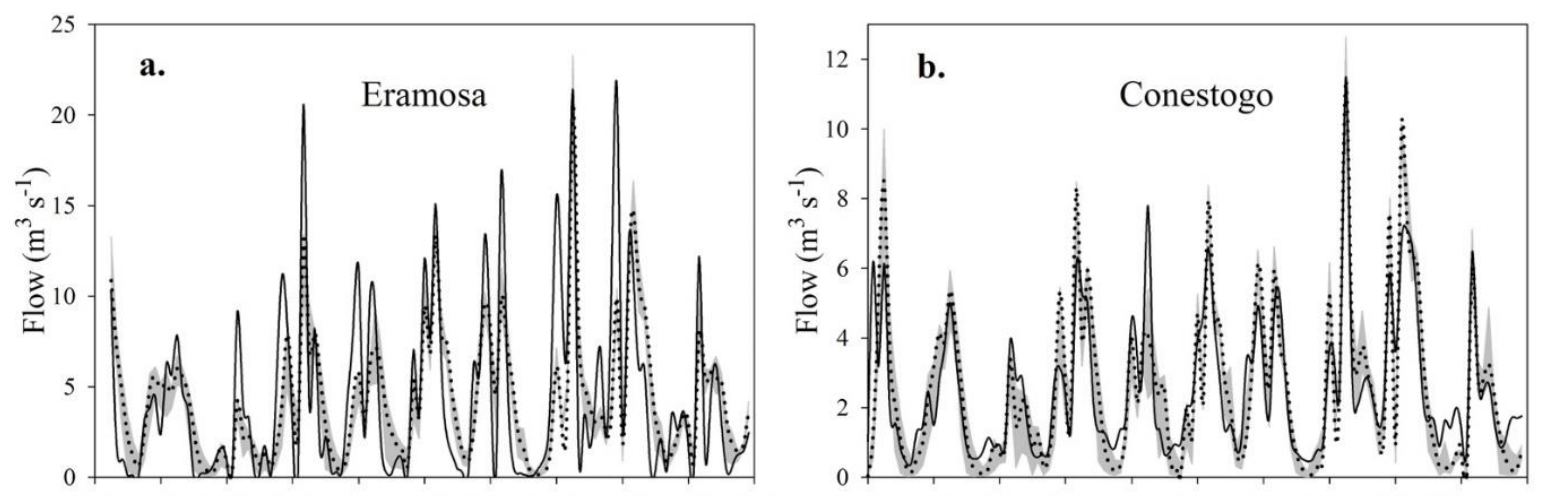

20012002200320042005200620072008200920102011

20012002200320042005200620072008200920102011
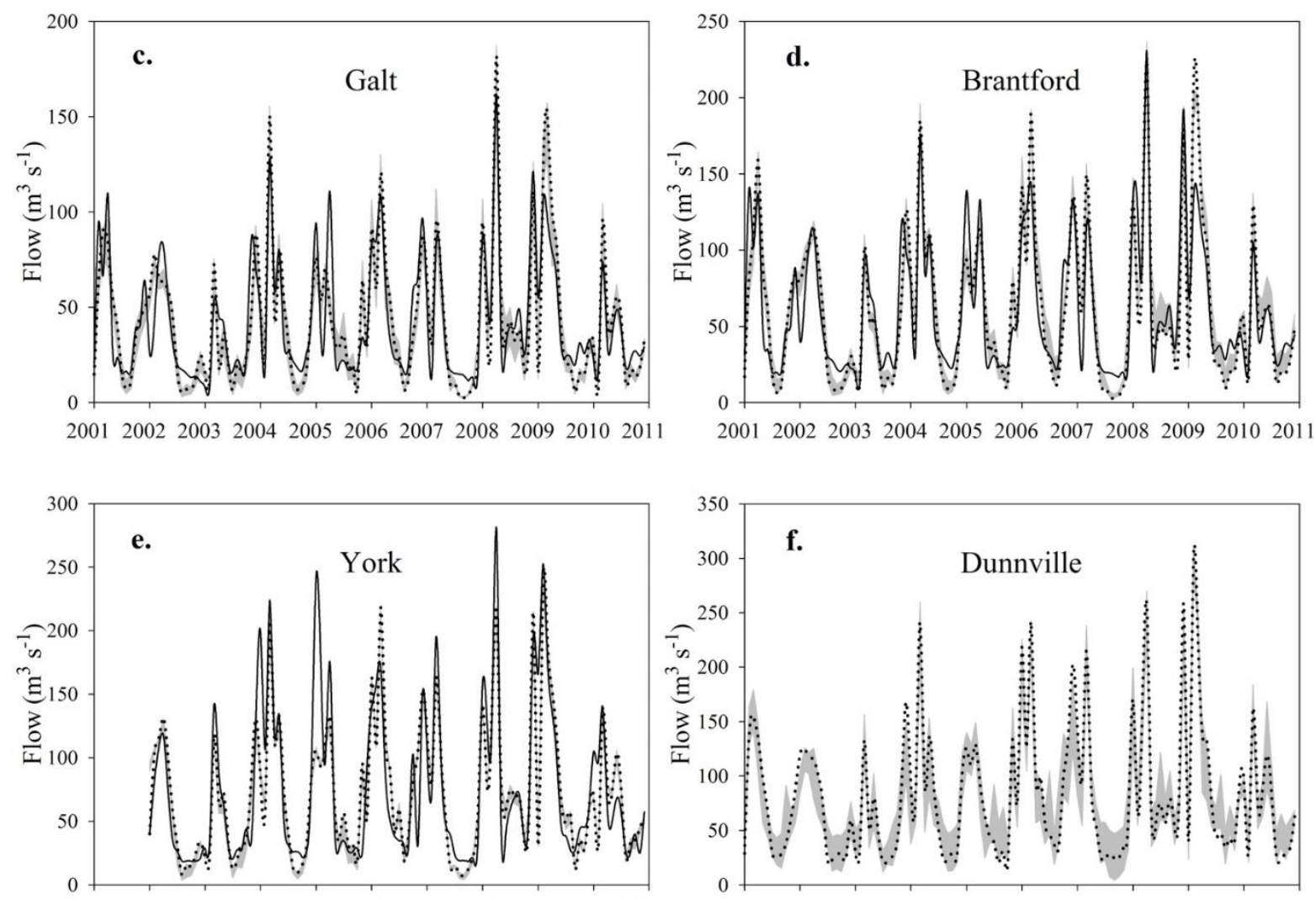

20012002200320042005200620072008200920102011

20012002200320042005200620072008200920102011

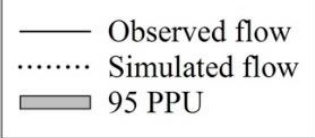

Figure 2.3: Hydrographs for stations used in calibration and validation. At Dunnville station, only a simulated hydrograph is presented since no flow measurements are taken at this location for the period 2001-2010. The 95PPU band contains the 95\% of predictive uncertainty corresponding to the behavioural parameter sets used during the simulation. 
A summary of all the hydrographs show an annual cycle of high spring flows and low summer flows that correspond to precipitation rates and snowmelts (Fig. 2.4). With respect to stream flow in the headwaters of Conestogo and Eramosa/Guelph areas, the most sensitive parameters that influenced stream flow were groundwater re-evaporation (5:V_GW_REVAP.gw; this coefficient defines the restrictions governing the movement of water from the shallow aquifer to the root zone), soil water holding capacity (7:R_SOL_AWC(..).sol), initial depth of water in shallow aquifers (14:R_SHALLST.gw) and SCS runoff cure number under prevailing moisture conditions (2:R_CN2.mgt) (Table 2.6). However, as one moves along the main channel through the lower Grand, flow is affected by additional parameters such as soil bulk density (9:R_SOL_BD(..).sol) and soil evaporation compensation (11:V_ESCO.hru) (Table 2.7).

Table 2.6: Sensitivity analysis for parameters used in headwater streams calibration.

\begin{tabular}{lll}
\hline Headwater parameter & t-statistics & p-value \\
\hline 10:V_SFTMP.bsn & 0.039 & 0.969 \\
11:V_SMTMP.bsn & 0.228 & 0.820 \\
8:R_CH_W2.rte & 0.332 & 0.740 \\
13:V_SMFMN.bsn & -0.370 & 0.712 \\
12:V_SMFMX.bsn & -0.397 & 0.692 \\
6:V_SURLAG.bsn & -0.486 & 0.627 \\
4:V_EPCO.bsn & 0.532 & 0.595 \\
1:R_ALPHA_BNK.rte & -0.618 & 0.537 \\
3:A_GW_DELAY.gw & 1.444 & 0.149 \\
9:R_CANMX.hru & 1.750 & 0.081 \\
2:R_CN2.mgt & -3.338 & 0.001 \\
14:R_SHALLST.gw & -8.432 & 0.000 \\
7:R_SOL_AWC(..).sol & 8.630 & 0.000 \\
5:V_GW_REVAP.gw & 40.841 & 0.000 \\
\hline
\end{tabular}


Table 2.7: Sensitivity analysis for parameters used in the main Grand River calibration.

\begin{tabular}{lll}
\hline Parameter & t-statistics & p-value \\
\hline 7:R_CANMX.hru & -0.0558 & 0.9555 \\
3:A_GW_DELAY.gw & 0.308865 & 0.7576 \\
1:R_ALPHA_BNK.rte & -1.24957 & 0.2121 \\
6:R_CH_W2.rte & 2.378414 & 0.0178 \\
10:R_SOL_K(..).sol & -2.81901 & 0.0050 \\
8:R_SHALLST.gw & -3.80804 & 0.0002 \\
5:R_SOL_AWC(..).sol & 5.819581 & 0.0000 \\
9:R_SOL_BD(..).sol & -8.29451 & 0.0000 \\
11:V_ESCO.hru & -15.5579 & 0.0000 \\
2:R_CN2.mgt & -26.7385 & 0.0000 \\
4:V_GW_REVAP.gw & 37.15096 & 0.0000 \\
\hline
\end{tabular}

The parameterized model was able to predict flow at Dunnville for the simulated time period. SWAT predicted a 10-year average maximum flow of $179 \mathrm{~m}^{3} \mathrm{~s}^{-1}$ in March and minimum flow of $20 \mathrm{~m}^{3} \mathrm{~s}^{-1}$ in August. It is also inferred that the simulated low flows may be lower than reality due to the effects of unknown variables with respect to reservoirs and water consumption within the watershed. Furthermore, on transferring the calibrated flow parameters from Brantford and York, base flow has greatly improved with maximum base flows of around 50 $\mathrm{m}^{3} \mathrm{~s}^{-1}$ (Fig. 2.4). 

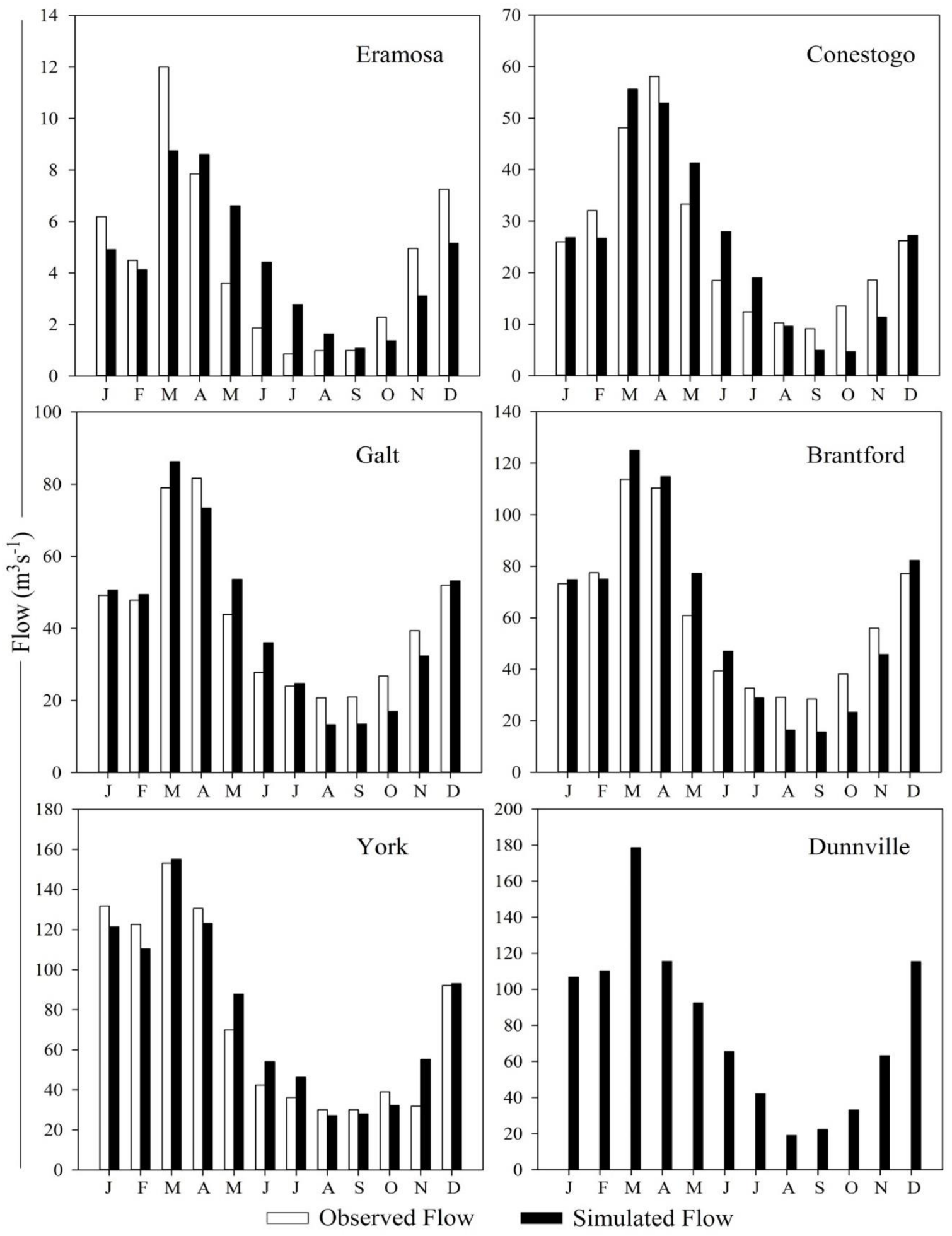

Figure 2.4: Monthly summaries of average water yield at different stations in the Grand River watershed. 


\subsubsection{Sediment (TSS) and Nutrient Simulation}

During the simulated time period, additional parameters were used for the calibration of sediment and phosphorus. Many of the flow sensitive parameters - such as snowfall temperature, melt factor for snow on December 21, melt factor for snow on June 21, snowmelt base temperature, snowmelt temperature lag factor, base flow alpha factor, groundwater delay time, curve number, Manning's n value for the main channel, effective hydraulic conductivity in the main channel, soil available water storage capacity, soil hydraulic conductivity, soil bulk density, maximum canopy storage - were also sensitive to sediment and phosphorus. While flow data were collected at a daily time scale, water quality data, such as sediment and nutrient, were only collected by the Ministry of the Environment between 3-5 times on an annual basis (some years were missing altogether). The GRCA does not collect water quality data. Grab sampling of such a low frequency is wholly inadequate for calibration and validation purposes. One work around was to apply a load estimating software such as LOAD ESTIMATOR (LOADEST) which is capable of estimating constituent loads in streams and rivers (Runkel et al., 2004). Given a time series of stream flow, additional data variables, and constituent concentration, LOADEST will produce a regression model for the estimation of the constituent load which can then be used as the observed values in SWAT calibration. However, the LOADEST output were statistically rejected due to too few sampling points. Given no other option, additional sediment and nutrient parameters that were not included in the flow sensitivity analysis were adjusted by means of manual calibration within ArcSWAT. Some of these parameters include sediment sensitive parameters such as sediment routing factor in main channels, channel re-entrained exponent parameter, channel re-entrained linear parameter, channel erodibility factor, and channel cover factor. Total phosphorus sensitive factors included phosphorus availability index, $\mathrm{P}$ enrichment ratio with sediment loading, rate 
constant for mineralization of organic P. These parameters where not changed by more than $10 \%$ of SWAT's default values.

After a semi-automated calibration of TSS, simulated TSS (Fig. 2.5a) at all sites were within the expected range based on long term observations by the Ministry of the Environment and illustrated by the GRCA (Wong, 2011). Similar to flow trends, TSS trends followed a seasonal pattern with higher TSS in spring and lower levels in summer. TSS, a measure of the actual mass of material per volume of water, displayed natural variation because of physical and or biological processes in the watershed. Since the native soil and geology of the watershed remain fairly constant throughout the year, it is the frequency and intensity of rainfall coupled with land use that affects how easily erosion occurs. Biologically, seasonal changes in algae populations also accounted for variation in TSS. Currently, there is no set Provincial Water Quality Objective (PWQO) for TSS that can be applied to streams. However, the Canadian Water Quality Guidelines (CWQG) does provide a more theoretical guideline, rather than practical, which states that the maximum increase of TSS should be no more than $25 \mathrm{~m} \mathrm{~L}^{-1}$ from base flow conditions for a short term pulse (e.g. 1 day period), and only a maximum average increase of $5 \mathrm{mg} \mathrm{L}^{-1}$ from base flow conditions for longer term (e.g. up to 30 days). In addition, if the base flow TSS levels are between 25 and $250 \mathrm{mg} \mathrm{L}^{-1}$, TSS should not increase by more than $25 \mathrm{mg} \mathrm{L}^{-1}$ during periods of high flow (CCME 2002; TRCA 2010). Although intended for practical purposes, these recommendations are very difficult to implement since the base flow TSS values need high frequency sampling and not three times a year as is currently practised. In addition, sampling only during months of high flow or only during months of base flow will certainly skew any inference on sediment interactions within the watershed (Tate et al. 1999). Furthermore, base flow is highly influenced by monthly and annual precipitation rates and thus, decades of samples have to be taken before one can 
accurately infer the base flow of a particular year. If August and September are used to calculate base flow TSS values, then at almost every site, the TSS values are $25 \mathrm{mg} \mathrm{L}^{-1}$ above the base flow TSS values for most of the remaining months of the year.

Based on a calibrated/validated hydrology and a semi-automated calibrated TSS model, simulated sediment yields from the watershed were extracted. In addition to the modified universal soil loss equation (MUSLE), SWAT predicts sediment yield by taking into account the competing channel processes of channel bed sediment erosion and deposition. Thus, sediment yield is the sum of total suspended sediment that is transported and bed-load sediment. Similar to flow and TSS trends, sediment yield also follows a seasonal pattern with higher TSS in spring and lower levels in summer (Fig. 2.5b), suggesting that the most important drivers of sediment yield are precipitation and land use.

Simulated total phosphorus (TP) levels throughout the Grand River watershed far exceed the provincial objective of $0.030 \mathrm{mg} \mathrm{L}^{-1}$. The model predicts average annual TP values of $0.90,0.34$ and $0.50 \mathrm{mg} \mathrm{L}^{-1}$ (as P) at Galt, York and Dunnville, respectively. TP values were similarly high in headwaters draining row crops on tile drained lands. These findings of elevated TP levels within the watershed are in agreement with many GRCA water quality reports (e.g. GRCA 2005, 2013; Wong 2011). Simulated TP values decreased by the time the river reached the Dunnville area. Loomer and Cooke (2011) indicated that the Grand River tends to recover as it flows toward Paris from Cambridge and this is perhaps due to the Grand flows through a steep valley and thus enhancing oxygenation of the river as it flows through many riffle sections. In addition, Loomer and Cooke (2011) suggested a significant contribution of groundwater to stream flow in this area helps to dilute the nutrient levels in the river. 
Most of the TP is in organic/bound form and would not be readily available for biotic assimilation. TP yields are very high during the months of November - March across the watershed and the majority of the TP is in the form of organic phosphorus. However, predicted soluble reactive phosphorus (SRP) increased in proportion during the low TP yield months (Fig. 2.5c). This may be due to increased residence time of water in the headwaters of the watershed which will facilitate greater nutrient cycling and decomposition of organic nutrients by benthic organisms. Predicted TP was correlated with TSS $(r=0.72)$ and both were generally highest during significant runoff events such as spring runoff. TP on an annual basis was higher in the highly agricultural sub-basins; however, annual export into Lake Erie at Dunnville ranged from 200-300 tonnes $\mathrm{y}^{-1}$.

With the exception of some sub-basins that have a high density of animal farms, nitrates are not a significant nutrient pollutant within the Grand River (PWQO $\left.=2.93 \mathrm{mg} \mathrm{L}^{-1}\right)$. Simulated total nitrate was found to be high in the headwaters and in the middle section of the Grand River (Fig. 2.5d). However, the nitrate concentrations decrease in the lower reaches due to the influx of significant amount of groundwater, and perhaps assimilation into biomass. 

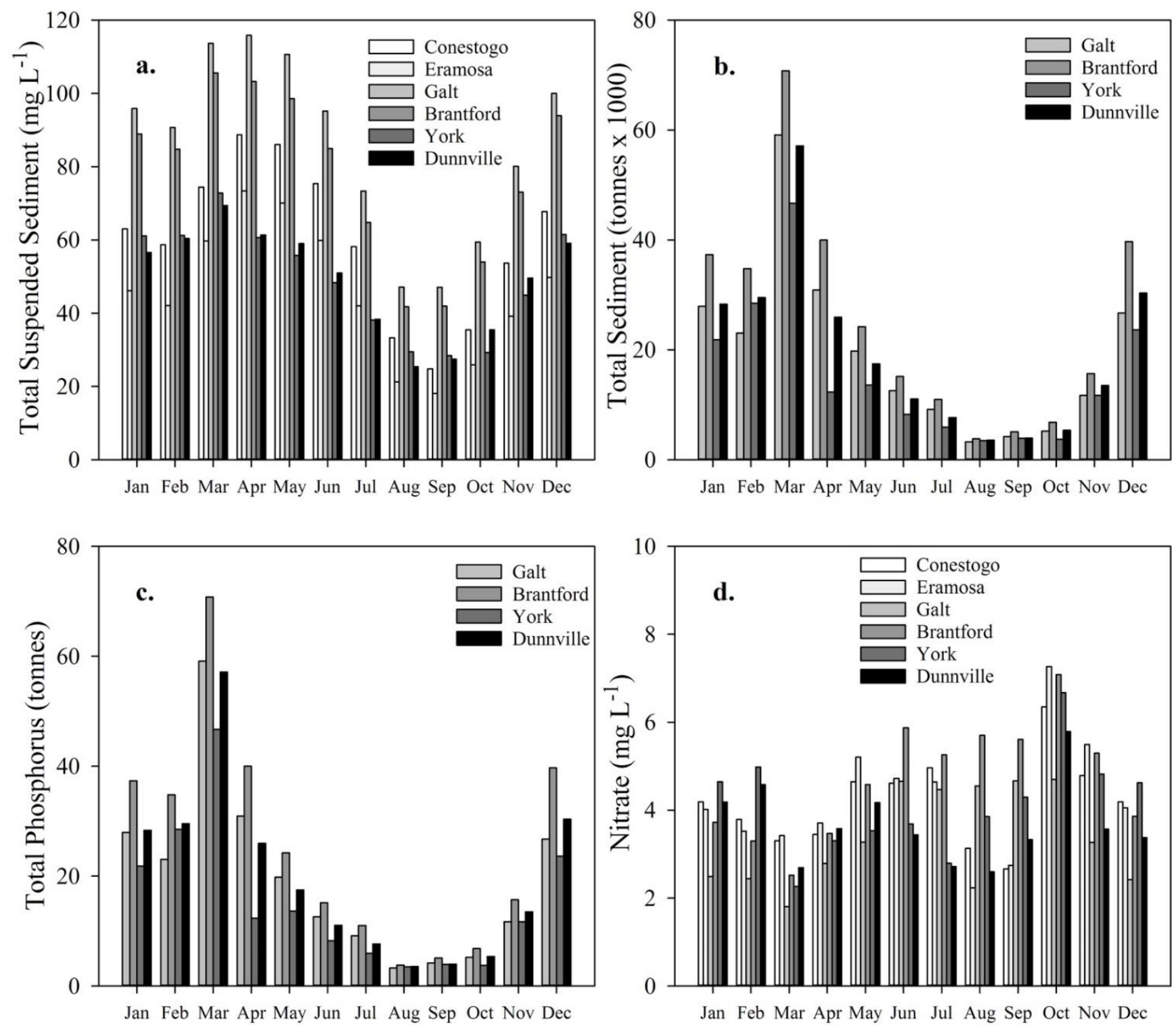

Figure 2.5: SWAT simulated values of a) average monthly total suspended sediment concentrations at different sites in the Grand River watershed for the years 2001-2010; b) average monthly sediment yield at different sites in the Grand River watershed for the years 2001-2010; c) average monthly total phosphorus yields at different sites in the watershed; d) average monthly nitrate concentration at different sites in the watershed. 


\subsection{Conclusion}

In this study a sub-basin-scale hydrologic representation of the highly agricultural Grand River watershed was constructed for the years 1996-2010 using the conceptual based, continuous time, distributed parameter SWAT model. With respect to hydrology, the constructed model was calibrated and validated for five stream discharge stations in headwaters and along the main tributary of the Grand River. The SUFI-2 software in SWAT-CUP package was used for sensitivity analysis, uncertainty analysis, calibration and validation using measured field data. SWAT was able to predict streamflow at different headwaters and downstream with a high degree of accuracy. Due to the infrequent collection of sediment, nitrate and phosphorus concentrations in the stream, SWAT was used to predict their concentrations within the limited available data range. Due to SWAT being physically based, it provided the unique opportunity to predict water quality in streams that are ungauged or those that have limited measured water quality. Furthermore, SWAT can now be applied to quantify the relative effects of alternative input data on hydrology and water quality in the GRW. Best Management Practices and alternative land use scenarios can be applied to this constructed model and their impacts on sustainable water management, hydrology, sediment and nutrient export can be evaluated. In addition, assessing the impact of climate change on seasonal distribution and changes in streamflow can be applied to this model in order to gain further insights of possible changes within the watershed and possible impacts on Lake Erie. 


\section{Modeling the natural drainage network of the Grand River, southern Ontario based on digital elevation models: agriculture may increase total channel length of low-order streams}

Aslam Hanief ${ }^{\mathrm{a}}$ and Andrew E. Laursen ${ }^{\mathrm{b}^{*}}$

${ }^{a}$ Environmental Applied Science and Management Program, Ryerson University, 350 Victoria Street, Toronto, ON M5B 2K3

${ }^{\mathrm{b}}$ Department of Chemistry and Biology, Ryerson University, 350 Victoria Street, Toronto, ON M5B 2K3

Core Ideas

- DEM resolution important for predicting location and lengths of stream channels

- Some actual first-order channels not predicted from topography

- Most unpredicted channels are in agricultural areas, perhaps extended for drainage

- DEM resolution had little effect on prediction of hydrology in SWAT model

- DEM resolution was important in prediction of sediment export by SWAT model 


\subsection{Abstract}

The Grand River watershed is an important agricultural area in southern Ontario, with several large and growing municipalities. As in many watersheds, there have been historical modifications to the drainage network related to various human endeavors. ArcHydro has been used to model how a natural drainage network would appear, based on Digital Elevation Models (DEMs) to predict flow paths. Channel lengths and locations of the predicted network were compared with a groundtruthed channel network to determine efficacy of the model. A stream network generated using DEM with $10 \mathrm{~m}$ resolution was marginally better at predicting the network than a model using the DEM with $25 \mathrm{~m}$ resolution; 88\% of the total channel length predicted by ArcMap overlapped with the actual location, and $>90 \%$ of the predicted channels laid within $5 \mathrm{~m}$ of the actual channel locations. Approximately 5\% of predicted channels lay $>40 \mathrm{~m}$ from actual channel locations. This amounted to $388 \mathrm{~km}$ of channel that had no corresponding channels in reality. The model was unable to predict, based on topography, 2,535 km of actual channel present in the watershed. Channels not anticipated by topography were mostly first-order, with low sinuosity, and were most common in areas with high agricultural land use, and are likely excavated extensions to headwater streams to facilitate drainage. In addition, this study showed that SWAT models produced using different DEM resolutions did not predict significantly different stream flows, even when resolution was as low as $200 \mathrm{~m}$. However, these low resolution DEMs did result in under prediction of sediment export entering Lake Erie, most likely because the low-resolution maps failed to account for small localized areas of high slope that would have relatively higher rates of erosion. 


\subsection{Introduction}

\subsubsection{Stream Modification and Modelling}

For centuries, rivers have been engineered to better suit the needs of people. This engineering may vary from simple stream channelization or straightening to the more complex building of levees and dams. Deliberate modifications of water courses have provided numerous benefits that include enhanced navigation, flood control, provision of hydropower, river bank stabilization (although in many cases, the result has been destabilization), and improved recreational value (Alexander et al. 2012).

Engineering of stream channels generally occurs within a context of broader changes in land use. Human activity dominates landscapes. Between one-third to one-half of the land surface has been modified by human activities (Vitousek et al. 1997). Land conversion to more economic uses (in a conventional sense of financial benefit to landowner) has been a chief component of economic growth; many land use and land cover changes are set in motion by individual landowners and land managers (Brown et al. 2014). Much engineering of stream channels has coincided with clearing of land for agriculture, launching the agrarian economy of the nineteenth and early twentieth century in the United States and Canada.

Agriculture is by far the greatest modifier of land use and land cover. Globally, crop lands have increased from $265 \mathrm{MHa}$ to $1491 \mathrm{MHa}$, and pastures have increased from 524 Mha to 3,451 Mha over the past 300 years (Richards 1990; Goldewijk 2001). This growth has come primarily at the expense of grasslands and forest, although the long-term loss of natural wetlands (64-71\% since 1900) (Davidson 2014) is also largely attributable to conversion for agriculture and urban development. In Canada, land in agricultural use (crop land + pasture) has grown from 1.5 MHa to $74 \mathrm{MHa}$ since 1700 (Goldewijk 2001). While land use conversion continues, the rate of 
conversion peaked in Canada in the late $19^{\text {th }}$ century. However, the rate of conversion continued to grow in many parts of the world well into the $20^{\text {th }}$ century, peaking in the $1950 \mathrm{~s}-1970 \mathrm{~s}$ in Asia, Africa, Central America, and Oceania (Goldewijk 2001), coincident with the chemical agriculture revolution.

The global extent of land modification will continue to increase with a growing population, its demand for food, and growth of urban development (Carpenter 2006). Conversion of land from forest, grasslands, and wetlands to agriculture has many social, economic, and environmental ramifications which are acknowledged, but which lay beyond the scope of this paper. Germane to this study, conversion of land to agricultural use continues to be accompanied by stream channel engineering.

Channelization can reduce the length of a meandering stream, replacing it with a straightened course with sometimes drastically altered channel width, depth and bank slopes. Channelized headwater streams increase flow carrying capacity and flow velocity, both of which result in ecological disturbances (Brooker 1985). Collateral effects of channelizing streams include removal of riparian vegetation, removal of in-stream substrate, an increase in bed gradient, reduced transient storage capacity, and a decrease in total network length of headwater streams (Brooker 1985). Removal of riparian vegetation and in-stream bottom substrate, coupled with the greater flow capacity, increase bank and bed erosion, leading to higher suspended sediment loads in the water column and subsequent sediment export from the watershed (Keller 1978; Brooker 1985; Urban and Rhodes 2003; Pedersen 2009). Streams originating in agricultural landscapes not only experience altered flow regimes, and increased transport of sediment, but also increased transport of nutrients downstream, contributing to cultural eutrophication in receiving water bodies (Mao et al. 2004). Headwater streams are particularly important in processing and retention of nutrients 
(Alexander et al. 2000). This nutrient retention capacity is compromised by increased depth (Alexander et al. 2000) and reduced transient hydrologic retention associated with channelization (Wohl 2006; Triska et al. 2007). Farmers dislike losing soil to the erosive forces of streams, and generally would rather not be under scrutiny by environmental regulators for contributing to nutrient export and eutrophication. However, steam channelization offers the trade-off of effective drainage and enhanced crop growth in wet soils. As a result, reaches that were channelized in past are often maintained, and in jurisdictions with weak environmental regulation and continued land use conversion, sinuous reaches are straightened.

The purpose of this research was to build a hydrological model of the Grand River Watershed (GRW) in southwestern Ontario. This is an important agricultural region of Ontario, and row crop agriculture is the predominant land use in the basin. The drainage network of the GRW was constructed, based on soil layers and topography, to serve as a null model for comparison against the existing drainage network. This provided an opportunity to consider how channel engineering associated with land use (primarily agriculture) has affected drainage density, total channel length, and sinuosity in the network.

Watersheds have emerged as the basic unit for most hydrologic analyses. A manual survey of a watershed can be expensive and time consuming. However Geographic Information Systems (GIS) have become valuable investigative tools with respect to stream visualization and analysis. With GIS, one can add spatial elements and also perform analysis of variables such as slope, aspect and other watershed parameters including climate, topography, soil type, vegetative cover, population density, point source of pollution, and farming practice (Heywood et al. 2006). With GIS, it is possible to greatly reduce processing time (as compared to field surveys) and elements of subjectivity that are frequently encountered with the manual measurement of features on maps 
and aerial photographs. When large watersheds are being studied, digital data resolution is of paramount importance since digital elevation models (DEMs) are the primary topographic inputs of hydrologic modelling. A secondary objective of this research was to consider the effect of spatial resolution in DEMs on prediction of hydrology and sediment export in the GRW.

The Soil and Water Assessment Tool (SWAT) is a continuous-time, semi-distributed, physically-based watershed model that operates on a daily time step (Arnold et al. 1998; Gassman et al. 2007; Arnold et al. 2012). Because it is physically based, SWAT provides the unique opportunity to simulate the hydrology and water quality of ungauged streams and to quantify the relative impacts of alternative input data on hydrology and water quality in watersheds. Today, SWAT is widely used to assess the environmental impacts of land use management on water quantity and quality in small agricultural fields to continental size watersheds with varying soil types, topography and land uses (Gassman et al. 2007; Arnold et al. 2012). In this study, SWAT was applied to the modeled and existing drainage networks to consider the effects channel engineering in the GRW had on hydrology and sediment yields for the years 1980-2010.

\subsubsection{The Grand River Basin, southern Ontario}

The Grand River Basin (GRB) covers an area of $6,965 \mathrm{~km}^{2}$ and it is the largest of the watersheds in southwestern Ontario that drain into Lake Erie (Fig. 3.1). Spanning a length of 290 $\mathrm{km}$ and having an elevation differential of about $362 \mathrm{~m}$ from source to mouth, the Grand River follows a dendritic pattern after it originates at the Dundalk Highlands, flows through Port Maitland and contributes about $10 \%$ of the drainage into Lake Erie (Scott and Imhof 2005). The total stream length of all tributaries in the GRB is 20,000 km (GRCA 2013). 


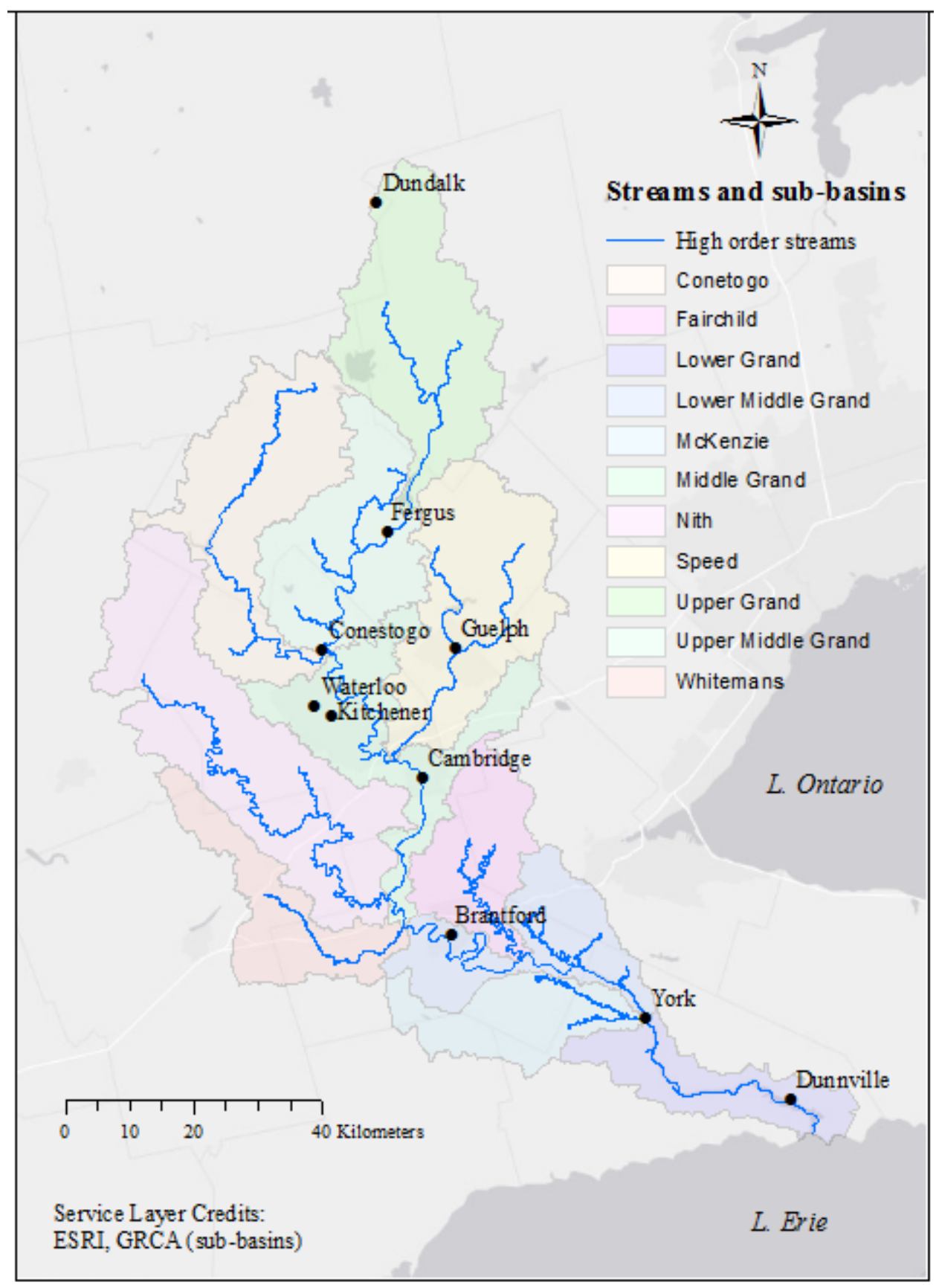

Figure 3.1: The Grand River watershed is located in southwestern Ontario and drains into Lake Erie. The latitude, altitude and proximity to Lake Erie influence the climate of the Grand River area. The headwaters of the Grand River lie in the north and as it makes its way to Lake Erie in the south, it traverses four different climate zones. On average, the GRB receives $93.3 \mathrm{~cm}$ of precipitation each year (GRCA 2013). The mean temperature of headwater streams is around $6^{\circ} \mathrm{C}$ while Lake Erie is around $9^{\circ} \mathrm{C}$ while the average annual temperature of the watershed is $7.8^{\circ} \mathrm{C}$ (Mayer and Delos Reyes 1996). (Credit: Sub-basins division modified from GRCA geospatial datasets). 


\section{Geology of the Grand River Basin}

The GRB is dominated primarily by three bedrock formations, the Guelph and Amabel formations located in the eastern basin, and the Salina formation in the west. These sedimentary bedrocks are porous, fractured limestone that strongly influences groundwater storage and availability for municipal and private use in the watershed (Mayer and Delos Reyes 1996; GRCA 2008).

The surficial geology of the GRB was shaped by the Wisconsin glaciers that covered southern Ontario 20,000 years ago. As the glaciers retreated 10,000 years ago, the present surface materials were left behind. Three distinct surficial geology types are present in the watershed. The northern till plains consist mainly of dense, fine-grained clay and silt-rich soils that sit on large, gently rolling landmasses. These dense soils restrict water from penetrating the soil horizon and result in a significant amount surface runoff from precipitation into the headwaters of the Grand River. The till plains are extensively farmed and tile drainage is a dominant feature throughout the area (GRCA 2008). The central region of the GRB consists mainly of sand and gravel and contributes to significant groundwater reserves. Moraines cover huge underground aquifers and supply the drinking water needs of the central urban areas of the watershed (Cooke 2006). Also, sub-lateral flows empty into tributaries resulting in the formation of coldwater streams that are ideal habitats for cold-water fish species. Finally, the Grand River crosses over the southern heavy, impermeable clay plains which are mostly used for livestock pastures. Like the northern till plains, these clay plains are poorly drained and generate significant surface runoff and sediments after a precipitation event, prior to emptying into Lake Erie (GRCA 2008). 


\section{Land cover and land use}

Prior to the arrival of Europeans around the mid-1770s, First Nations inhabited the basin which was dominated by pristine forests, marshes and swamps. From the 1750s, wetlands and forests in the GRB have been progressively modified to make way for lumber exploitation, agriculture, pasture, settlements and industry. Nearly $95 \%$ of historical forest has been removed and there has been extensive stream engineering of the waterscapes (Scott and Imhof 2005), especially by damming and channelization (GRCA 2008). By the early 1900s, almost $70 \%$ of all drained wetlands in southern Ontario were converted into agricultural lands and the historical landscape of the Grand River had been altered to such an extent that there was noticed degradation in water quality. In 1934, the Grand River Commission received its charter, tasked with finding a solution to the degradation in stream flows and water quality (Scott and Imhof 2005). With about 6,000 farms, agriculture has remained the dominant land use (93\% of land is rural) in the GRB (Farwell et al. 2008). Around $70 \%$ of the total watershed area is in agriculture. Approximately $82 \%$ of land on the upper Grand (e.g., Nith and Conestogo sub-basins) is in agriculture as compared to $\sim 64 \%$ in the central Grand (Holeton 2013). At present, forests and wetlands occupy around $20 \%$ of the total watershed (Holeton 2013). Based on the 2001 Census of Agriculture, row crops, small grains, forage and bare agricultural fields accounted for $20.5 \%, 12.1 \%, 19.2 \%$ and 15.9\% of the GRB, respectively (Statistics Canada 2002). The GRB is currently marked by some

of the fastest growing urban centres in Canada (Cooke 2006). Just over one million people live in the GRB; however, $81 \%$ reside on $7 \%$ of the land area in the urban centres of Kitchener, Waterloo, Cambridge, Guelph and Brantford (Farwell et al. 2008). 
A 1982 Grand River Basin Water Management Study clearly identified intensive agricultural practices as the main nonpoint source of pollution responsible for the impairment of the water quality in the Grand River (GRIC 1982). Based on the Water Quality Index that is used by the Canadian Council of Ministries of the Environment, the headwaters of the Grand River are classified as 'good'; however, as the tributaries flow past major agricultural areas, they pick up contaminants and their status drops to 'fair'; and finally, as these larger tributaries and the main Grand River flow past urban centres, water quality drops to 'poor' due to the addition of high levels of phosphorus and nitrogen from storm water and sewage treatment plants (Scott and Imhof 2005). Together with straightening of ditches for agricultural purposes and high livestock density, current land use practices are contributing to further degradation in both water quality, via chronic nutrient loading, and degradation of habitat for many aquatic species within the watershed (Cooke 2006).

\subsection{Methodology}

\subsubsection{Stream delineation}

ESRI's ArcMap 10.2 Hydrology tool (ESRI, Redlands, CA) was used to delineate the Grand River watershed using a preprocessed digital elevation model (DEM) at 10, 25 and 200 metres spatial resolutions. (DEM data derived from Ontario Base Mapping - Specification (Nominal Scale of Mapping - 1:10000; Absolute Positional Accuracy - 5 m; Absolute Vertical Accuracy (contours \& DTM) - 2.5 m; Spot Elevation Point (vertical accuracy) - $1.25 \mathrm{~m})$ )

A blank map document in ArcMap 10.2 was opened and a clipped DEM dataset of the study area was loaded. The Fill tool was used to smooth imperfections (sinks) in the DEM raster to allow water to flow across the grid cells uninterruptedly. The filled layer was then processed 
using the Flow Direction tool for each cell in the DEM to determine the flow along cells connected hydrologically. The Flow Accumulation tool was activated to generate a new layer that displayed the number of cells upstream on any given cell in the Flow Direction layer. A stream network followed by stream links were built by choosing a $4.5 \mathrm{~km}^{2}$ threshold that generated a seventh order stream (Strahler's method) for the Grand River. Since stream networks and stream links were built before determining stream order in the Hydrology tool, the threshold value was determined iteratively, determining the value necessary to generate a seventh order stream from the watershed to match the ground-truthed published stream network (source layer obtained from the Ministry of Natural Resources, Ontario). The Stream to Feature tool was used to convert the stream raster to a polyline feature class. In order to generate the Grand River watershed, a new empty shapefile was created using ArcCatalog and a pour point was added at the farthest point downstream prior to entering Lake Erie so that all areas upstream from the pour point were delineated as belonging to a single watershed. The pour point was then affixed onto the Flow Accumulation layer by using the Snap Pour Point tool. A radius of 50 metres was indicated to ensure the pour point was snapped onto the cell with the highest flow accumulation within the specified radius. For geoprocessing and subsequent and stream analyses, the watershed raster was converted to a polygon using the appropriate Raster Conversion tool.

Comparisons of distances and lengths of the DEM-derived streams (target layer) and the ground-truthed reference stream network were carried out using the Select By Location and Within a Distance tools. Spatial queries were run at $0 \mathrm{~m}, 2.5 \mathrm{~m}, 5 \mathrm{~m}, 10 \mathrm{~m}, 20 \mathrm{~m}$ and $40 \mathrm{~m}$ to evaluate the extent of overlap between the two stream networks. 
To determine the stream sinuosity of every reach within the watershed, the XY tool was used to determine the straight line distance of each stream segment in the watershed. The Field Calculator was used to calculate the stream sinuosity.

A shapefile containing the different sub-basins within the Grand River watershed (downloaded from https://data.grandriver.ca/downloads-geospatial.html) was used to clip subbasins in the DEM derived watersheds, soil (downloaded from Land Information Ontario: https://www.ontario.ca/page/land-information-ontario), tile drainage (downloaded from the Ontario Ministry of Agriculture, Food, and Rural Affairs: https://www.ontario.ca/page/landinformation-ontario), and land cover (downloaded from Grand River Conservation Authority: https://data.grandriver.ca/downloads-geospatial.html) layers. Analyses were performed on each sub-basin to determine land use, soil drainage and type, tile drainage area, stream length, order and reach sinuosity. Sinuosity is the extent of curving and is a quantitative measure of reach meandering. Stream sinuosity is calculated as a ratio of the actual reach length to its straight-line distance between two points at $100 \mathrm{~m}$ intervals on the reaches.

\subsubsection{Effects of DEM on SWAT model performance}

A SWAT model has been recently developed for the Grand River Basin. This model is described, along with calibration and validation for prediction of discharge and export of sediments and nutrients from the GRB (Hanief and Laursen, in review). In the model described, a DEM with $10 \mathrm{~m}$ resolution was used for the delineation of the Grand River Basin, sub-basins, hydrologic response units (HRUs), and for identification of pour points from the watershed overall, and from

each sub-basin, and HRU. This model's layers for sub-basins, HRUs and pour points were overlaid with the actual stream network, so the $10 \mathrm{~m}$ DEM was not used to predict the channel network, as was described above. 
The availability of a ground-truthed digital river network, and of a 10-m resolution DEM for the GRB is a luxury. Not all watersheds for which one might wish to build a SWAT model have either available. It is not clear how strongly the use of a lower resolution elevation model may affect the quality of the SWAT model, particularly if the DEMs must be used not only to predict topographical features (e.g. HRUs), but also to predict the channel network. In the current study, the effects of DEM resolution on SWAT model predictions for hydrology and sediment transport were evaluated by delineating the stream network, the basin, sub-basin, and pour points using 10-m, 25-m, and 200-m resolution DEMs. As the SWAT model, constructed using a 10-m resolution DEM with an actual stream network layer, has been calibrated and validated with respect to predicting discharge and sediment load, it serves as the comparator against which performance of SWAT models, built using DEMs of varying resolution, can be assessed.

\subsubsection{Preparation of SWAT Model Input Data}

A Digital Elevation Model (DEM) for Ontario was obtained via the Scholars Geospatial Portal at Ryerson (http://geo2.scholarsportal.info/). This DEM (version 2.0.0) is a 3-D raster data set which captures terrain elevations and has cell resolutions of $10 \mathrm{~m}$ in southern Ontario. A rectangular clipped portion of the DEM was used to delineate the watershed and the pour point was snapped on the main stream network as it entered Lake Erie. The GRCA's ground-truthed stream network (https://data.grandriver.ca/downloads-geospatial.html) was burned onto the raster during the watershed delineation process to produce more accurate sub-basin delineations in subsequent steps. The virtual stream layer is a single line, fully connected network that represents the inferred flow through watercourses and water bodies. DEMs with lower resolution (25- and 200-m) were also obtained from GRCAs website (https://data.grandriver.ca/downloadsgeospatial.html). 
Land cover / land use

Land cover classification was based on Landsat 7 TM Imagery in 1999 and updated in 2005 (downloaded from Grand River Conservation Authority: https://data.grandriver.ca/downloads-geospatial.html). Pixel sizes in the landcover GRID were $25 \mathrm{~m} \times 25 \mathrm{~m}$. To date, SWAT has a library of 97 plant types and 8 urban land uses in its database. The GRW was divided into 19 of these different land cover categories, listed here along with corresponding SWAT code in parentheses: built-up (residential) (URHD), built-up (commercial/industrial) (UCOM), row crops (AGRR), small grains (AGRL), forage (ALFA), pasture/sparse forest (PAST), dense forest (deciduous) (FRSD), dense forest (conifer) (FRSE), dense forest (mixed) (FRST), plantation (mature) (AGRL), open water (WATR), wetlands (WETL), extraction/bedrock/roads/beaches (BARR), golf courses (FESC) and bare agricultural fields (AGRL).

Soil classification

Geospatial data were obtained from the Soil Landscapes of Canada's online geospatial database that is maintained by the Canadian Soil Information Service or CanSIS (http://sis.agr.gc.ca/cansis/). A soil database was built to identify and link the physiochemical properties of the top 10 layers (if present) of the soil profile to the soil groups in the watershed. The names and characteristics of the different soil layers were also downloaded from the CanSIS website in the Soil Name Table and the Soil Layer Table. SWAT requires the following properties for each layer within the soil: soil hydrologic group, maximum rooting depth of soil profile, fraction of porosity from which anions are excluded, maximum crack volume of soil profile, texture of soil layer, depth from soil surface to bottom of layer, moist bulk density, available water capacity of the soil layer, saturated hydraulic conductivity, organic carbon content, clay content, 
silt content, sand content, rock fragment content, moist soil albedo, USLE K, electrical conductivity, soil $\mathrm{CaCO}_{3}$, and soil $\mathrm{pH}$. This database was then appended to the SWAT usersoil database.

Soil slope was divided into four groups based on a modification of the Canada Slope Gradients classification: little or no slope (0-3\% gradient), gentle slope (3-9\% gradient), moderate slope (9-15\% gradient), and steep or excessively steep slope (>15\% gradient). After the watershed was delineated, SWAT generated HRUs by overlaying and combining land use, soil and slope.

\section{Weather data}

Daily maximum and minimum $\left({ }^{\circ} \mathrm{C}\right)$, precipitation $\left(\mathrm{mm} \mathrm{d}^{-1}\right)$, wind speed $\mathrm{s}^{-1}$ ), solar radiation $\left(\mathrm{MJ} \mathrm{m}^{-2}\right)$, and relative humidity (fractional) are required weather inputs provided for the length of SWAT run (31 years in total). Weather data were assigned to every sub-basin using data from the station that is closest to the centroid of that sub-basin. All weather data were downloaded from the SWAT's Global Weather Data tool (http://globalweather.tamu.edu/). This simulated data set, referred to as the Climate Forecast System Reanalysis (CFSR), was prepared by the National Centers for Environmental Prediction (NCEP) over the 36-year period from 1979-2014 and is based on a spectral model which includes variables within all major earth and atmospheric processes (Kalnay et al. 1996; Saha et al. 2010). Also, due to absence of measured daily solar radiation, humidity and wind speed datasets, the Hargreaves' method of simulating potential evapotranspiration was selected for the model run. This method of inferring PET rates has shown reliable estimates when compared to measured values (Jensen et al. 1990; Itenfisu et al. 2003).

SWAT model construction and run 
The duration of the SWAT run was set up from 1980 to 2010 and the model was run on a monthly time scale using a 10/10/10 Multiple HRU threshold for soils, landuse and slope. The model was run on a monthly scale for four different scenarios: (a) 10-m DEM using the groundtruthed stream network (referred to as a comparator), (b) 10-m DEM using ArcSWAT for stream delineation, (c) 25-m DEM using ArcSWAT for stream delineation, and (d) 200-m DEM using ArcSWAT for stream delineation. Manual calibration of streamflow and sediment discharge was done using parameters as outlined in a SWAT model for the GRB that has been constructed, calibrated, and validated for prediction of water discharge, sediment transport, and phosphorus transport (Hanief and Laursen, in review).

\subsection{Results and Discussion}

\subsubsection{Stream network delineation}

The quality of predicted stream networks, based on DEMS at 10-m and 25-m resolution, was assessed by comparing the total channel length predicted by these models versus the actual channel length in the GRB network, and by determining how well the predicted stream channels spatially coincided with actual stream channels. The total stream length for the GRB network in the reference network source layer is $11,329 \mathrm{~km}$. The stream network derived from the $10-\mathrm{m}$ and 25 m resolution DEMs predicted similar total stream lengths of 9,182 $\mathrm{km}$ and 8,958 km, respectively, or $81.0 \%$ and $79.1 \%$ of the actual total stream length. Hence, approximately $20 \%$ of the stream network cannot be topographically derived. The actual stream network has greater total stream channel density than the predicted network derived from either DEM, as illustrated by comparing the actual network versus that predicted from the 10-m resolution DEM (Fig. 3.2).

Spatial agreement between predicted stream networks and the actual GRB network was considered based upon how much of the total predicted channel length lies within various distances 
of actual stream channels. Of the total $9,182 \mathrm{~km}$ of channel length predicted from the $10-\mathrm{m}$ resolution DEM, 8,102 km, or 88.2\%, overlapped with actual channel positions (Table 3.1), while $8,325 \mathrm{~km}$ or $90.7 \%$ of the total length of predicted channels lie with $5 \mathrm{~m}$ of actual channel positions. The 25-m resolution DEM was also useful in predicting channel position, with 7,818 $\mathrm{km}$ of the total predicted network overlapping with actual channel positions. However, the 10-m resolution DEM provided a better correspondence to the actual network, as $95 \%$ of the total predicted channel length fell within $17 \mathrm{~m}$ of actual channel positions, while $95 \%$ of predicted channel length fell within $40 \mathrm{~m}$ of actual channel positions for the network derived using the 25-m resolution DEM.

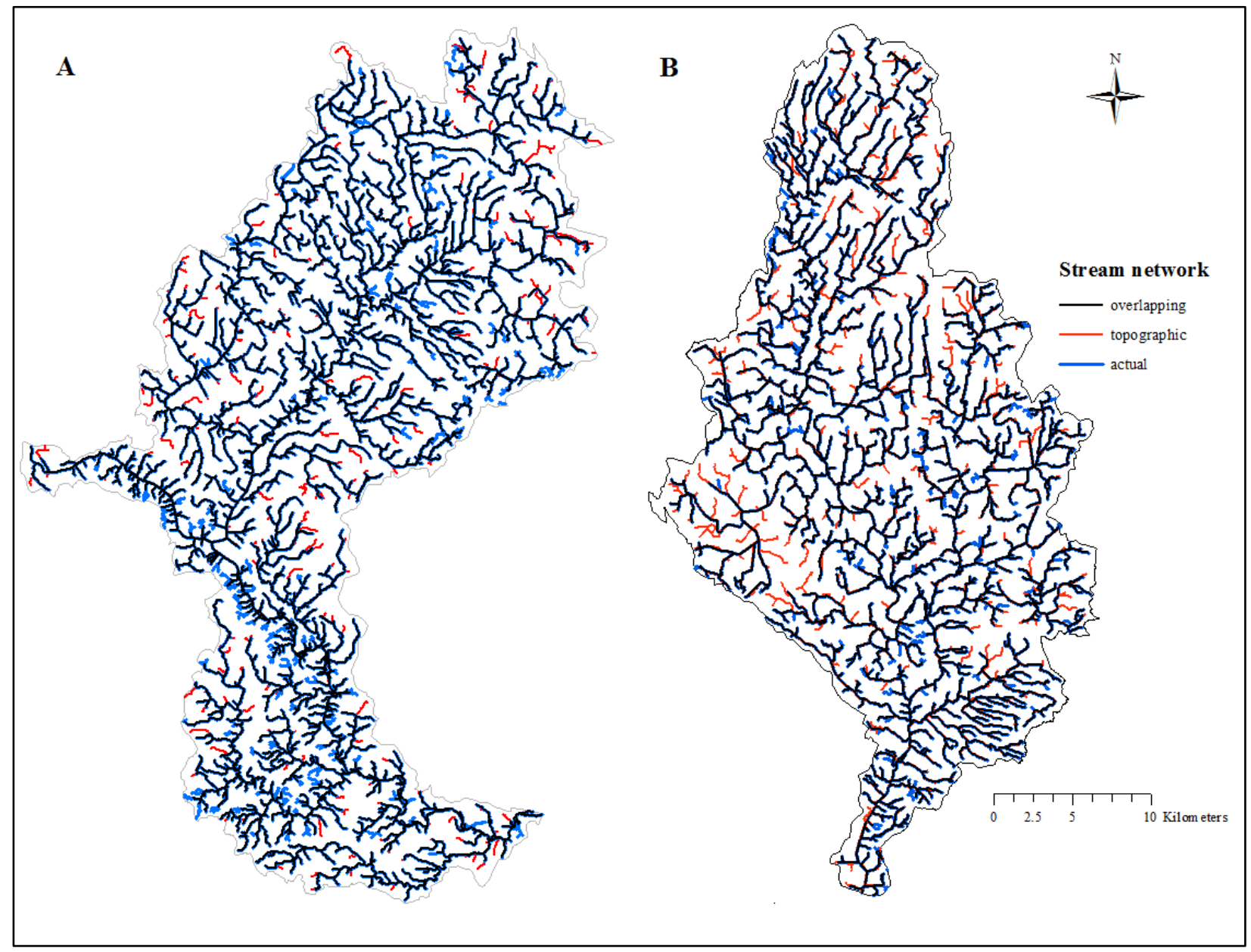

Figure 3.2: Comparison of the actual stream network to topographically derived stream networks demonstrating higher stream density in the actual stream network versus the topographically extracted stream network in the Conestogo (A) and Upper Grand (B) sub-basins of the GRB. 
Table 3.1: Total $\mathrm{km}$ of the predicted channels in stream networks derived from DEM models that overlap or lie within varying distances of the existing channels in the Grand River Basin.

Total overlap in $\mathrm{km}$ (and \% total channel length)

\begin{tabular}{llllllll} 
DEM model & $0 \mathrm{~m}$ & $2.5 \mathrm{~m}$ & $5 \mathrm{~m}$ & $10 \mathrm{~m}$ & $17 \mathrm{~m}$ & $20 \mathrm{~m}$ & $40 \mathrm{~m}$ \\
\hline & 8102 & 8209 & 8325 & 8551 & 8727 & 8756 & 8795 \\
$10 \mathrm{~m} \mathrm{DEM}$ & $(88.2 \%)$ & $(89.4 \%)$ & $(90.7 \%)$ & $(93.1 \%)$ & $(95.0 \%)$ & $(95.4 \%)$ & $(95.8 \%)$ \\
& 7817.6 & 7911 & 8002 & 8174 & & 8381 & 8512 \\
$25 \mathrm{~m}$ DEM & $(87.3 \%)$ & $(88.3 \%)$ & $(89.3 \%)$ & $(91.2 \%)$ & --- & $(93.6 \%)$ & $(95.0 \%)$ \\
\hline \hline
\end{tabular}

Approximately $48 \%$ of the total channel length in the GRB network is first-order, with an additional $23 \%$ being second-order (Fig. 3.3), consistent with the distribution in basins described elsewhere (e.g. Horton 1945; Leopold et al. 1964; Seitzinger et al. 2002; Alexander et al. 2007). Predicted network models based on DEMs were good at predicting the positions of channels second-order or higher, but were less accurate in predicting positions of first-order channels. If one considers only those predicted channels that did not lie within $10 \mathrm{~m}$ of existing channels, one would expect $48 \%$ of the total length to be represented by first-order streams. This would be true if the model predicted positions of all channels equally well regardless of size (stream order). Similarly, one would predict $23 \%$ of the total length of these outlying channels to be second-order. However, when considering only those predicted channels that fail to lie within $10 \mathrm{~m}$ of actual channels, $82 \%$ and $76 \%$ of the total basin-wide channel length are first-order in networks derived from the 10-m and 25-m resolution DEMs, respectively (Table 3.2). In contrast, $16 \%$ and $17 \%$ of the predicted channels that do not lie within $10 \mathrm{~m}$ are second-order for networks derived from 10$\mathrm{m}$ and 25-m resolution DEMs. 


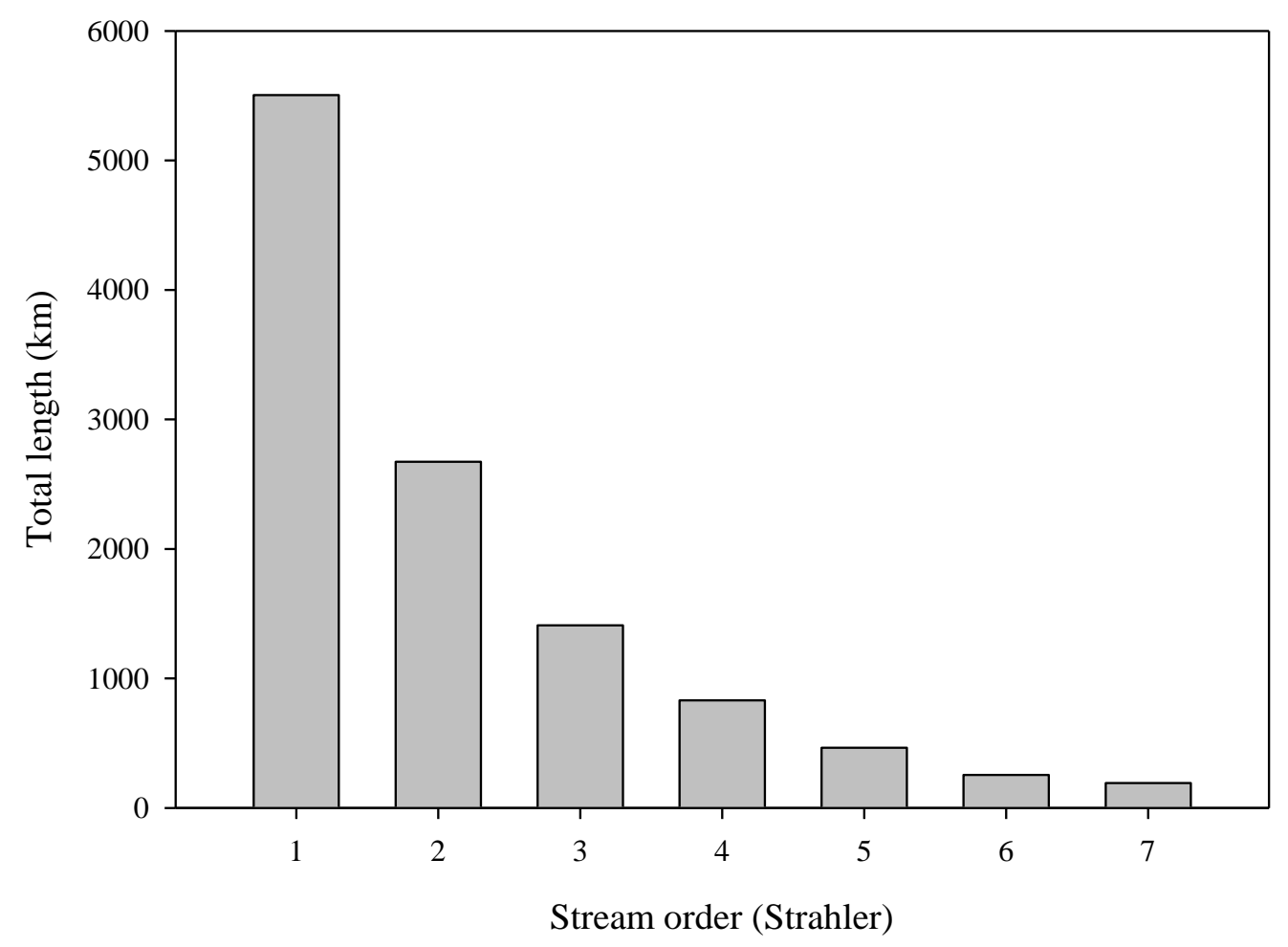

Figure 3.3: Stream length of different stream order of the Grand River stream network.

Table 3.2: Performance of stream network models derived from $10 \mathrm{~m}$ and $25 \mathrm{~m}$ DEMs in predicting locations of first and second order channels.

\begin{tabular}{|c|c|c|}
\hline & \multicolumn{2}{|c|}{ DEM resolution } \\
\hline & $10 \mathrm{~m}$ & $25 \mathrm{~m}$ \\
\hline $\begin{array}{l}\text { Total length of non-overlapping (within } 10 \mathrm{~m} \text { ) first order channels } \\
\text { (model predicted versus actual) }\end{array}$ & $515 \mathrm{~m}$ & $598 \mathrm{~m}$ \\
\hline $\begin{array}{l}\% \text { of non-overlapping (within } 10 \mathrm{~m} \text { ) channels that are first order } \\
\text { (model predicted versus actual) }\end{array}$ & $81.6 \%$ & $76 \%$ \\
\hline $\begin{array}{l}\text { Number of predicted first order stream segments that do not } \\
\text { overlap actual first order channels }\end{array}$ & 2,151 & 3,078 \\
\hline Sinuosity of actual first order channels not predicted by DEM & 1.06 & 1.05 \\
\hline $\begin{array}{l}\text { Total length of non-overlapping (within } 10 \mathrm{~m} \text { ) second order } \\
\text { channels (model predicted versus actual) }\end{array}$ & $101 \mathrm{~m}$ & $132 \mathrm{~m}$ \\
\hline $\begin{array}{l}\% \text { of non-overlapping (within } 10 \mathrm{~m} \text { ) channels that are second order } \\
\text { (model predicted versus actual) }\end{array}$ & $16.1 \%$ & $16.8 \%$ \\
\hline $\begin{array}{l}\text { Number of predicted second order stream segments that do not } \\
\text { overlap actual first order channels }\end{array}$ & 485 & 877 \\
\hline Sinuosity of actual second order channels not predicted by DEM & 1.06 & 1.04 \\
\hline
\end{tabular}


Stream networks predicted by DEM models include some channels that do not exist in reality. These missing channels (or sub-networks) may be a result of a variety of factors, such as burial in the course of urban development. In contrast, predicted networks were missing some channels that do exist in reality. Upon closer inspection of these missing channels, many were relatively straight headwater channels, extending upstream of their predicted starting locations based on DEMs (Fig. 3.2). The sinuosity of these channels was very low, $\leq 1.06 \mathrm{~km}$ channel length per linear $\mathrm{km}$ (Table 3.2). Channelization, or straightening of meandering reaches of streams, is a common practice in agricultural areas, but contrary to expectations, there is little evidence that this type of modification has occurred to a substantial degree in the GRB. Actual total network channel length is greater than that predicted from topography, and sinuosity in all major sub-basins, and for the network overall, was greater than sinuosity predicted from DEMs (Table 3).

The stream network density for a drainage basin, is widely used as the starting point for stream restoration (Elmore et al. 2013). Comparing predicted versus actual network density can indicate areas where restoration efforts might be focused on increasing channel length, or where regulatory actions might be indicated to protect further loss of stream network density (Elmore et al. 2013). Interestingly, in the GRB it appears that land use modifications may marginally increase, rather than decrease, total channel length and stream network density. Possibly this is a result of extending headwater streams as channels or ditches to increase drainage from agricultural lands. Sub-basins of the GRB differ in land use, with percent of land in agricultural production varying from $43.4 \%$ (Middle Grand) to $78.0 \%$ (Conestogo River) (Table 3.3). The percentage of total stream network that is first-order also varied among sub-basins, and was correlated with percent agriculture $(r=0.61, p=0.04)$. Extending headwater streams for drainage from agricultural 
lands may contribute to this pattern, although the circumstantial concentration of agricultural activity in the northern portion of the GRB, the headwaters of the basin, likely contributes more to the relationship. However, the difference between DEM-predicted and actual \% first-order stream length ([\% predicted $-\%$ actual] / \% actual) is also correlated with percent agricultural activity across sub-basins $(r=0.70, p=0.015)$, suggesting that extension of headwater streams for agricultural purposes has a pervasive effect on the GRB channel network.

Headwaters are important lotic systems that represent hydrological connectivity (Freeman et al. 2007) between upland and downstream waters (King et al. 2009) by facilitated transferral of mass, momentum, energy, or biota within or between various components of the hydrologic cycle (Nadeau and Rains 2007). Whether perennial or intermittent, headwater streams are important sites for biogeochemical transformation of nutrients (King et al. 2009). Due to their dendritic, hierarchical patterns and their large width to depth ratio, headwater streams are critical in controlling the amount of nutrients that are exported downstream (Peterson et al. 2001). Alexander et al. (2007) have shown that it is the dynamic coupling of hydrological and biogeochemical processes in headwaters that regulates not only the chemical form of the nutrient that is being transported, but also its residence time and longitudinal transport to downstream receiving waters. Peterson et al. (2001) have concluded that the fastest uptake and subsequent transformation of nitrogen takes place in headwater streams.

The Grand River basin is highly agricultural. The apparent increase in first order channel length by extending headwaters to facilitate drainage may mitigate some of the impacts of agricultural runoff on the Grand River. This notwithstanding, the Grand River is consistently rated poor with respect to water quality prior to entering Lake Erie (GRCA 2008 2013). 
These extended reaches of headwater channels provide a unique opportunity for land owners, the conservation authority, municipalities and other stakeholders, to target effective stream restoration polices and agricultural best management processes within major basins in the watershed, particularly in those with especially high agricultural activity such as Conestogo, Nith and Upper Middle Grand, in an effort to abate sediment and nutrient export into Lake Erie. Restoration activities might be concentrated on these extended reaches (effectively ditches) to improve sediment and nutrient retention and processing near the site of loading. Such activities come at cost, and it is important to first define what impact such targeted efforts in these relatively small stretches of the watershed might have on water quality. Recently, a SWAT model for the GRB was constructed, calibrated, and validated for prediction of water discharge, sediment transport, and phosphorus transport (Hanief and Laursen, in review). This model can provide an effective tool for future testing of the application of Best Management Practices to these extended headwater channels, to reduce sediment and nutrient transport. This would provide some guidance on how best to balance management goals and objectives with costs of implementation. This, as well as full discussion of the SWAT model, are beyond the scope of the current study, however the SWAT model for the GRB was developed using the $10 \mathrm{~m}$ DEM to generate the predicted channel network. As this paper considered the effects of DEM resolution on predictive fidelity to the true network, the effects of DEM resolution on SWAT model are considered next. 
Table 3.3: Analysis of stream network and land use in major sub-basins in the Grand River basin.

\begin{tabular}{|c|c|c|c|c|c|c|c|c|c|c|c|c|}
\hline Sub-basin & $\begin{array}{l}\text { Area } \\
\left(\mathrm{km}^{2}\right)\end{array}$ & $\begin{array}{l}\text { Strahler } \\
\text { stream order } \\
\text { (main channel) }\end{array}$ & $\begin{array}{l}\text { Sinuosity all } \\
\text { actual } \\
\text { channels }\end{array}$ & $\begin{array}{l}\begin{array}{l}\text { Sinuosity } \\
\text { all }\end{array} \\
\text { predicted } \\
\text { channels } \\
(10 \quad \mathrm{~m} \\
\text { DEM) }\end{array}$ & $\begin{array}{l}\text { Sinuosity } \\
\text { actual first } \\
\text { order } \\
\text { channels }\end{array}$ & $\begin{array}{l}\text { Sinuosity } \\
\text { predicted first } \\
\text { order channels } \\
(10 \mathrm{~m} \text { DEM })\end{array}$ & $\%$ Agri. & $\begin{array}{l}\% \text { forest/ } \\
\text { wetland }\end{array}$ & $\begin{array}{l}\% \text { network } \\
\text { length that is } \\
\text { first order } \\
\text { (actual) }\end{array}$ & 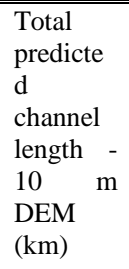 & $\begin{array}{l}\text { Total } \\
\text { predicted } \\
\text { length } \\
\text { first order } \\
\text { channels - } \\
10 \quad \mathrm{~m} \\
\begin{array}{l}\text { DEM } \\
(\mathrm{km})\end{array}\end{array}$ & $\begin{array}{l}\% \text { network } \\
\text { length that is } \\
\text { first order } \\
\text { (predicted) }\end{array}$ \\
\hline Conestogo River & 819.9 & 6 & 1.13 & 1.12 & 1.13 & 1.11 & 78.0 & 9.2 & 50.0 & 1078.2 & 505.8 & 46.9 \\
\hline Fairchild Creek & 400.7 & 5 & 1.17 & 1.14 & 1.14 & 1.11 & 63.4 & 21.3 & 46.2 & 620.8 & 278.8 & 44.9 \\
\hline Lower Grand & 355.9 & 7 & 1.14 & 1.11 & 1.13 & 1.1 & 62.4 & 22.0 & 48.9 & 482.6 & 233.6 & 48.4 \\
\hline $\begin{array}{l}\text { Lower Middle } \\
\text { Grand }\end{array}$ & 475.6 & 6 & 1.17 & 1.15 & 1.13 & 1.12 & 66.0 & 14.7 & 48.6 & 743.3 & 333.9 & 44.9 \\
\hline McKenzie Creek & 368.2 & 5 & 1.21 & 1.13 & 1.15 & 1.10 & 58.8 & 30.5 & 47.8 & 515.3 & 237.5 & 46.1 \\
\hline Middle Grand & 604.6 & 7 & 1.15 & 1.11 & 1.15 & 1.11 & 43.4 & 19.1 & 44.5 & 788.8 & 363.1 & 46.0 \\
\hline Nith River & 1128.0 & 6 & 1.16 & 1.10 & 1.14 & 1.10 & 76.3 & 11.7 & 49.1 & 1487.0 & 682.8 & 45.9 \\
\hline Speed River & 780.8 & 6 & 1.15 & 1.09 & 1.15 & 1.09 & 56.8 & 24.6 & 49.7 & 1031.8 & 508.5 & 49.3 \\
\hline Upper Grand & 791.2 & 6 & 1.13 & 1.10 & 1.13 & 1.10 & 69.9 & 18.9 & 48.0 & 992.9 & 478.8 & 48.2 \\
\hline $\begin{array}{l}\text { Upper } \quad \text { Middle } \\
\text { Grand }\end{array}$ & 639.8 & 6 & 1.15 & 1.09 & 1.14 & 1.09 & 77.7 & 9.6 & 47.8 & 838.2 & 386.7 & 46.1 \\
\hline Whitemans Creek & 403.9 & 6 & 1.18 & 1.11 & 1.16 & 1.10 & 70.0 & 16.5 & 48.2 & 555.4 & 253.6 & 45.7 \\
\hline Summary & 6768.8 & 7 & 1.16 & 1.11 & 1.14 & 1.10 & 69.7 & 18.0 & 48.1 & 9134.3 & 4263.1 & 46.7 \\
\hline
\end{tabular}




\subsubsection{Effects of DEM resolution on SWAT model}

The resolution of the DEM used had varying impacts on the delineated watersheds with respect to watershed sizes, sub-basin number and sizes, and HRU number and sizes (Table 3.4). The use of a 10-m DEM to generate stream channel networks, and to delineate basins, sub-basins, and HRUs produced a larger watershed with fewer sub-basins but more HRUs relative to the SWAT model using a 10-m DEM, but with the actual stream network layer. The number of subbasins and HRUs delineated, as well as predicted watershed area decreased with DEM resolution. The SWAT model using the 200-m DEM delineated $92 \%$ of the total number of sub-basins (based on comparator model), however it only delineated $60 \%$ as many HRUs. This difference in number of HRUs may result in loss of important information on watershed heterogeneity and may affect SWAT outputs such as stream flow, sediment and nutrient yields.

SWAT models built with lower resolution DEMs had lower predicted discharge and sediment export (Table 3.4). However, all models performed well in predicting discharge, agreeing to within $\sim 5 \%$ of the comparator model. This agreement held over 10 years of the model simulation (Fig. 3.4a), and for monthly averages across all years (Fig. 3.4b). By default, the SWAT model mainly estimates watershed runoff using the Soil Conservation Service (SCS) runoff equation. The runoff curve number $(\mathrm{CN})$ is an empirical parameter that predicts surface runoff and infiltration rates from a rainfall event in a particular area. $\mathrm{CN}$ is essentially a coefficient that reduces the total precipitation to runoff potential, after accounting for evapotranspiration, infiltration and surface storage. $\mathrm{CN}$ is highly dependent on the hydrologic soil group and land use and to a lesser extent, treatment and hydrologic condition. Although DEM reflects topography and slope, these are not the primary variables that influence runoff, hence, differences in DEM 
resolution resulted in negligible differences in monthly stream flow into Lake Erie from the Grand River watershed.

Table 3.4: Comparison of SWAT models constructed using different DEM resolutions, compared against a SWAT model constructed using a ground-truthed stream network and $10 \mathrm{~m}$ resolution.

\begin{tabular}{lllll}
\hline \hline & DEM resolution & & & \\
Hydrology & $\begin{array}{l}\text { 10 m with Actual stream } \\
\text { network }\end{array}$ & $10 \mathrm{~m}$ & $25 \mathrm{~m}$ & $200 \mathrm{~m}$ \\
\hline Watershed area & 6782 & 6909 & 6443 & 6358 \\
Sub-basins & 787 & 771 & 742 & 722 \\
HRUs & 7219 & 7357 & 7218 & 4364 \\
Streamflow/precipitation & 0.5 & 0.5 & 0.5 & 0.5 \\
Baseflow/Total flow & 0.34 & 0.33 & 0.34 & 0.33 \\
Surface runoff/Total flow & 0.66 & 0.67 & 0.66 & 0.67 \\
Percolation/precipitation & 0.19 & 0.19 & 0.19 & 0.19 \\
Deep recharge/precipitation & 0.01 & 0.01 & 0.01 & 0.01 \\
ET/precipitation & 0.47 & 0.47 & 0.47 & 0.47 \\
Average stream discharge $\left(\mathrm{m}^{3} \mathrm{~s}^{-1}\right)$ & 126.3 & 126.7 & 121.5 & 119.9 \\
Average sediment discharge $(\mathrm{TSS})\left(\mathrm{mgL}^{-1}\right)$ & 27.9 & 29.2 & 28.3 & 22.5 \\
\hline \hline
\end{tabular}

The models using 10-m and 25-m spatial resolution also agreed well with the comparator model for sediment export, again to within 5\%. These models generally over predicted TSS export. This was true across years, but the overestimate in TSS export was most observed in years with high discharge such as in the early 1980s (Fig. 3.4c), and similarly in spring months with high discharge (Fig. 3.4d). The SWAT model constructed using 200-m spatial resolution under predicted sediment export, by $\sim 20 \%$ relative to the comparator model. This was consistent across years, and was also most pronounced in spring months when discharge was highest. SWAT uses the Modified Universal Soil Loss Equation to estimate soil loss from sub-basins. MUSLE depends on the slope-length gradient which in turn depends on slope length and slope steepness - both of 
which are determined from the DEM base layer. Based on SWAT's watershed delineation and subsequent MUSCLE calculation, slopes were higher and slope lengths were shorter for higher resolution DEMs when compared to coarser resolution. Consequently, the SWAT model using low resolution DEM recognized little heterogeneity in slope within HRUs, missing local but relatively small areas of high slope which contribute to greater erosion. 

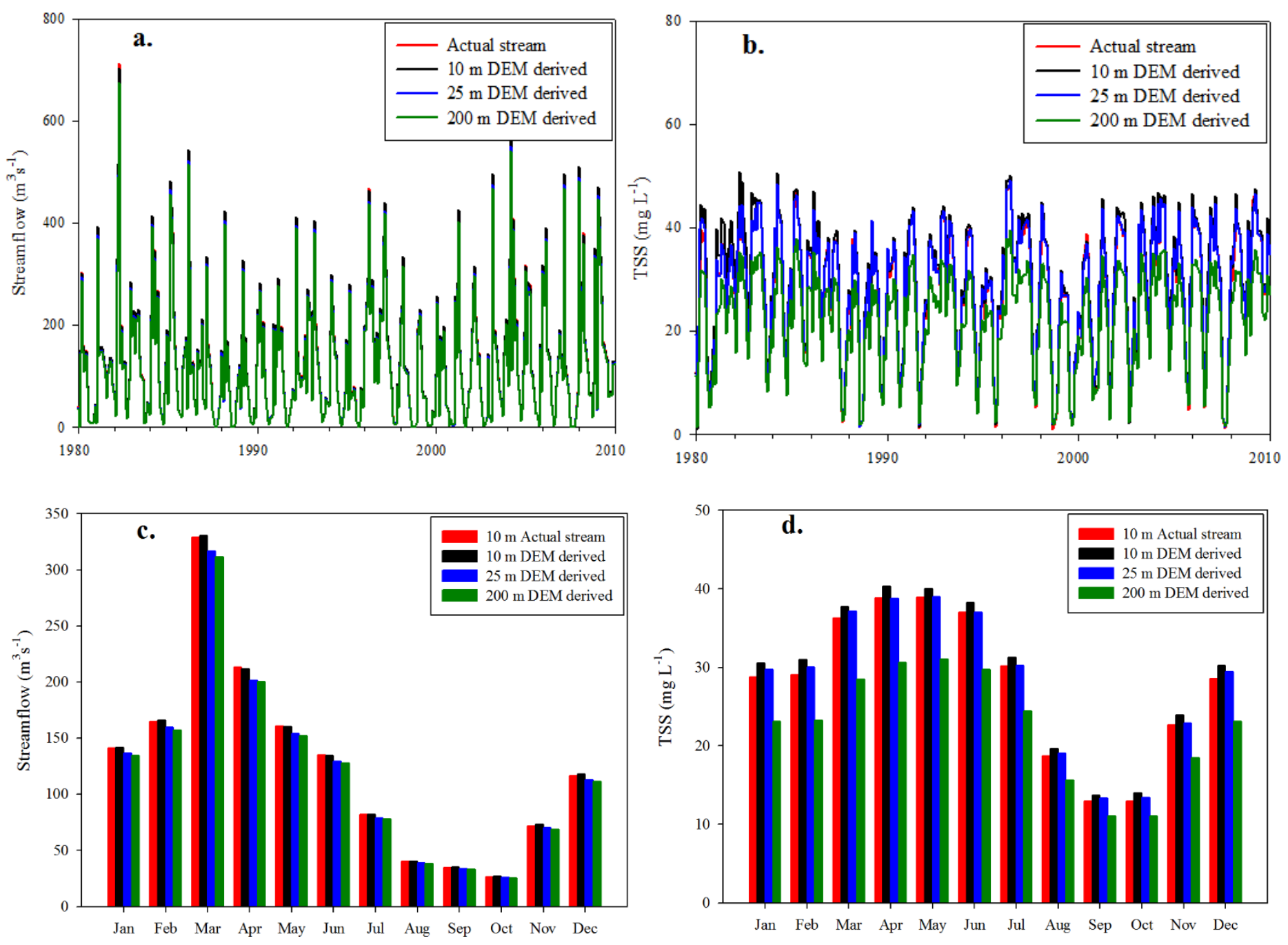

Figure 3.4: a) simulated stream flow (1980-2010) predicted by SWAT model using DEMs of varying resolutions, b) comparison of average monthly simulated stream flow (over period 1980 - 2010) predicted by SWAT model using DEMs of varying resolutions, c) simulated total suspended solids (1980-2010) predicted by SWAT model using DEMs of varying resolutions, d) comparison of average monthly total suspended solids (over period 1980 -2010) predicted by SWAT model using DEMs of varying resolutions. 


\subsection{Conclusions}

The DEM resolution is important in predicting the extent of a river network and the location of stream channels. The use of a DEM with $10-\mathrm{m}$ resolution did a better job in simulating the actual river network than DEMs of lower resolution.

The existing river network includes first order channels that are not predicted from topography. Perhaps this is a function of resolution and 10-m is too coarse to predict the upper limits of first order channels with fidelity. Or, perhaps these reflect an extension of headwater channels to serve in drainage from agricultural areas. This is supported by the low sinuosity of these unpredicted portions of headwater streams, sinuosity being less for these reaches then for first order streams overall in the sub-watersheds. Also supporting this is the relationship between agricultural activity and the percent of the channel network that is comprised of first order streams, as extension of headwater channels for drainage would increase the overall percent of a network that is first-order. Moreover, the relationship between agricultural activity and the percent difference between actual and predicted first-order streams suggests that there are more unaccounted for kilometers of firstorder streams in more agricultural sub-basins.

DEM resolution is less important in predicting river network hydrology, as there was little difference in output of SWAT models using 10-m, 25-m, or 200-m resolution. Predicted discharge was similar among models regardless of resolution, although the low resolution DEM did result in under prediction of sediment export, primarily because coarse resolution did not account for small, localized areas of high slope.

While higher resolution DEMs may be preferable for simulating natural flow paths and river networks, and for use in constructing SWAT models, the results suggest there is little drop off in 
performance with a decrease in resolution from 10 to $25 \mathrm{~m}$. Moreover, resolution as low as $200 \mathrm{~m}$ was sufficient to predict discharge in the Grand River, although SWAT models constructed with low resolution DEMs may not perform as well in watersheds with greater local variation in topography. 


\section{Impact of Best Management Practices (BMPs) on Sediment and Phosphorus loading from the Grand River Watershed to Lake Erie using the Soil and Water Assessment Tool (SWAT)}

Aslam Hanief ${ }^{\mathrm{a}}$ and Andrew E. Laursen ${ }^{\mathrm{b}}$

${ }^{a}$ Environmental Applied Science and Management Program, Ryerson University, 350 Victoria Street, Toronto, ON M5B 2K3

${ }^{\mathrm{b}}$ Department of Chemistry and Biology, Ryerson University, 350 Victoria Street, Toronto, ON M5B2K3

GRW Grand River Watershed

SWAT Soil and Water Assessment Tool

BMP Best Management Practice

TP Total phosphorus

TN Total nitrogen

HAB Harmful Algal Bloom

\section{Core Ideas}

Hydrological modelling is a relatively fast and useful tool that aids all stakeholders in the understanding of watershed processes.

SWAT is very efficient in predicting water quality parameters under different land uses.

The application of BMPs in agricultural watersheds can be modelled and changes quantified by scenario analysis in SWAT. 


\subsection{Abstract}

Nonpoint source pollution is the leading cause of water impairment in agricultural watersheds. However, the water quality in these watersheds can be improved by implementing various best management practices (BMPs) for control of erosion and nutrient loss from watersheds. The Grand River watershed (GRW) occupies about $6800 \mathrm{~km}^{2}$ and is an important agricultural area in Southern Ontario. Changes in land use over the past century in the Grand River watershed have led to altered hydrology and greater export of sediment and nutrient loads into Lake Erie. The objective of this study was to investigate the impact of various BMPs in reducing sediment and P loading rates on various spatial and temporal scales in the watershed using SWAT for the years 2001-2010. The baseline sediment and P loading at Dunnville, prior to the Grand River's discharge to Lake Erie, were predicted to be $2 \times 10^{5}$ tonnes $\mathrm{yr}^{-1}$ and $2 \times 10^{5} \mathrm{~kg} \mathrm{yr}^{-1}$, respectively. Different source, transport and water body treatment BMPs were simulated. With respect to reducing sediment and P loading into Lake Erie, implementing wide buffer strips resulted in a decrease of $23 \%$ and $50 \%$, stabilizing channel banks resulted in $38 \%$ and $36 \%$, and grassed waterways resulted in $15 \%$ and $17 \%$, respectively. 


\subsection{Introduction}

For over 60 years, Lake Erie has been under stress from cultural eutrophication resulting in episodic severe harmful algal blooms (HABs) (Herbert 1957; Rosa et al. 1987; Dolan 2005; Richards 2006). In the past two decades, Lake Erie has returned to more frequent HABs, covering larger areas (USEPA 2011; Michalak et al. 2013; Scavia et al. 2014; Watson et al. 2016). The largest $\mathrm{HAB}$ on record (over 5,000 $\mathrm{km}^{2}$ ) occurred during summer 2011, with the most severe bloom on record (based on biomass production rather than areal extent) occurring in 2015 (International Joint Commission (IJC) 2014). Recent HABs have included cyanobacteria that produce hepatotoxins and neurotoxins (Michalak et al. 2013; Scavia et al. 2014). A bloom in 2014 shut down the water supply in Toledo, $\mathrm{OH}$, limiting access to safe drinking water for more than 500,000 people for 2 days. Water shortage will affect not only residential use, but economic uses of water in these communities. Re-eutrophication can, thus, have a substantial impact on communities in the Lake Erie basin, home to 12.4 million residents and a provides over $\$ 50$ billion annual income to many industries including tourism, recreational boating, shipping and fisheries (Watson et al 2016).

Phosphorus is most commonly implicated as the limiting (or co-limiting) nutrient for the growth and abundance of phytoplankton in freshwater systems (Schindler 1974, 1978; Carlson 1977), and in Lake Erie, the limitation of primary production by phosphorus is well established (e.g. Logan 1987). The 1972 Great Lakes Water Quality Agreement (GLWQA) decreased P loading from wastewater treatment plants in the Lake Erie watershed, which had been a major source of P loading to Lake Erie (Scavia et al. 2014, and sources therein). During the 1980s, Lake Erie showed signs of recovery with fewer blooms and lower productivity (Scavia et al. 2014 and 
sources therein). However, with re-emergence of HABs, there is a renewed urgency to reduce phosphorus loading to Lake Erie, targeting non-point sources.

Agricultural use of fertilizers and manure is generally understood to be the most important non-point source of total P to Lake Erie (Dolan 2005; Richards 2006; IJC 2014; Scavia et al. 2014). Dissolved reactive phosphorus (DRP) appears to be the key driver nuisance growth of algae (e.g., Cladophora) and cyanobacteria (e.g., Microcystis spp.) within the lake (Richards et al. 2006, Richards et al. 2010), and DRP has been steadily increasing from many of the tributaries of Lake Erie while TP loading rates have remained fairly constant (Richards et al. 2010). However, particulate phosphorus constitutes a greater fraction of total $\mathrm{P}$. About half of the particulate organic phosphorus deposited as lake sediments goes through reduction and inorganic bioavailable phosphorus enters the water column (Schwab et al. 2009; Ohio Environmental Protection Agency (OEPA) 2010). Thus, internal cycling of phosphorus may promote HABs for many years after reduction in phosphorus loading to the lake (OEPA 2010). Limiting erosion and export of sediment from rivers to Lake Erie, in conjunction with limiting DRP export, may be necessary to constrain eutrophication and prevalence of HABs.

The Grand River watershed (GRW) covers 10\% of the total Lake Erie Basin, and 25\% of the Canadian portion of the Basin. It is an important agricultural area. Nutrient loss from the GRW contributes $\sim 5 \%$ of total annual phosphorus loading to Lake Erie (IJC 2014; Scavia et al. 2014), and $40 \%$ of the annual total to the eastern basin (Shaker 2014). Scavia et al. (2014) have indicated that manure application is the largest single source of phosphorus export from the Grand River. Over the years, water quality (based on dissolved oxygen, total phosphorus and suspended solids) has been consistently rated as poor when measured at the Dunnville Dam monitoring site prior to the Grand River entering Lake Erie (Cooke 2006). The objective of this study is to explore 
through watershed modeling how agricultural best management practices (BMPs) could mitigate P loading to Lake Erie from the GRW, through the reduction of sediment and nutrient transfer from the watershed.

Agricultural BMPs are practical, cost-effective actions that farmers can implement to reduce the loading of sediments, fertilizers, animal wastes, and pesticides to surface waters, and their transport in streams. For example, the state of New York successfully implemented BMPs in over $5100 \mathrm{~km}^{2}$ of the combined Croton, Catskill and Delaware watersheds to reduce phosphorus export as a cost-effective alternative to water filtration systems (Scott et al. 1998; National Research Council 2000; Sharpley et al. 2006). These BMPs improved water quality without sacrifice of crop yields and dairy production.

The Soil and Water Assessment Tool (SWAT) model (Arnold et al. 1998), is a continuoustime, semi-distributed, process based model, has been applied successfully to simulate hydrology and water quality parameters in gauged and ungauged watersheds. The model has also been used extensively to predict the effects of alternative management decisions that include BMPs on water quality in fields to large scale watersheds (Giri et al. 2012; Bosch et al. 2013; Strauch et al. 2013; Yang et al. 2013, 2016; Daneshvar et al. 2017). For the western US watersheds, Michalak et al. (2013) used SWAT to investigate the effects of increased spring precipitation, coupled with longterm changes in agricultural land use on DRP loading to Lake Erie and the effects of different BMPs on curtailing P exports. They found that precipitation intensity produced the largest effect on TP and DRP exports and fertilizer application timing had the least impact on TP and DRP exports (Michalak et al. 2013). Also for the Huron, Raisin, Maumee, Sandusky, Cuyahoga and Grand watersheds of western and central Lake Erie, Bosch et al. (2013) applied SWAT modeling to investigate nutrient loading under BMPs and climate scenarios in these Lake Erie watersheds 
and found that BMPs (cover crop, filter strip, residue management) should be widely implemented throughout the watershed to significantly reduce nutrient exports.

In this study, a baseline SWAT model was built that is reflective of streamflow and crop management practices within the GRW for the years 2001-2010. The model was then used to predict sediment and phosphorus yields that are exported from the basin at Dunnville, ON into Lake Erie. The SWAT model was then used to investigate changes in sediment and phosphorus loading rates into Lake Erie during the same time period with implementation of different BMPs within the watershed.

\subsection{Methodology}

\subsubsection{Study site}

The Grand River watershed in southern Ontario is approximately $6,800 \mathrm{~km}^{2}$ and sits on the north-eastern shore of Lake Erie (Fig. 4.1). Spanning a length of about $300 \mathrm{~km}$ and having an elevation differential of about $362 \mathrm{~m}$ from its source to its mouth, the Grand River originates at the Dundalk Highlands and flows through Port Maitland into Lake Erie. The latitude, altitude and proximity to Lake Erie influence the climate of the Grand River area (Mayer and Delos Reyes 1996). On average, the GRB receives $93.3 \mathrm{~cm}$ of precipitation each year (GRCA 2013). The mean annual temperature of headwater streams is around $6^{\circ} \mathrm{C}$ while that of Lake Erie is around $9^{\circ} \mathrm{C}$, and the average annual air temperature of the watershed is $7.8^{\circ} \mathrm{C}$ (Mayer and Delos Reyes 1996).

The GRW can be separated into three distinct geological areas. The northern till plains drain the upper section of the watershed and contribute a significant amount of surface runoff, temporarily stored in Bellwood and Conestogo lakes. The central basin region is made up moraines of highly permeable sands and gravels that replenish huge underground aquifers and supply the drinking water needs of the central urban areas of the watershed. Finally, in the lower basin, dense 
clay plains, like the northern till, contribute to significant runoff that flows into Lake Erie (Cooke 2006).

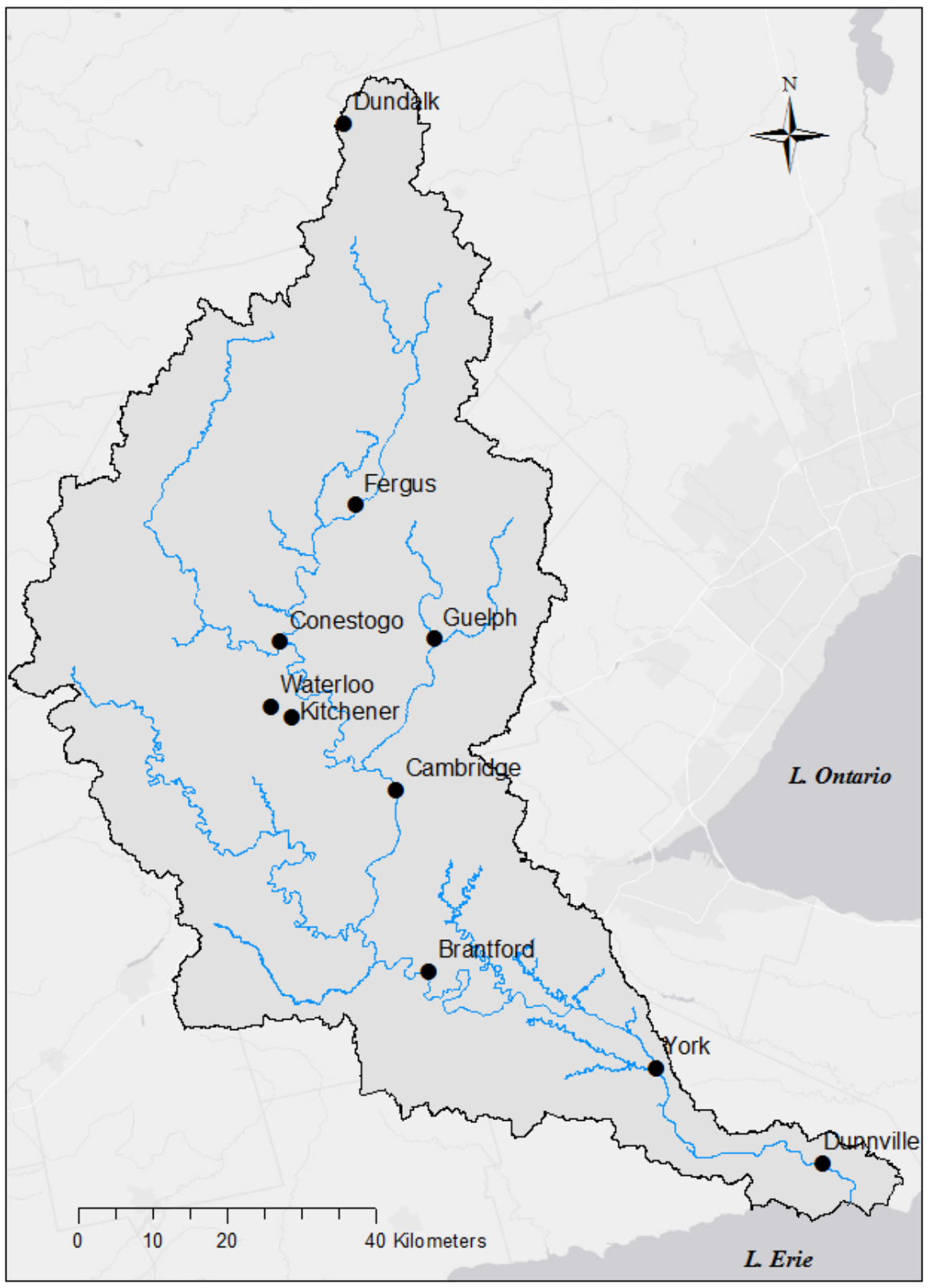

Figure 4.1: The Grand River watershed in southern Ontario is an intense agricultural basin that originates at the Dundalk Highlands and flows through Dunnville into Lake Erie. 
Before the arrival of Europeans around the mid-1770s, forests and wetlands dominated the GRW (Scott and Imhof 2005). The GRW has been progressively modified to make way for lumber exploitation, agriculture, pasture, settlements and industry. In the process, nearly $95 \%$ of historical forest has been removed, and waterscapes have been engineered, especially by damming (Scott and Imhof 2005). Agriculture is the dominant land use in the watershed with $\sim 6,000$ farms (Farwell et al. 2008), and accounting for $76 \%$ of watershed land area. Forested areas (historic and regrowth) cover $17 \%$ of the watershed, while the centrally located urban centres cover about $5 \%$ of the total area (Cooke 2006). The Grand River Conservation Authority's digital land use and land cover data indicated that row crops, small grains, forage and bare agricultural fields accounted for $20.5,12.1,19.2$ and $15.9 \%$ of the GRW, respectively (GRCA 2005). In intensive agricultural sub-watersheds in southern Ontario, corn and soybeans were the dominant row crops, covering $25 \%$ and $16 \%$ of these watersheds, respectively (Ontario Ministry of the Environment 2012). This ratio of corn to soybeans was assumed to apply to the GRW, and these two crops (in proportion) were applied to the total area of the GRW under row crop cultivation, substituting for minor row crops (e.g. root crops, potatoes, sunflowers) for which there are limited data on coverage in the GRW. Intensive livestock operations are a dominant feature in the middle GRW (Mayer and Delos Reyes 1996). A 2001 census estimated 290,000 head of cattle, 500,000 head of swine and almost 8.8 million head of poultry in the Grand River area (GRCA 2005).

\subsubsection{SWAT Model}

The construction, calibration, and validation of a SWAT model for the Grand River Watershed has been previously described (Hanief and Laursen, in review). The model was developed for the period 1996 to 2010 with a setup or warm-up period from 1996-2000, a 
streamflow calibration period from 2001-2005, and a streamflow validation period from 20062010.

The data sources underpinning the GRW SWAT model are briefly described below. A Digital Elevation Model (DEM) for Ontario was obtained from Land Information Ontario (LIO). This DEM (version 2.0.0) was a 3-D raster data set capturing terrain elevations, with cell resolutions of $10 \mathrm{~m}$ in southern Ontario. The GRCA's virtual stream network was burned onto the raster during the watershed delineation process to produce more accurate sub-basin delineations in subsequent steps. A soil map layer, and soil database linking the physiochemical properties of the top 10 layers of the soil profile to the soil groups in the watershed, were obtained from the Canadian Soil Information Service or CanSIS (http://sis.agr.gc.ca/cansis/). A land cover/land use layer was downloaded from the geospatial portal of the Grand River Conservation Authority (https://maps.grandriver.ca/data-gis.html). This land cover classification was based on Landsat 7 TM Imagery in 1999 and updated in 2005. Pixel sizes were $25 \mathrm{~m}^{2}$ in the land cover grid. Based on a modification of the Agriculture and Agra-Food Canada classification, three slope classes were defined in SWAT: $<3 \%$ (none-low), $3-15 \%$ (moderate) and $>15 \%$ (high) gradient. After the watershed was delineated, SWAT generated HRUs by overlaying and combining land use, soil data and slope.

Temperature and precipitation data were obtained from GRCA and Environment Canada. Weather data were assigned to every sub-basin using the station closest to the centroid of that subbasin. In cases of missing weather data, SWAT's Global Weather Data tool was used to provide all missing data (http://globalweather.tamu.edu/). This simulated data set, referred to as the Climate Forecast System Reanalysis (CFSR), was prepared by the National Centers for Environmental Prediction (NCEP) over the 36-year period from 1979-2014. Also, due to absence 
of sufficient daily solar radiation, humidity and wind speed datasets, the Hargreaves' method of simulating potential evapotranspiration (PET) was selected for the model run. This method of inferring PET rates has shown reliable estimates when compared to measured values (Jensen et al. 1990; Itenfisu et al. 2003). Jensen et al. (1990) investigated of PET rates from well-watered grasslands and agricultural lands in the midwestern US, including Indiana and Minnesota, while Itenfisu et al. (2003) investigated weather data scattered throughout the contiguous US to determine PET rates. Both studies found that measured PET rates were well estimated by the Hargreaves method of simulating PET in watersheds. Based on these studies, the Hargreaves method should provide reliable estimates of PET rates in the GRW.

Average monthly outputs from major reservoirs were fed into the model run along with tile drains data (depth, time to drain fields, and length of time to for tile flow to reach stream).

Specific agricultural practices (e.g. crops, crop rotation cycles, tillage operation, planting, fertilizer application, irrigation and harvesting) were compiled from farmers, agricultural specialists at Ontario Ministry of Agriculture, Food and Rural Affairs (OMAFRA) and from similar studies conducted in Southern Ontario and the lower Great Lakes region (Greg Stuart (OMAFRA specialist), email communication; Cooke 2006; GRCA 2005, 2013; Yang et al. 2013).

The SWAT model previously constructed was highly effective in predicting discharge at stream gauging stations within the GRW from 2001 to 2010 (Hanief and Laursen, in review; model calibration and parameters used described therein). Once calibrated to discharge, SWAT models can also be used to predict sediment and nutrient load. For the Grand River Watershed, total suspended solids (TSS) and phosphorus load were predicted under the baseline conditions of 20012010, baseline meaning current land use and type, agricultural practices, and channel 
characteristics. The model was then used to predict the TSS and phosphorus load, and export of TSS and P to Lake Erie, with implementation of Best Management Practices.

\subsubsection{Best Management Practices}

Different best management practices (BMPs) were implemented in the calibrated model of the GRW to determine how each might affect TSS and P load and export to Lake Erie, relative to baseline conditions. These included: implementation of filter strips, implementation of grassed waterways, bank stabilization to reduce erosion, conversion of cropland to forest or wetland, planting of winter cover crops, and reduction in fertilizer application.

Filter strips and fertilizer reduction: Conservation tillage was applied in combination with three other BMPs: two different filter strip scenarios and a reduction in fertilizer application of 20\%. Reducing fertilizer application rates should not affect sediment export in a sub-basin. Since an objective is to consider how both sediment and phosphorus export from the GRW might be reduced by BMPs, reduced fertilizer was not modeled on its own, but rather in combination with conservation tillage, an increasingly common practice in Ontario.

The USEPA (1999) defines a vegetated filter strip as a "permanent, maintained strip of planted or indigenous vegetation located between nonpoint sources of pollution and receiving water bodies for the purpose of removing or mitigating the effects of nonpoint source pollutants such as nutrients, pesticides, sediments, and suspended solids." The Ontario Nutrient Management Act 2002 has stipulated a minimum width of $3 \mathrm{~m}$ for VFS while the USEPA recommends a minimum of $7.6 \mathrm{~m}$ on slopes of $1-3 \%$. In SWAT, a buffer strip of natural vegetation was implemented along channels draining agricultural land and with a slope of $<3 \%$. The model was run with a $3 \mathrm{~m}$ buffer and with a $7.6 \mathrm{~m}$ buffer in agricultural land uses in the SWAT module. 
In the fertilizer reduction SWAT scenario, fertilizers were applied at $20 \%$ reduced rates when compared to baseline application rates. The fertilizer reduction scenario was applied in combination with conservation tillage, an increasingly common practise in Ontario.

Grassed waterways: According to the United States Department of Agriculture (USDA 2012), "grassed waterways (GWW) are constructed graded channels that are seeded to grass or other suitable vegetation. The vegetation slows the water and the grassed waterway conveys the water to a stable outlet at a non-erosive velocity." In this study, GWWs were applied to channels draining all categories of land use associated with agriculture (row crop, generic agricultural land use, pastures and hay fields) and were set to $10 \mathrm{~m}$ wide and grass height of $1 \mathrm{~m}$. Filter strips and grassed waterways are examples of conservation buffer strips. In the case of filter strips, vegetation is planted along the stream course while in grassed waterways, vegetation is planted in the stream course.

Bank stabilization: Bank stabilization can be achieved in various ways, most commonly by adding logs and boulders in the stream channel, engineering vanes and dike-like structures, or using geotextiles, rock fills, and plants along banks. The benefits derived from stream bank stabilization with respect to sediment and phosphorus reduction are dependent on the capacity for trapping sediment and nutrients. In this BMP scenario, stream bank stabilization was applied to all sub-basins, slopes and soils along channels draining all categories of land use associated with agriculture (row crop, generic land use, pastures and hay fields). Specific methods of bank stabilization were not considered in SWAT, rather trapping efficiencies were defined for sediment, $\mathrm{PP}$ and soluble $\mathrm{P}$ as 20, 20 and 5\%, respectively.

Conversion of croplands to forests and wetlands: Afforestation offers numerous ecological, economic and environmental benefits. Most germane to this study are reduced soil 
erosion and NPS pollution. In the afforestation BMP scenario, $15 \%$ of agricultural lands were converted to forests, $5 \%$ to each forest type (deciduous, evergreen and mixed). In the wetland BMP scenario, $10 \%$ percent of agricultural lands were converted to wetlands. It should be noted that conversion of one land use to another is only possible in SWAT in a sub-basin that contains both land use; therefore, there was no land use conversion in sub basins that are $100 \%$ agricultural land use or in those sub-basins lacking forests or wetlands.

Planting of winter cover crops: In the SWAT Cover Crop scenario on row crop agricultural lands, red clover - a legume, was added to corn-soybean rotations and planted in early fall. In the model, it is assumed the red clover is ploughed into the soil in May of the following year when the main crop is planted.

\subsection{Results and Discussion}

\subsubsection{Sediment and nutrient calibration}

The baseline hydrology model previously described (Hanief and Laursen, in review) had very good correlation values during calibration and validation at various sites in the headwater and along the main channel of the Grand River. For example, during monthly calibration for the years 2002-2005 at York, the PBIAS, coefficient of determination $\left(\mathrm{R}^{2}\right)$ and Nasch-Sutcliffe coefficient were 7.1, 0.64, and 0.63; whereas, for the validation years of 2006-2010, the values for these objective functions were $0,0.75$ and 0.75 , respectively.

Automated calibration of a SWAT model requires a high frequency of data collection (direct measurements) against which to compare model output. For the GRW, there have been too few phosphorus and sediment measurements to support automated calibration of phosphorus and sediment export from the GRW. Instead, a manual calibration was applied by adjusting various 
sediment and phosphorus sensitive SWAT parameters, using values within a range determined by other studies (e.g. Abbaspour et al. 2007; Yang et al. 2013; Golmohammadi et al. 2014) to be appropriate for these parameters. Values associated with hydrology were not manipulated during this calibration, since the model was already well calibrated for flow. Manual calibration was performed against the data that were available for sediment and phosphorus in the GRW. Manual calibration is a coarse approach and less desirable than automated calibration. The reliance on manual calibration is a limitation to modelling and BMP efficiency. However, manual calibration of water quality parameters in SWAT modeling has been applied successfully in other large watersheds. For example, Yang et al. (2013) used SWAT to model the Gully Creek watershed on the eastern side of Lake Huron. Given a limited water quality dataset, these parameters were calibrated manually. Calibrations were evaluated graphically with time series plots, together with statistical analyses that included root mean square errors (RMSE), root mean squared deviation (CV), and correlation coefficients (CORR). A similar approach was taken in the Grand River watershed. This approach resulted in effective prediction of total suspended solids and phosphorus (e.g. Fig. 4.2). 


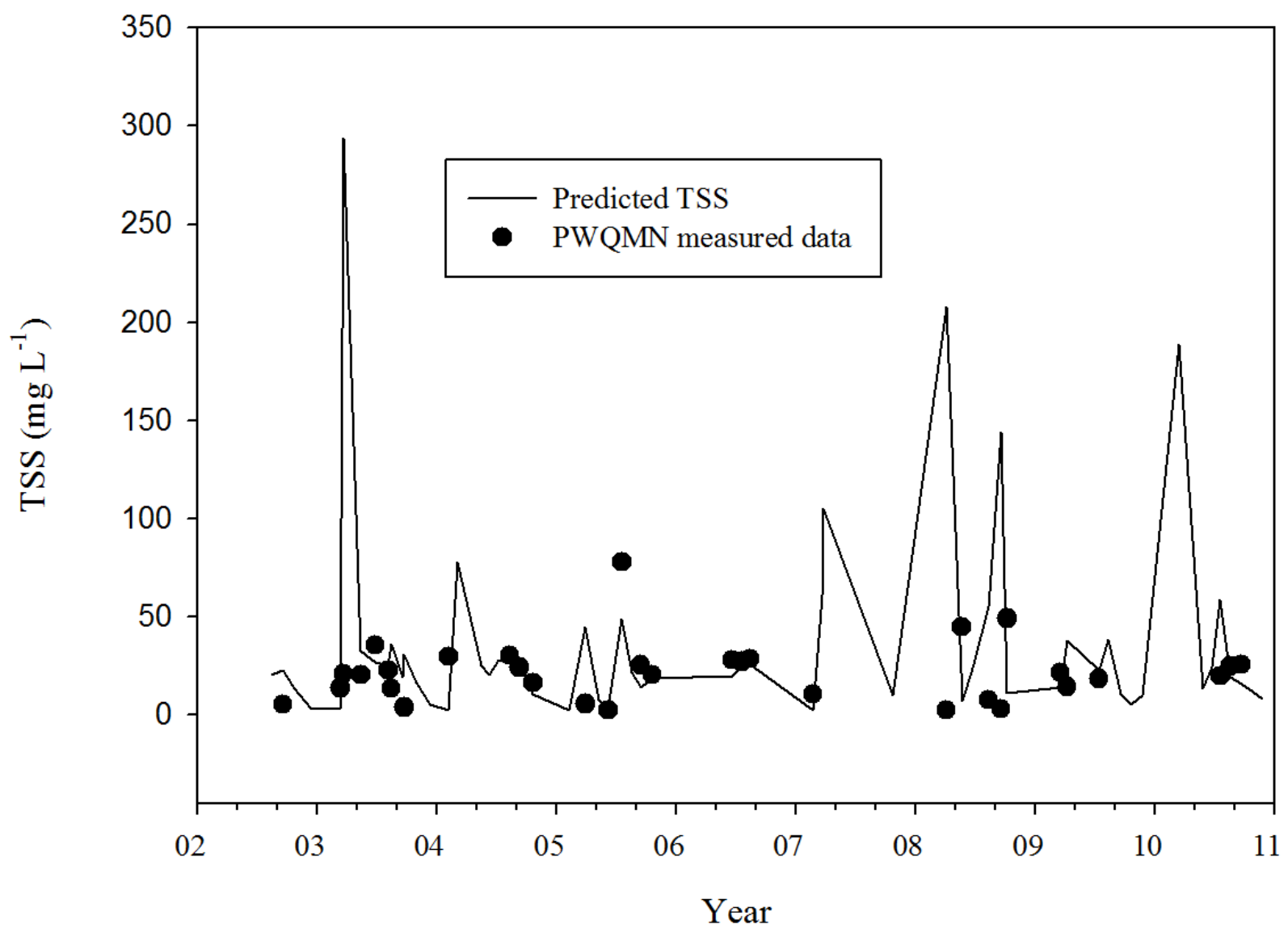

Figure 4.2: Comparison of simulated total suspended sediment (TSS) and measured TSS at York monitoring station, 2002-2010. Measured TSS data from Ontario's Provincial (Stream) Water Quality Monitoring Network.

\subsubsection{Baseline scenario SWAT results}

With the automated SUFI2 calibration for streamflow and manual calibration for sediment and phosphorus, SWAT was run for the period 2001-2010 under existing climatic and land management conditions. The simulated annual average flow, sediment, organic $\mathrm{P}$, particulate $\mathrm{P}$ (or sediment $\mathrm{P}$ ) and TP loading at the Dunnville near the outflow to Lake Erie outlet were $80.3 \mathrm{~m}^{3} \mathrm{~s}^{-1}$

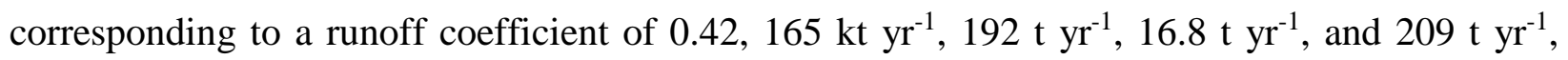
respectively (Table 4.1). Under current conditions and nutrient management practices, the basinwide annual average sediment loading (2001-2010) was 2.9 tonnes $\mathrm{ha}^{-1} \mathrm{yr}^{-1}$. During this same 
period, annual average soluble $\mathrm{P}$ loading was $0.2 \mathrm{~kg} \mathrm{ha}^{-1} \mathrm{yr}^{-1}$, and particulate $\mathrm{P}$ loading was $2.9 \mathrm{~kg}$ $\mathrm{ha}^{-1} \mathrm{yr}^{-1}$. Sediment and phosphorus yields $\left(\mathrm{ha}^{-1}\right)$ varied among sub-basins with generally higher yields from the central portion of the watershed (Fig. 4.3). This portion of the watershed has both intensive agriculture and the highest human population density. Most of the total $\mathrm{P}$ was accounted for as particulate, or sediment associated $\mathrm{P}$. Therefore, there was a strong relationship $\left(\mathrm{r}^{2}=0.87\right)$ between sediment export and TP export from HRUs.

Table 4.1: Sediment, organic $P$, particulate $P$, and TP loading at the Dunnville under various BMP scenarios, values in parentheses represent percent reduction relative to baseline model.

\begin{tabular}{|l|c|c|c|c|c|}
\hline Scenario & $\begin{array}{c}\text { Sediment } \\
\left(10^{3} \mathrm{t} \mathrm{yr}^{-1}\right)\end{array}$ & $\begin{array}{c}\text { Organic P } \\
\left(\mathrm{t} \mathrm{yr}^{-1}\right)\end{array}$ & $\begin{array}{c}\text { DRP } \\
\left(\mathrm{t} \mathrm{yr}^{-1}\right)\end{array}$ & $\begin{array}{c}\text { Particulate } \\
\mathrm{P}\left(\mathrm{t} \mathrm{yr}^{-1}\right)\end{array}$ & $\begin{array}{c}\mathrm{TP} \\
\left(\mathrm{t} \mathrm{yr}^{-1}\right)\end{array}$ \\
\hline Baseline & 164.6 & 21.2 & 12.2 & 175.2 & 208.6 \\
\hline Filter strips (3m)+ & 143.3 & 13.9 & 10.0 & 112.8 & 136.7 \\
conservation tillage & $(13 \%)$ & $(34 \%)$ & $(18 \%)$ & $(36 \%)$ & $(34 \%)$ \\
\hline Filter strips (7.6 m) + & 126.6 & 10.7 & 6.3 & 87.3 & 104.3 \\
conservation tillage & $(23 \%)$ & $(50 \%)$ & $(48 \%)$ & $(50 \%)$ & $(50 \%)$ \\
\hline Fertilizer reduction (20\%) & 151.7 & 20.2 & 8.2 & 132.1 & 160.5 \\
+ conservation tillage & $(8 \%)$ & $(5 \%)$ & $(33 \%)$ & $(25 \%)$ & $(23 \%)$ \\
\hline Grassed waterway & 139.9 & 17.5 & 11.9 & 144.6 & 174.1 \\
& $(15 \%)$ & $(17 \%)$ & $(2 \%)$ & $(17 \%)$ & $(17 \%)$ \\
\hline Bank stabilization & 102.1 & 13.2 & 9.2 & 110.9 & 133.3 \\
& $(38 \%)$ & $(38 \%)$ & $(24 \%)$ & $(37 \%)$ & $(36 \%)$ \\
\hline Agricultural lands to & 149.0 & 18.9 & 12.3 & 157.7 & 188.9 \\
forests & $(9 \%)$ & $(11 \%)$ & $1 \%$ & $(10 \%)$ & $(9 \%)$ \\
\hline Agricultural lands to & 161.3 & 20.1 & 12.3 & 168.4 & 200.8 \\
wetland & $(2 \%)$ & $(5 \%)$ & $1 \%$ & $(4 \%)$ & $(4 \%)$ \\
\hline Addition of winter cover & 156.3 & 17.8 & 10.8 & 158.0 & 186.6 \\
crop & $(5 \%)$ & $(16 \%)$ & $(11 \%)$ & $(10 \%)$ & $(11 \%)$ \\
\hline
\end{tabular}



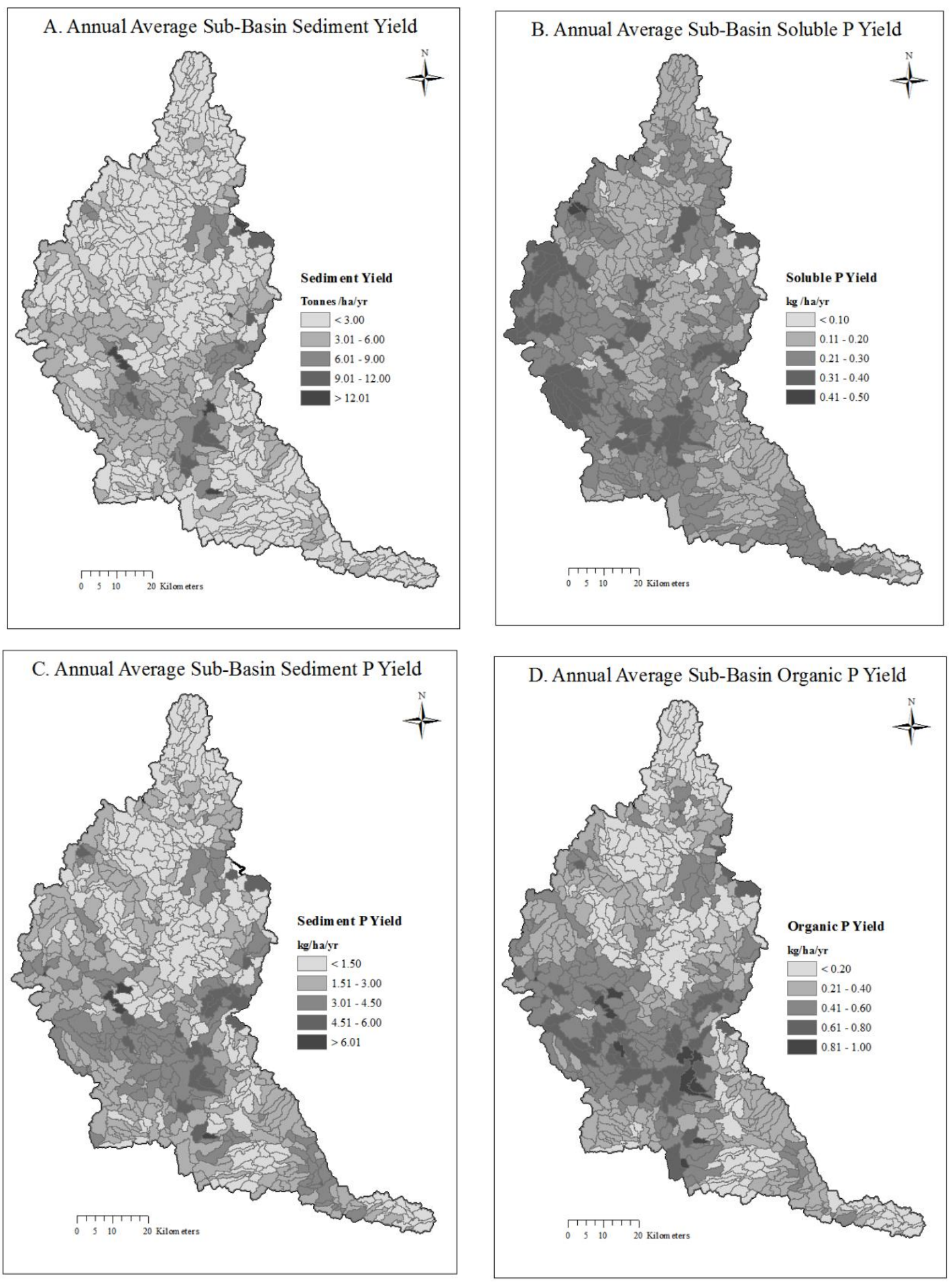

Figure 4.3: SWAT simulated sub-basin baseline yields of a) annual average sediment; b) annual average soluble P (DRP); c) annual average soluble P (DRP); d) annual average sediment P (particulate P), for the years 2001-2010 in the Grand River Watershed. 


\subsubsection{SWAT results with various BMPs implemented}

The simulated average monthly flow did not change by more than $1 \%$ under varying BMP scenarios; however, sediment, organic P, mineral P, and TP loading at the Grand River watershed outlet did vary according to the BMP scenario implemented (Table 4.1). The effects of the various BMPs, therefore, can be interpreted as affecting sediment and total $\mathrm{P}$ export directly, rather than indirectly through an overall reduction of surface water discharge to the lake.

Filter strips and fertilizer reduction: The roots of grasses and other plants incorporated into vegetative filter strips enhance the rate of infiltration, which in turn reduces surface runoff, protects soil from erosion, and prevents nutrients from surface loss. At the same time, the greater the width of a buffer strip, the greater protection it offers in restraining the export of sediments and phosphorus from HRUs. This was clearly reflected in decreased annual sediment and TP exports by $13 \%$ and $34 \%$, for a $3 \mathrm{~m}$ buffer, and $23 \%$ and $50 \%$ for a $7.6 \mathrm{~m}$ buffer placed stream edges in agriculturally-dominated HRUs (Table 4.1). The implementation of the $7.6 \mathrm{~m}$ buffer was one of the most effective BMPs modeled for reduction of total $\mathrm{P}$. The reduction in fertilizer application by $20 \%$, in conjunction with conservation tillage, was more modest. SWAT predicted that this combination of practices would result in a reduction of annual sediment and TP exports of $8 \%$ and $22 \%$, respectively.

Grassed waterways: Adding grassed waterways on to reaches within agricultural HRUs with a slope of more than $3 \%$, resulted in annual sediment and TP export reductions of $15 \%$ and $17 \%$, respectively.

Bank stabilization: Bank stabilization would be a highly effective BMP in any watershed. SWAT predicted that bank stabilization, if applied to all reaches in agricultural sub-basins, would 
reduce annual sediment and TP export by $38 \%$ and 36\%, respectively. Among all BMPs modeled, bank stabilization was most effective in reducing both sediment and TP export.

Conversion of croplands to forests and wetlands: In sub-basins that contain both agricultural and forests land use, conversion of $15 \%$ of the agricultural lands to forests decreased annual sediment and TP loads each by $9 \%$. Since no fertilizer is applied to the new forest land use in SWAT, it makes sense that P export would decrease. Also, the increase Leaf Area Index of the growing forests will decrease erosion and reduce sediment export. Furthermore, young forests in any watershed remove large quantities of nutrients from the soil and this further reduced the nutrient loading from the sub-basins. The effect of land use conversion was modest over the 10 years of the simulation. However, over a longer period, as forests mature, the benefit of land use conversion in terms of nutrient retention would grow.

Healthy and functional wetlands are highly effective at trapping and retaining nutrients in a watershed. However, very little effect is observed in the conversion of $10 \%$ of the agricultural lands to wetlands ( $2 \%$ reduction in sediment and $4 \%$ reduction in TP). However, SWAT can only perform land use conversion in HRUs that contain both land covers (agricultural and wetland). The land cover and wetlands layers that were available from the GRCA portal (https://maps.grandriver.ca/data-gis.html) wetlands covering only $1 \%$ of the watershed. After SWAT performed HRU delineation, wetlands and agriculture were both present in only 174 subbasins (out of 699). Therefore, the total land conversion in the SWAT model for this BMP implementation was very small, making the effect of conversion to wetland relatively effective on a per area basis.

Planting of winter cover crops: Planting a winter cover crop between corn-soybean rotations decreased annual sediment and TP loads by 5\% and 11\%, respectively. The red clover 
helped in reducing the erosive force of the runoff and sheet flow and perhaps in increasing uptake of nutrients from the soil. Since the red clover was implemented in SWAT to act as a green manure, farmers can benefit by reducing the amount nitrogenous fertilizers that are applied in the following year. Although modeling of $\mathrm{N}$ export was not an objective of this study, the planting of clover might be a useful BMP for reducing $\mathrm{N}$ export, perhaps more so than $\mathrm{P}$ export.

\subsubsection{Effects of BMPs on phosphorus fractions}

The 2012 Great Lakes Water Quality Agreement (GLWQA) between Canada and the US has set a target of 40 percent reduction in total $\mathrm{P}$ entering the western and central basins of Lake Erie. While the focus of the GLWQA is in those basins, a prophylactic reduction in P loading to the eastern end will benefit of the whole lake. The Grand River accounts for $40 \%$ of total P loading to the eastern basin (Shaker 2014), and 5\% to the lake overall (Scavia et al 2014), and implementation of BMPs within the GRW to reduce P export will strongly support the objectives of the GLWQA.

Beyond effects on quantities of total P exported, BMPs influenced the forms of P lost from sub-basins. The preceding discussion on modeled effects of BMPs was couched in terms of total $\mathrm{P}$ reduction, however reduction of DRP export is, perhaps, more salient. Dissolved reactive phosphorus is a key driver of eutrophication and development of HABs. While the International Joint Commission (IJC 2014) found the increase HABs in Lake Erie from the 2000s were caused by multiple stressors, the report specifically highlighted the rising proportion of DRP as the primary cause of water quality deterioration. The implementation of $7.6 \mathrm{~m}$ filter strips had one of the the greatest impact not only on total P, but importantly on DRP (Table 4.1). While reduction in fertilizer application had a modest effect on total $\mathrm{P}$ export, it was highly effective in reducing DRP export (reduction of $33 \%$ relative to baseline model). This is significant in that, among all 
BMPs modeled, it would be the easiest to implement from a technical standpoint. However, from a practical standpoint it might be among the more difficult to implement, requiring a change in both outlook and practice. The potential cost (if decline in crop yield is greater than savings on fertilizer) would be borne by farmers, whereas costs for other BMPs might be more broadly distributed. Bank stabilization also had a substantial effect on DRP reduction. This may be among the more expensive BMPs to implement; however, the cost of implementation would be more widely distributed.

\subsection{Conclusion}

Simulated total phosphorus (TP) levels throughout the Grand River watershed far exceed the provincial objective of $0.030 \mathrm{mg} \mathrm{L}^{-1}$. SWAT predicted TP values as high as $0.50 \mathrm{mg} \mathrm{L}^{-1}$ at Dunnville, near the discharge to Lake Erie. Phosphorus export from the GRW was strongly related to agricultural land use, particularly from lands that had subsurface drainage. However, different agricultural BMPs have been shown to substantially reduce sediment and P export from the GRW under current conditions (land use, crop preference, and climate). This is a necessary starting point. Future work will need to explore barriers to, and incentives for implementation of different BMPs. With such information, it will be possible to model a tapestry of BMPs based on sub-basin constraints, and appropriate distribution of burden (effort and cost), to achieve provincial water quality objectives. Moreover, future work will need to consider how to achieve these objectives in the context of predicted changes to local climate, so that BMP-based solutions meet needs going forward. 


\section{Conclusion}

\subsection{The need for data in the modelling environment}

Models, simpler representations of reality, are widely used in many fields of study and they provide three main functions: they allow us to represent a framework to gather processes and to examine the subsequent system behaviours that are a function of this understanding; they enable us to examine the implications of measured data by hypothesis testing; and they allow us to perform scenario analysis (Silberstein 2004).

Ecohydrology is an interdisciplinary science that incorporates the interactions among hydrological, biogeochemical and ecological processes in soils, rivers and lakes, and at the basin scale in agricultural lands, forests, deserts, and other terrestrial ecosystems. In watershed modelling, it is the hydrological factors that drive the dynamics of the terrestrial ecosystems, whereas, the ecological factors drive the dynamics of streamflow and water quality. Watersheds are ideal functional units for application of ecohydrological models due to the presence of welldefined terrestrial boundaries and stream networks. The SWAT model is an example of an ecohydrological model that has been widely applied in watershed development and management, water quantity studies (for example: water discharge, groundwater dynamics, flood prediction and design, and water management), water quality assessment (land-use and land management change, BMPs in agriculture) and climate change impact (Krysanova and Arnold 2009). Irrespective of the application of the model, some form of calibration and validation is performed during the modelling process. Also, the spatial and temporal resolution of the model at which it is operating require data. The kind and resolution of the required data are totally dependent on the scale of application and the objectives of the study. Applying SWAT to study sediment erosion rates on a 
farm requires data at high resolution while applying SWAT to predict water quality of the Mississippi river on entering the Gulf of Mexico requires data at much coarser resolutions.

Models can only do so much. Data in hydrological models are needed to drive, calibrate and validate them. This study highlighted the urgent need for data collection and availability in a reasonable time at all levels of governance: municipalities, conservation authorities, provincial and federal. While DEMs may be readily available, the required resolutions may not. The implication of this fundamental piece of data was first examined and it was determined that DEM resolution was less important in predicting river network hydrology, as there was little difference in output of SWAT models using $10 \mathrm{~m}, 25 \mathrm{~m}$, or $200 \mathrm{~m}$ resolution. Predicted discharge was similar among models regardless of resolution, although the low-resolution DEM did result in under prediction of sediment export, primarily because coarse resolution did not account for small, localized areas of high slope. While this may be true of a medium size watershed ( $\mathrm{GRW}=7,000 \mathrm{~km}^{2}$ ), it may not hold true for smaller watersheds or field plot studies. To compensate for the lack of a highresolution DEM which provides a better understanding of slope lengths and subtle changes in topography, the modeller may have to instead alter other basin wide soil, sediment transfer, and sediment routing parameters during the calibration process in order to achieve intended acceptable values for different objective functions (such as high $\mathrm{R}^{2}$, PBIAS and $b \mathrm{R}^{2}$ ).

SWAT required the following datasets: (1) catchment surface - DEM, land use map, soil map with detail properties, stream network and waterbodies map, (2) daily climate data temperature $\left({ }^{\circ} \mathrm{C}\right)$, precipitation $\left(\mathrm{mm} \mathrm{day}^{-1}\right)$, solar radiation $(\mathrm{W})$, wind speed $\left(\mathrm{m} \mathrm{s}^{-1}\right)$ and relative humidity (\%), (3) agricultural management data on seasonal or annual basis - dominant crop types, crop yields $\left(\mathrm{kg} \mathrm{ha}^{-1}\right)$, fertilizer application (kind, timing and amount $\left(\mathrm{kg} \mathrm{ha}^{-1}\right)$ ), soil treatment practice (tillage: timing and equipment used), sowing dates, harvesting dates, irrigation practice 
(amount, location, timing, techniques), and use of tile drainage, (4) point source data with monthly measurements (wastewater treatment plants, industry, septic tanks) - discharge rates $\left(\mathrm{m}^{3}\right.$ day $\left.^{-1}\right)$ $\mathrm{TN}\left(\mathrm{kg} \mathrm{day}^{-1}\right) \mathrm{TP}\left(\mathrm{kg} \mathrm{day}^{-1}\right) \mathrm{CBOD}\left(\mathrm{kg} \mathrm{day}^{-1}\right),(5)$ reservoir operation, (6) calibration and validation data with frequent measurements - stream flow $\left(\mathrm{m}^{3} \mathrm{~s}^{-1}\right), \mathrm{TN}\left(\mathrm{mg} \mathrm{N} \mathrm{L}^{-1}\right), \mathrm{NO}_{3}{ }^{-}\left(\mathrm{mg} \mathrm{N} \mathrm{L}^{-1}\right), \mathrm{NH}_{4}^{+}$ (mg N L $\left.{ }^{-1}\right)$, PON (mg N L $\left.{ }^{-1}\right)$, DON (mg N L $\left.{ }^{-1}\right)$, TP (mg P L $\left.{ }^{-1}\right)$, SRP (mg P L $\left.{ }^{-1}\right)$, POP (mg P L $\left.{ }^{-1}\right)$, DOP (mg P L $\left.{ }^{-1}\right)$, and suspended sediment (mg SS L$\left.{ }^{-1}\right)$. By examining the extent and resolution of the data requirements, one can be deterred from building and relying on such data intensive models.

While a 10-m resolution DEM was available for the GRW, the soil layer proved more problematic. The Ontario survey soil layer $(1: 10,000)$ available through OMAFRA was completed on a county- by-county basis between 1929 and 2002 and exists at different map scales. In fact, the GRW had huge areas with missing soil layers where no survey was done. In such cases, data were interpolated by clipping soil layers from the Agriculture and Agri-Food Canada soil layer for Ontario which exists at resolutions of 1:50,000 up to 1:250,000.

In Canada, each level of government has a different role when it comes to the management of water resources. The Canada Water Act stipulates a framework for collaboration among the different levels of government in areas pertaining to water resources monitoring. The National Hydrometric Program is made up of nearly 2,800 hydrometric monitoring stations throughout Canada and one is extremely grateful if some of these stations lie within the watershed of interest. The most readily available dataset is streamflow. Beyond streamflow, there are very limited available data on water quality throughout Canada. Water quality datasets are needed to calibrate and validate model predictions. A lack of any comprehensive water quality dataset was perhaps the biggest limitation in this study. For the study years (2001-2010), some years had no reported 
data while some had, on average, four to six time point measurements spanning only two seasons. The available data were only used to guide manual calibration of SWAT, and to determine ranges for the parameter measurements. This is unacceptable. There must be an appreciation of the need for enhanced water quality measurements throughout Canada and this can only be achieved when all levels of government begin to recognise the importance of protecting and conserving our watercourses for sustainable use and development.

\subsection{SWAT and hydrology, sediment and nutrient export from the GRW into Lake Erie}

Hydrology is the most important basin characteristic that is accounted for in ecohydrological models. The GRW SWAT model was able to predict flow with a high degree of accuracy within the watershed. Based on the results of the model performance as measured by the objective functions, SWAT simulated stream flows were matched up well to the measured flows with respect to magnitude, peak time, and flow volume. The calibrated and validated model predicted flow rates similar to observed flow at all the monitoring stations in the watershed. This would imply that the model is very robust and would be able to predict flow at ungauged streams at different locations in the watershed, such as at Dunnville prior to entering Lake Erie. While the model gave overall acceptable results, on a finer point, the model underpredicted summer flows in the main channel of the Grand River, but not in the headwaters. The GRW is dotted with both large and small dams. In addition to 28 dams owned and operated by the GRCA, over 200 more dams in the watershed are owned by municipalities and private landowners. SWAT requires data on each of these dams, but for simplicity sake, the model can function by inputting data for the seven large reservoirs, specifically, their volumes and surface areas at principal spillway and at emergency spillway along with daily or monthly release rates. Again, the majority of these data 
were unavailable for the reservoirs leading to low predicted flow rates in summer flows when flow augmentations are needed to maintain Total Maximum Daily Loads (TMDLs) for P and $\mathrm{N}$ within the Grand River. In addition, another unknown variable that affected water yields was the amount of water that is removed from various reaches. There were over 800 active water extractions in the watershed that included municipalities, farm irrigators, golf courses, aggregate producers and industry. SWAT required the location of each site of water extraction, the day of extraction and the quantity of water extracted either from the reach or aquifer. Again, these data were not known except as is mentioned in a few GRCA reports.

The GRCA does not collect water quality data. Grab sampling of such a low frequency is wholly inadequate for calibration and validation purposes even from load estimating software such as LOAD ESTIMATOR (LOADEST). The same limitation is referenced in many GRCA reports. After a semi-automated calibration of TSS, simulated TSS at all sites were within the expected range based on long term observations by the Ministry of the Environment. This study also found that similar to flow trends, TSS trends followed a seasonal pattern with higher TSS in spring and lower levels in summer. TSS, a measure of the actual mass of material per volume of water, displayed natural variation because of physical and or biological processes in the watershed.

This study also found that simulated total phosphorus (TP) levels throughout the Grand River watershed far exceed the provincial objective of $0.030 \mathrm{mg} \mathrm{L}^{-1}$. The model predicts average annual TP values of over $0.50 \mathrm{mg} \mathrm{L}^{-1}$ in the lower reaches of the Grand prior to entering Lake Erie. TP values were similarly high in headwaters draining row crops on tile drained lands. It was determined that, with the exception of some sub-basins that have a high density of animal farms, nitrates were not a significant nutrient pollutant within the Grand River. Simulated nitrate was found to be high in the headwaters and in the middle section of the Grand River; however, the 
nitrate concentrations decreased in the lower reaches of the main channel though periodically there were bouts of elevated nitrates entering Lake Erie and these spells corresponded to events of high precipitation that flushed nitrates out of the soil and into receiving waterbodies.

\subsection{Impact of agriculture on stream network}

While watershed characteristics such as surficial geology, soil hydrologic group, hydrology and climate are important factors that determine the physiochemical properties of receiving waterbodies, the most important is land use. Changes in land use are, without a doubt, the most pervasive socioeconomic factor that results in the degradation of ecosystems throughout the world. The impact of agriculture on the landscape can be tremendous. Not only is vegetation replaced, wildlife displaced and natural watershed processes affected, but also the hydrology and stream networks are altered.

In this study, the impact of specific land uses, in particular agriculture, on the stream network of the GRW was investigated. It was found that the existing stream network included many first-order channels that were not predicted from the current topography of the landscape. While it is plausible that stream network prediction is a function of resolution and $10 \mathrm{~m}$ is too coarse to predict the upper limits of first order channels with fidelity, a sounder inference is that these streams that are missing from a predictive model reflect an extension of headwater channels to serve in drainage from agricultural areas. This is supported by the low sinuosity of these unpredicted portions of headwater streams, sinuosity being less for these reaches then for firstorder streams overall in the sub-watersheds. Also, the model accurately predicted reference stream networks in relatively undisturbed forested land use. In addition, supporting this is the relationship between agricultural activity and the percent of the channel network that is comprised of first- 
order streams, as extension of headwater channels for drainage would increase the overall percent of a network that is first-order. Moreover, the relationship between agricultural activity and the percent difference between actual and predicted first order streams suggests that there are more unaccounted for kilometers of first order streams in more agricultural sub-basins. These extended reaches of headwater channels provide a unique opportunity for farmers, the conservation authority, municipalities and other stakeholders, to target effective stream restoration polices and agricultural BMPs within major basins in the watershed, particularly in those with especially high agricultural activity such as Conestogo, Nith and Upper Middle Grand, in an effort to abate sediment and nutrient export into Lake Erie. Restoration activities might be concentrated on these extended reaches to improve sediment and nutrient retention and processing near the site of loading. Such activities come at cost, and it is important that we first define what impact such targeted efforts in these relatively small stretches of the watershed might have on water quality. Due to this finding, the actual ground-truthed stream network was always used in SWAT set up as opposed to a topographically derived stream network and sub-basin delineation in the modelling environment.

\subsection{Remediating agricultural watersheds with BMPs}

Agricultural Best Management Practices (BMPs) provides a practical approach to conserving water, soil, and nutrients at all spatial scales ranging from fields and sub-basins to watersheds. The problem of cultural re-eutrophication in Lake Erie can be mitigated through the reduction of sediment and nutrient transfer from the surrounding watersheds by the implementation of BMPs. In this study, different BMPs were simulated in the GRW in order to determine how each might affect TSS and P load and export into Lake Erie, relative to baseline conditions. These BMPs included: implementation of filter strips, implementation of grassed 
waterways, bank stabilization to reduce erosion, conversion of cropland to forest or wetland, planting of winter cover crops, and reduction in fertilizer application rates.

The predicted average monthly streamflow did not change by more than $1 \%$ under varying BMP scenarios; however, sediment, organic P, mineral P, and TP loading into Lake Erie did vary with different BMP scenario. The percent reduction of sediment ranged from $2 \%$ for conversion of agricultural lands to wetlands, to $38 \%$ for stabilizing of stream banks throughout the watershed while the reduction of phosphorus ranged from $4 \%$ for conversion of agricultural lands to wetlands to $50 \%$ for the addition of $7.6 \mathrm{~m}$ filter strips on all land use associated with agricultural use. While these results are somewhat comforting with respect to implementation of BMPs in agricultural watersheds, it should be realised that stream restoration will not solve the problem of excessive nutrient loading; rather, any such effort at remediation should be applied along with a better understanding of the crops' agronomic needs, cultural practices, and application timings of fertilizers. At present, current watershed management practices will not help to realize targeted goals of $40 \%$ TP reduction as set forth in the GLWQA's agreement, assuming the patterns of TP export are similar in GRW to those of watersheds in the western portion of the basin.

\subsection{Future application of the SWAT model in the GRW}

The vast majority of climate scientists agree, based on a preponderance of evidence, that climate change is real, and that human activities are a principal driver (Intergovernmental Panel on Climate Change (IPCC) 2007). According to the Government of Canada Climate Change site (http://www.climatechange.gc.ca/default.asp?lang=En\&n=036D9756-1), for the period 1948 to 2013, Canada's average annual temperature has increased by $1.6^{\circ} \mathrm{C}$ (relative to the $1961-1990$ average) and this represents a higher rate of warming when compared to other regions of the earth. 
Thus, climate change will result in warmer temperatures and higher amount of liquid precipitation in Southern Ontario. While warmer temperatures will result in longer growing season and increased heat units that may benefit soybean, corn and wheat, it will also result in more rainfall in winter which will inevitably flush out DRP and nitrates from agricultural watersheds into receiving waterbodies. In fact, climate change is already severely impacting the western basin of Lake Erie where it is exacerbating the magnitude, duration and frequency of hypoxia in Lake Erie. Also, a warmer land surface and waterbody temperature will induce an earlier and longer period of lake stratification during summer months, leading to increased HABs and longer hypoxic conditions of lakes and other waterbodies.

The effects of climate change on phosphorus loading into Lake Erie from the GRW is a sensible future direction from this study. The model is already built and parametrized based on current available data. It would be interesting to know if under future climate scenario whether the GRW will continue to contribute around 5\% of total phosphorus to the whole basin annually and $40 \%$ to the eastern basin. And most importantly, would DRP loading rates be altered under future climate scenarios? Moreover, if expected increased precipitation would result in higher loading of $\mathrm{P}$ and sediments, what combination of BMPs might mitigate the effects of climate change, and at what cost?

Another area of interest is actual stream restoration and how restoring stream sinuosity may affect flow regimes, sediment and nutrient export from headwater streams. While headwater streams function as the delicate link between terrestrial and aquatic ecosystems, agricultural practices have placed an enormous stress on their ability to attenuate, retain and transform nutrients that are exported from their watersheds. Needless to say, this approach must be coupled with actual field experiments in order to validate the model. 
Many conservation authorities are reintroducing wetlands in the watershed. This model can be optimized to investigate not only the generic benefits of the introduction of wetlands in the subbasins, but also whether there are differences in the impact based on the effect of size and location of wetland areas within the area of study. 


\section{References}

Abbaspour KC, Rouholahnejad E, Vaghefi S, Srinivasan R, Yang H, Kløve B. 2015. A continental-scale hydrology and water quality model for Europe: Calibration and uncertainty of a high-resolution large-scale SWAT model. J. Hydrol. 524:733-752.

Abbaspour KC, Yang J, Maximov I, Siber R, Bogner K, Mieleitner J, Zobrist J, Srinivasan R. 2007. Modelling hydrology and water quality in the pre-alpine/alpine Thur watershed using SWAT. J. Hydrol. 333:413-430. doi:10.1007/s00402-009-1032-4

Ahmad HMN, Sinclair A, Jamieson R, Madani A, Hebb D, Havard P, Yiridoe EK. 2011. Modeling sediment and nitrogen export from a rural watershed in eastern Canada using the soil and water assessment tool. J. Environ. Qual. 40:1182-1194. doi: 10.2134/jeq2010.0530

Alexander JS, Wilson RC, Green WR. 2012. A brief history and summary of the effects of river engineering and dams on the Mississippi River system and delta: U.S. Geological Survey Circular 1375, 43 p.

Alexander RB, Boyer EW, Smith RA, Schwarz GE, Moore RB. 2007. The Role of Headwater Streams in Downstream Water Quality. J. Am. Water Resour. Assoc. 43:41-59. doi:10.1111/j.1752-1688.2007.00005.x

Alexander RB, Boyer EW, Smith RA, Schwarz GE, Moore RB. 2007. The Role of Headwater Streams in Downstream Water Quality. J. Am. Water Resour. Assoc. 43:41-59. 
Alexander RB, Elliott AH, Shankar U, McBride GB. 2002. Estimating the sources and transport of nutrients in the Waikato River Basin, New Zealand. Water Resour. Res. 38:1268. doi:10.1029/2001WR000878

Alexander RB, Smith RA, Schwarz GE. 2000. Effect of stream channel size on the delivery of nitrogen to the Gulf of Mexico. Nature 403:758-761.

Almendinger JE, Murphy MS, Ulrich JS. 2014. Use of the Soil and Water Assessment Tool to Scale Sediment Delivery from Field to Watershed in an Agricultural Landscape with Topographic Depressions. J. Environ. Qual. 43:9.

Arnold JG, Kiniry JR, Srinivasan R, Williams JR, Haney EB, Neitsch SL. 2012. Soil \& Water Assessment Tool: Input/output documentation. version 2012. Texas Water Resour. Institute, TR-439:650.

Arnold JG, Srinivasan R, Muttiah RS, Williams JR. 1998. Large area hydrologic modeling and assessment part I: model development. J. Am. Water Resour. Assoc. 34:73-89. doi:10.1111/j.1752-1688.1998.tb05961.x

Beechie T, Pess G, Roni P, Giannico G. 2008. Setting River Restoration Priorities: A Review of Approaches and a General Protocol for Identifying and Prioritizing Actions. North Am. J. Fish. Manag. 28:891-905.

Brooker MP. 1985. The Ecological Effects of Channelization. Geogr. J. 151:63-69.

Brown MA, Clarkson BD, Theo Stephens RT, Barton BJ. 2014. Compensating for ecological harm - The state of play in New Zealand. N. Z. J. Ecol. 38:139-146. 
Bukaveckas PA. 2007. Effects of Channel Restoration on Water Velocity, Transient Storage, and Nutrient Uptake in a Channelized Stream. Environ. Sci. Technol. 41:1570-1576. doi: $10.1021 / \mathrm{es} 061618 \mathrm{x}$

Canadian Council of Ministers of the Environment (CCME). 2002. Canadian water quality guidelines for the protection of aquatic life: Total particulate matter. In: Canadian Environmental Quality Guidelines, Canadian Council of Ministers of the Environment, Winnipeg.

Caraco NF, Cole JJ. 1999. Human impact on nitrate export: An analysis using major world rivers. Ambio. 28: 167-170. http://www.jstor.org/stable/4314870

Carlson RE. 1977. A trophic state index for lakes. Limnol. Oceanogr. 22:361-369. http://www.jstor.org/stable/2834910

Carpenter SR, Caraco NF, Correll DL, Howarth RW, Sharpley AN, Smith VH. 1998. Nonpoint source pollution of surface waters with phosphorus and nitrogen. Ecological Applications 8(3): 559-68. doi:10.1890/1051-0761(1998)008[0559:NPOSWW]2.0.CO;2

Carpenter S, Pingali P, Bennett EM, Zurek MB. 2006. Millennium Ecosystem Assessment: Report of Scenarios Working Group. Vol. 2, Island Press, $551 \mathrm{pp.}$

Chamberlin TC. 1897. A Group of Hypotheses Bearing on Climatic Changes. J. Geol. 5:653683. doi: $10.1086 / 607921$ 
Conan C, Bouraoui F, Turpin N, de Marsily G, Bidoglio G. 2003. Modeling flow and nitrate fate at catchment scale in Brittany (France). J. Environ. Qual. 32:2026-2032. doi:10.2134/jeq2003.2026

Conley DJ, Carstensen J, Aigars J, Axe P, Bonsdorff E, Eremina T, et al. 2011. Hypoxia Is Increasing in the Coastal Zone of the Baltic Sea. Environ. Sci. Technol., 2011, 45 (16), 6777-6783 doi:10.1021/es201212r

Cooke S. 2006. Water quality in the Grand River: A Summary of Current Conditions (20002004) and Long Term Trends. Grand River Conservation Authority, Cambridge, Ontario. http://www.grandriver.ca/water/2006_WaterQuality_complete.pdf

Daneshvar F, Nejadhashemi AP, Adhikari U, Elahi B, Abouali M, Herman MR, MartinezMartinez E, Calappi TJ, Rohn BG. 2017. Evaluating the significance of wetland restoration scenarios on phosphorus removal. J. Environ. Manage. 192:184-196. doi:10.1016/j.jenvman.2017.01.059

David MB, McIsaac GF, Royer T V, Darmody RG, Gentry LE. 2001. Estimated historical and current nitrogen balances for Illinois. Scientific World Journal. Suppl. 2:597-604. doi:10.1100/tsw.2001.283

Davidson NC. 2014. How much wetland has the world lost? Long-term and recent trends in global wetland area. Mar. Freshw. Res. 65:934-941. doi:10.1071/MF14173

Díaz RJ, Rosenberg R. 2008. Spreading dead zones and consequences for marine ecosystems. Science, 321: 926-929. doi:10.1126/science.1156401 
Dodds WK, Bouska WW, Eitzmann JL, Pilger TJ, Pitts KL, Riley AJ, Schloesser JT, Thornbrugh DJ. 2009. Eutrophication of U.S. Freshwaters: Analysis of Potential Economic Damages. Environ. Sci. Technol. 43:12-19. http://pubs.acs.org/doi/abs/10.1021/es801217q

Dolan DM, McGunagle KP. 2005. Lake Erie Total Phosphorus Loading Analysis and Update: 1996-2002. J. Great Lakes Res. 31:11-22. doi:10.1016/S0380-1330(05)70301-4

Drummond JD, Bernal S, von Schiller D, Martí E. 2016. Linking in-stream nutrient uptake to hydrologic retention in two headwater streams. Freshw. Sci. 35:1176-1188. doi: $10.1086 / 688599$

Elmore AJ, Julian JP, Guinn SM, Fitzpatrick MC. 2013. Potential Stream Density in MidAtlantic U.S. Watersheds. Deng ZD, editor. PLoS One 8:e74819.

Farwell J, Boyd D, Ryan T. 2007. Making Watersheds More Resilient to Climate Change A Response in the Grand River Watershed, Ontario, Canada. Retrieved from http://www.grandriver.ca/AboutGrand/ClimateChange08.pdf

Farwell J, Boyd D, Ryan T. 2008. Making Watersheds More Resilient to Climate Change A Response in the Grand River Watershed, Ontario Canada. Retrieved from http://www.grandriver.ca/AboutGrand/ClimateChange08.pdf

Freeman MC, Pringle CM, Jackson CR. 2007. Hydrologic Connectivity and the Contribution of Stream Headwaters to Ecological Integrity at Regional Scales1. JAWRA J. Am. Water Resour. Assoc. 43:5-14. doi:10.1111/j.1752-1688.2007.00002.x 
Gassman PW, Reyes MR, Green CH, Arnold JG. 2007. The soil and water assessment tool:

Historical development, applications, and future research directions. Trans. Asabe 50:12111250.

Gassman PW, Sadeghi AM, Srinivasan R. 2014. Applications of the SWAT Model Special Section: Overview and Insights. J. Environ. Qual.:1-8. doi:10.2134/jeq2013.11.0466

Giri S, Nejadhashemi AP, Woznicki SA. 2012. Evaluation of targeting methods for implementation of best management practices in the Saginaw River Watershed. J. Environ. Manage. 103:24-40. doi:10.1016/j.jenvman.2012.02.033

Goldewijk KK. 2001. Estimating global land use change over the past 300 years: The HYDE Database. Global Biogeochem. Cycles 15:417-433. doi:10.1029/1999GB001232

Golmohammadi G, Prasher S, Madani A, Rudra R. 2014. Evaluating Three Hydrological Distributed Watershed Models: MIKE-SHE, APEX, SWAT. Hydrology 1:20-39. doi:10.3390/hydrology 1010020

Gomi T, Sidle RC, Richardson JS. 2002. Understanding processes and downstream linkages of headwater systems. Bioscience 52, 905-916. doi:10.1641/00063568(2002)052[0905:UPADLO]2.0.CO;2

GRCA (Grand River Conservation Authority). 2005. Watershed Report Card. Retrieved from http://www.grandriver.ca/WatershedReportCard/2005_Fall_Grand_Pg10.pdf

GRCA. 2008. Grand River Characterization - Executive Summary. Retrieved from http://www.sourcewater.ca/swp_watersheds_grand/Characterization_summary_Grand.pdf 
GRCA. 2013. Grand River Water Management Plan 2013 Update Sources of Nutrients and Sediments in the Grand River Watershed. https://www.grandriver.ca/en/ourwatershed/resources/Documents/WMP/Water_WMP_Report_NutrientSources.pdf

Grand River Implementation Committee (GRIC). 1982. Grand River basin watershed management study. Grand River Conservation Authority, Cambridge, Ontario. http://www.grandriver.ca/WaterPlan/1982_BasinStudy.pdf

Gupta HV, Kling H, Yilmaz KK, Martinez GF. 2009. Decomposition of the mean squared error and NSE performance criteria: Implications for improving hydrological modelling. J. Hydrol. 377:80-91. doi:10.1016/j.jhydrol.2009.08.003

Hecky RE, Kilham P. 1988. Nutrient limitation of phytoplankton in freshwater and marine environments: A review of recent evidence on the effects of enrichment1. Limnol. Oceanogr. 33:796-822. doi:10.4319/lo.1988.33.4part2.0796.

Herbert C. 1957. A Source of Phosphorus for the Western Basin of Lake Erie1. Limnol. Oceanogr. 2:315-320. doi:10.1002/lno.1957.2.4.0315

Heywood I, Cornelius S, Carver S. 2006. An Introduction to Geographical Information Systems (3rd ed.). Essex, England: Prentice Hall.

Holeton C. 2013. Sources of Nutrients and Sediments in the Grand River Watershed. Grand River Watershed Water Management Plan. Prepared by the Water Quality Working Group. Grand River Conservation Authority, Cambridge, ON. Retrieved from 
https://www.grandriver.ca/en/our-

watershed/resources/Documents/WMP/Water_WMP_Report_NutrientSources.pdf

Horton RE. 1945. Erosional development of streams and their drainage basins: hydro-physical approach to quantitative morphology. Geological Society of America Bulletin. Geol. Soc. Am. Bull. 56:151-180.

Howarth RW, Billen G, Swaney D, Townsend A, Jaworski N, Lajtha K, Downing JA, Elmgren R, Caraco N, Jordan T, et al. 1996. Regional Nitrogen Budgets and Riverine N \& P Fluxes for the Drainages to the North Atlantic Ocean: Natural and Human Influences.

Biogeochemistry 35:75-139. doi:10.1007/BF02179825

Intergovernmental Panel on Climate Change (IPCC). 2007. Climate Change 2007: The Physical Science Basis. Contribution of Working Group I to the Fourth Assessment Report of the Intergovernmental Panel on Climate Change [Solomon S, D Qin, Manning M, Chen Z, Marquis M, Averyt KB, Tignor M. Miller HL. (eds.)]. Cambridge University Press, Cambridge, United Kingdom and New York, NY, USA, 996 pp.

International Joint Commission (IJC). 2014. A Balanced Diet for Lake Erie: Reducing Phosphorus Loadings and Harmful Algal Blooms. Report of the Lake Erie Ecosystem Priority. ISBN: 978-1-927336-07-6.

Itenfisu D, Allen RG, Walter IA, Elliott RL. 2003. Comparison of Reference Evapotranspiration Calculations as Part of the ASCE Standardization Effort. J. Irrig. Drain. E-ASCE 129(6):440-448. Doi:10.1061/(ASCE)0733-9437(2003)129:6(440) 
Jensen ME, Burman RD, Allen RG. 1990. Evapotranspiration and Irrigation Water

Requirements. ASCE Manuals and Reports on Engineering Practice No. 70, Am. Soc. Civil Engr., New York, NY.

Jordan MA, Castañeda AJ, Smiley PC, Gillespie RB, Smith DR, King KW. 2016. Influence of instream habitat and water chemistry on amphibians in channelized agricultural headwater streams. Agric. Ecosyst. Environ. 230:87-97. doi:10.1016/j.agee.2016.05.028

Kalnay E, Kanamitsu M, Kistler R, Collins W, Deaven D, Gandin L, Iredell M, Saha S, White G, Woollen J, et al. 1996. The NCEP/NCAR 40-year reanalysis project. Bull. Am. Meteorol. Soc. 77:437-471. doi:10.1175/1520-0477(1996)077<0437:TNYRP>2.0.CO;2

Keller EA. 1978. Pools, riffles, and channelization. Environ. Geol. 2:119-127. doi:10.1007/BF02380474

King KW, Smiley Jr. PC, Fausey NR. 2009. Hydrology of channelized and natural headwater streams. Hydrol. Sci. J. 54:929-948. doi:10.1623/hysj.54.5.929

King SL, Sharitz RR, Groninger JW, Battaglia LL. 2009. The ecology, restoration, and management of southeastern floodplain ecosystems: a synthesis. Wetlands 29:624-634. doi:10.1672/08-223.1

Krause P, Boyle DP. 2005. Comparison of different efficiency criteria for hydrological model assessment. Adv. Geosci. 5:89-97. doi: 1680-7359/adgeo/2005-5-89

Krysanova V, Arnold JG. 2008. Advances in ecohydrological modelling with SWAT—a review. Hydrol. Sci. J. 53:939-947. doi:10.1623/hysj.53.5.939 
Leon L, Booty W, Wong I, McCrimmon C, Fong P. 2014. NPS Watershed Modeling Inflows for Lake Models. SWAT Modeling Workshop University of Michigan, Ann Arbor, US 18-19 Mar, 2014. Retrieved from http://graham.umich.edu/media/files/watercenter/Leon_NPSwatershed-modeling-inflows-for-lake-models.pdf

Leopold LB, Wolman MG, Miller JP. 1964. Fluvial processes in geomorphology. San Francisco, CA: W. H. Freeman and Company.

Logan TJ. 1987. Diffuse (Non-Point) Source Loading of Chemicals to Lake Erie. J. Great Lakes Res. 13:649-658. doi:10.1016/S0380-1330(87)71679-7

Loomer HA, Cooke SE. 2011. Water Quality in the Grand River Watershed: Current Conditions and Trends (2003-2008). Retrieved from https://www.sourcewater.ca/en/source-protectionareas/resources/Documents/Grand/Grand_Reports_WaterQuality_2011.pdf

Mao Z, Yin C, Shan B. 2004. Spatial and temporal variability of agricultural pollutants in an agricultural headwater stream within a multipond system, southeastern China. Environ. Sci. J. 16(4), 697-704.

Mayer T, Delos Reyes E. 1996. Phosphorus and metal contaminant transport in two southern Ontario rivers: The Grand River and its tributary, the Nith River. Water Qual. Res. J. Canada 31:119-151.

Mayorga E, Seitzinger SP, Harrison JA, Dumont E, Beusen AHW, Bouwman AF, Fekete BM, Kroeze C and Van Drecht G. 2010. Global Nutrient Export from WaterSheds 2 (NEWS 2): 
Model development and implementation. Environmental Modelling and

Software 25(7):837-853, doi:10.1016/j.envsoft.2010.01.007.

Michael HJ, Boyle KJ, Bouchard R. 1996. Water Quality Affects Property Prices: A Case Study of Selected Maine Lakes. Maine Agricultural and Forest Experiment. Station Miscellaneous Report 398, University of Maine, Orono, Maine, U.S.A. http://www.umaine.edu/mafes/elec_pubs/miscrepts/mr398.pdf

Michalak AM, Anderson EJ, Beletsky D, Boland S, Bosch NS, Bridgeman TB, Chaffin JD, Cho K, Confesor R, Daloğlu I, et al. 2013. Record-setting algal bloom in Lake Erie caused by agricultural and meteorological trends consistent with expected future conditions. Proc. Natl. Acad. Sci. 110:6448-6452. doi:10.1016/j.jglr.2013.06.004

Ministry of Natural Resources (MNRF). 1994. Ontario Government Specifications For the Delivery of Digital Topographic Data and Cartographic Representation Products at Medium Scales, Geographic Information Branch, Science and Information Resources Division, 59p.

Moriasi DN, Arnold JG, Van Liew MW, Binger RL, Harmel RD, Veith TL. 2007. Model evaluation guidelines for systematic quantification of accuracy in watershed simulations. Trans. ASABE 50:885-900.

Nadeau T-L, Rains MC. 2007. Hydrological Connectivity Between Headwater Streams and Downstream Waters: How Science Can Inform Policy1. JAWRA J. Am. Water Resour. Assoc. 43:118-133. doi:10.1111/j.1752-1688.2007.00010.x 
Nash JE, Sutcliffe JV. 1970. River flow forecasting through conceptual models part I - a discussion of principles. J. Hydrol. 10:282-290. doi:10.1016/0022-1694(70)90255-6

National Oceanic and Atmospheric Administration (NOAA). 2015. Experimental Lake Erie Harmful Algal Bloom Bulletin. Retrieved from https://www.glerl.noaa.gov//res/HABs_and_Hypoxia/lakeErieHABArchive/bulletin_2015027.pdf.

Neitsch S, Arnold J, Kiniry J, Williams J. 2011. Soil \& Water Assessment Tool Theoretical Documentation Version 2009. Texas Water Resour. Institute, TR-406:1-647.

NRC (National Research Council). 2000. Watershed management for potable water supply: assessing the New York City strategy. National Academy Press, Washington, DC.

Nunnally NR. 1978. Stream renovation: An alternative to channelization. Environ. Manage. 2:403-411. doi:10.1007/BF01872915

Ohio Environmental Protection Agency(OEPA). 2010. Ohio Lake Erie Phosphorus Task Force Final Report. : 109. Retrieved from https://www.motherjones.com/files/task_force_report_october_2013.pdf

Ontario Ministry of the Environment (OMOE). 2012. Water quality of 15 streams in agricultural watersheds of Southwestern Ontario 2004-2009. Retrieved from https://dr6j45jk9xcmk.cloudfront.net/documents/1180/98-15-streams-in-agriculturalwatersheds-en.pdf 
Pedersen ML. 2009. Effects of channelisation, riparian structure and catchment area on physical habitats in small lowland streams. Fundam. Appl. Limnol. 174:89-99.

Peierls BL, Caraco NF, Pace ML, Cole JJ. 1991. Human influence on river nitrogen. Nature 350:386-387. doi:10.1038/350386b0

Peterson BJ, Wolllheim WM, Mulholland PJ, Webster JR, J.L. M, Tank JL, Martí E, Bowden WB, Valett HM, E. HA, et al. 2001. Control of Nitrogen Export from Watersheds by Headwater Streams. Science. 292:86-90. doi:10.1126/science.1056874

Preston SD, Alexander RB, Woodside MD, Hamilton PA. 2009. SPARROW MODELING Enhancing Understanding of the Nation's Water Quality. USGS Fact Sheet 3019:1-6.

Reichert P. 2001. River water quality model No. 1. IWA Publishing.

Richards JF. 1990. Land transformation, in The Earth as Transformed by Human Action, edited by B.L. Turner II et al., pp. 163-178, Cambridge Univ. Press, New York.

Richards RP. 2006. Trends in sediment and nutrients in major Lake Erie tributaries, 1975-2004. Lake Erie Lake Wide Management Plan 2006 Update 10-22.

Richards RP, Baker DB, Crumrine JP, Stearns AM. 2010. Unusually large loads in 2007 from the Maumee and Sandusky Rivers, tributaries to Lake Erie. J. Soil Water Conserv. 65:450462. doi:10.2489/jswc.65.6.450

Ritchey T. 2012. Outline for a Morphology of Modelling Methods: Contribution to a General Theory of Modelling. Acta Morphol. Gen. AMG Vol 1:1-20. 
Rosa F, Burns NM. 1987. Lake Erie Central Basin Oxygen Depletion Changes from 1929-1980. J. Great Lakes Res. 13:684-696. doi:10.1016/S0380-1330(87)71683-9

Rouholahnejad, E., K.C. Abbaspour, R. Srinivasan, V. Bacu and AL. 2014. Water resources of the Black Sea Basin at high spatial and temporal resolution. Water Resour. Res. 50(7):58665885. doi:10.1002/2013WR014132

Rousseau AN, Savary S, Hallema DW, Gumiere SJ, Foulon É. 2013. Modeling the effects of agricultural BMPs on sediments, nutrients, and water quality of the Beaurivage River watershed (Quebec, Canada). Can. Water Resour. J. / Rev. Can. des ressources hydriques 38:99-120. doi:10.1080/07011784.2013.780792

Runkel RL, Crawford CG, Cohn TA. 2004. Load estimator (LOADEST): a FORTRAN program for estimating constituent loads in streams and rivers. http://pubs.er.usgs.gov/publication/tm4A5

Saha S, Moorthi S, Pan HL, Wu X, Wang J, Nadiga S, Tripp P, Kistler R, Woollen J, Behringer D, et al. 2010. The NCEP climate forecast system reanalysis. Bull. Am. Meteorol. Soc. 91:1015-1057. doi:10.1175/2010BAMS3001.1

Scavia D, David Allan J, Arend KK, Bartell S, Beletsky D, Bosch NS, Brandt SB, Briland RD, Daloğlu I, DePinto J V., et al. 2014. Assessing and addressing the re-eutrophication of Lake Erie: Central basin hypoxia. J. Great Lakes Res. 40:226-246. doi:10.1016/j.jglr.2014.02.004

Schindler DW. 1974. Eutrophication and Recovery in Experimental Lakes: Implications for Lake Management. Science. 184:897 LP-899. doi:10.1126/science.184.4139.897 
Schindler DW. 1977. Evolution of phosphorus limitation in lakes. Science. 195:260-262. doi:10.1126/science.195.4275.260

Schindler DW. 1978. Factors regulating phytoplankton production and standing crop in the world's freshwaters. Limnol. Oceanogr. 23:478-486. doi: 10.4319/lo.1978.23.3.0478

Schoof R. 1980. Environmental impact of channel modification. Water Resources Bulletin 16, 697-701. doi:10.1111/j.1752-1688.1980.tb02451.x

Schwab DJ, Beletsky D, DePinto J, Dolan DM. 2009. A hydrodynamic approach to modeling phosphorus distribution in Lake Erie. J. Great Lakes Res. 35:50-60. doi:10.1016/j.jglr.2008.09.003

Schwarz GE, Hoos AB, Alexander RB, and Smith RA. 2006. The SPARROW Surface WaterQuality Model: Theory, Application and User Documentation. In U.S. Geological Survey Techniques and Methods - Book 6, Section B, chapter Chapter 3. USGS.

Scott CA, Walter MF, Brooks ES, Boll J, Hes MB, Merrill MD. 1998. Impacts of Historical Changes in Land Use and Dairy Herds on Water Quality in the Catskills Mountains. J. Environ. Qual. 27:1410-1417. doi:10.2134/jeq1998.00472425002700060018x

Scott R, Imhof J. 2005. Exceptional Waters Reach State of the Resource Report. Exceptional Waters Reach Community Advisory Committee, Grand River Conservation Authority: Cambridge, Ontario. Retrieved from http://www.grandriver.ca/ExceptionalWaters/2005_stateofresource.pdf 
Seitzinger SP, Kroeze C. 1998 Global distribution of nitrous oxide production and N inputs in freshwater and coastal marine ecosystems, Global Biogeochem. Cycles 12(1), 93-113. doi:10.1029/97GB03657

Seitzinger SP, Kroeze C, Bouwman AF, Caraco N, Dentener F, Styles R V. 2002. Global patterns of dissolved inorganic and particulate nitrogen inputs to coastal systems: Recent conditions and future projections. Estuaries 25:640-655. doi:10.1007/BF02804897

Seitzinger SP, Styles RV, Boyer EW, Alexander RB, Billen G, Howarth RW, Mayer B, Breemen N. 2002. Nitrogen retention in rivers: model development and application to watersheds in the northeastern U.S.A. Biogeochemistry 57/58(1), 199-237. doi:10.1023/A:1015745629794

Seitzinger SP, Harrison JA, Dumont E, Beusen AHW, and Bouwman AF. 2005. Sources and delivery of carbon, nitrogen, and phosphorus to the coastal zone: An overview of Global Nutrient Export from Watersheds (NEWS) models and their application, Global Biogeochem. Cycles, 19, GB4S01, doi:10.1029/2005GB002606.

Shaker S. 2014. Historical Trends in Water Quality in the Grand River, Ontario: Reconstruction of Phosphorus Loadings. MS thesis. Waterloo, Ontario, Canada. University of Waterloo, Earth Sciences. UWSpace. http://hdl.handle.net/10012/8237

Sharpley AN, Daniel T, Gibson G, Bundy L, Cabrera M, Sims T, Stevens R, Lemunyon J, Kleinman P, Parry R. 2006. Best Management Practices To Minimize Agricultural Phosphorus Impacts on Water Quality. United States Dep. Agric. ARS-163. 
Silberstein R, Barr A, Hodgson G, Pollock D, Salama R, Hatton T. 2004. Perth Regional Aquifer Modelling System (PRAMS) model development: A Vertical Flux Model for the Perth Groundwater Region. Report prepared by CSIRO.

Singh VP. 1995. Computer models of watershed hydrology. Water Resources Publications, Littleton, Colorado.

Smith RA, Schwarz GE, Alexander RB. 1997. Regional interpretation of water-quality monitoring data, Wat. Resour. Res. 33, 2781-2798. Retrieved from http://water.usgs.gov/nawqa/sparrow/wrr97/results.html

Srinivasan R, Arnold JG, Muttiah RS, Walker C, Dyke PT. 1993. Hydrologic Unit Model for the United States HUMUS). In: Advances in Hydroscience and Engineering. CCHE, School of Engineering, University of Mississippi, Oxford, Mississippi.

Statistics Canada. 2002. 2001 Census of Agriculture - Canadian Farm Operations in the 21st Century. Retrieved from http://www.statscan.ca/Daily/English/020515/d020515a.htm

Strahler AN. 1952. Hypsometric (Area - Altitude) Analysis of Erosional Topography. Geol. Soc. Am. Bull. 63:1117-1142.

Strauch M, Lima JEFW, Volk M, Lorz C, Makeschin F. 2013. The impact of Best Management Practices on simulated streamflow and sediment load in a Central Brazilian catchment. J. Environ. Manage. 127, Supplement: S24-S36. doi:10.1016/j.jenvman.2013.01.014

Streeter HW, Phelps EB. 1925. A Study of the pollution and natural purification of the Ohio river. III. Factors concerned in the phenomena of oxidation and reaeration, Public Health 
Bulletin no. 146, Reprinted by U.S. Department of Health, Education and Welfare, Public Health Service, 1958, ISBN B001BP4GZI.

Tate KW, Dahlgren RA, Singer MJ, Allen-Diaz B, Atwill ER. 1999. Timing, frequency of sampling affects accuracy of water-quality monitoring. Calif. Agr. 53(6):44-48.

Toronto and Region Conservation Authority (TRCA). 2010. Etobicoke and Mimico Creeks Watersheds Technical Update Report. Retrieved from http://www.trca.on.ca/dotAsset/148571.pdf

Triska FJ, Duff JH, Sheibley RW, Jackman AP, Avanzino RJ. 2007. DIN Retention-Transport Through Four Hydrologically Connected Zones in a Headwater Catchment of the Upper Mississippi River. JAWRA J. Am. Water Resour. Assoc. 43:60-71. doi:10.1111/j.17521688.2007.00006.x

United States Department of Agriculture (USDA). 2012. Grassed Waterway. http://www.nrcs.usda.gov/Internet/FSE_DOCUMENTS/nrcs142p2_007306.pdf

United States Environmental Protection Agency (USEPA). 1999. Storm Water Technology Fact Sheet: Sand Filters (EPA 832-F-99-007).

USEPA. 2005. Stream Channelization: Fact Sheet Number 1. Region 7. Retrieved on March 28, 2013. http://www.epa.gov/region7/wetlands/pdf/ChannelizationFS04-Final.pdf

USEPA. 2011. Detroit River-Western Lake Erie Basin Indicator Project. Retrieved on June 10, 2013. http://www.epa.gov/med/grosseile_site/indicators/algae-blooms.html 
USEPA. 2011. Report on action toward limiting nitrogen and phosphorus loads from NPDESpermitted facilities. http://www2.epa.gov/nutrient-policy-data/action-towards-limiting-totalnitrogen-total-phosphorus-and-total-inorganic

Urban MA, Rhoads BL. 2003. Catastrophic Human-Induced Change in Stream-Channel Planform and Geometry in an Agricultural Watershed, Illinois, USA. Ann. Assoc. Am. Geogr. 93:783-796. doi:10.1111/j.1467-8306.2003.09304001.x

Vachaud G, Chen T. 2002. Sensitivity of a large-scale hydrologic model to quality of input data obtained at different scales; distributed versus stochastic non-distributed modelling. J. Hydrol. 264:101-112. doi:10.1016/S0022-1694(02)00069-0

Vitousek PM, Mooney HA, Lubchenco J, Melillo JM. 1997. Human Domination of Earth’s Ecosystems. Science 277:494 LP-499. doi:10.1126/science.277.5325.494

Vollenweider RA. 1968. Scientific fundamentals of the eutrophication of lakes and flowing waters, with particular reference to nitrogen and phosphorus as factors in eutrophication. DAS/CSI/68.27, Organisation for Economic Cooperation and Development, Paris.

Watson SB, Miller C, Arhonditsis G, Boyer GL, Carmichael W, Charlton MN, Confesor R, Depew DC, Höök TO, Ludsin SA, et al. 2016. The re-eutrophication of Lake Erie: Harmful algal blooms and hypoxia. Harmful Algae 56:44-66. doi:10.1016/j.hal.2016.04.010

Withers PJA, Jarvie HP. 2008. Delivery and cycling of phosphorus in rivers: A review. Sci. Total Environ. 400:379-395. doi:10.1016/j.scitotenv.2008.08.002 
Wohl E. 2006. Human impacts to mountain streams. Geomorphology 79:217-248. doi:10.1016/j.geomorph.2006.06.020

Wong A. 2011. Water Use Inventory Report for the Grand River Watershed. Retrieved from https://www.grandriver.ca/en/ourwatershed/resources/Documents/Water_Supplies_WaterUse_2011.pdf

Wu RSS. 2002. Hypoxia: from molecular responses to ecosystem responses. Mar. Pollut. Bull. 45:35-45. doi:10.1016/S0025-326X(02)00061-9

Yang Q, Leon LF, Booty WG, Wong IW, McCrimmon C, Fong P, Michiels P, Vanrobaeys J, Benoy G. 2014. Land Use Change Impacts on Water Quality in Three Lake Winnipeg Watersheds. J. Environ. Qual. 43:1690-1701. doi:10.2134/jeq2013.06.0234

Yang W, Liu Y, Ou C, Gabor S. 2016. Examining water quality effects of riparian wetland loss and restoration scenarios in a southern Ontario watershed. J. Environ. Manage. 174:26-34. doi:10.1016/j.jenvman.2016.03.001

Yang W, Liu Y, Simmons J, Oginskyy A, Mckague K, Wilson R, Gutteridge A, Mcpherson T, Brock H, Monk K. 2013. SWAT Modelling of Agricultural BMPs and Analysis of BMP Cost Effectiveness in the Gully Creek Watershed. Retrieved from http://abca.on.ca/downloads/WBBE-Huron-SWAT-Modelling-2013-08-21.pdf 